U.S. Department of the Interior

U.S. Geological Survey

Open-File Report 2004-1083

Version 1.0

2004

\title{
Cross-Sections and Maps Showing Double-Difference Relocated Earthquakes from 1984-2000 along the Hayward and Calaveras Faults, California
}

\author{
By Robert W. Simpson, Russell W. Graymer, Robert C. Jachens, David A. \\ Ponce, and Carl M. Wentworth
}

\section{Introduction}

We present cross-section and map views of earthquakes that occurred from 1984 to 2000 in the vicinity of the Hayward and Calaveras faults in the San Francisco Bay region, California. These earthquakes came from a catalog of events relocated using the double-difference technique, which provides superior relative locations of nearby events. As a result, structures such as fault surfaces and alignments of events along these surfaces are more sharply defined than in previous catalogs.

This pdf document contains just the cross sections and local maps for easier and better quality printing.

The full online report can be found at http://pubs.usgs.gov/of/2004/1083/.

For questions about the content of this report, contact Robert Simpson (simpson@usgs.gov)

| Department of the Interior | U.S. Geological Survey |

URL of the full report: http://pubs.usgs.gov/of/2004/1083/

Maintained by: Carolyn Donlin 

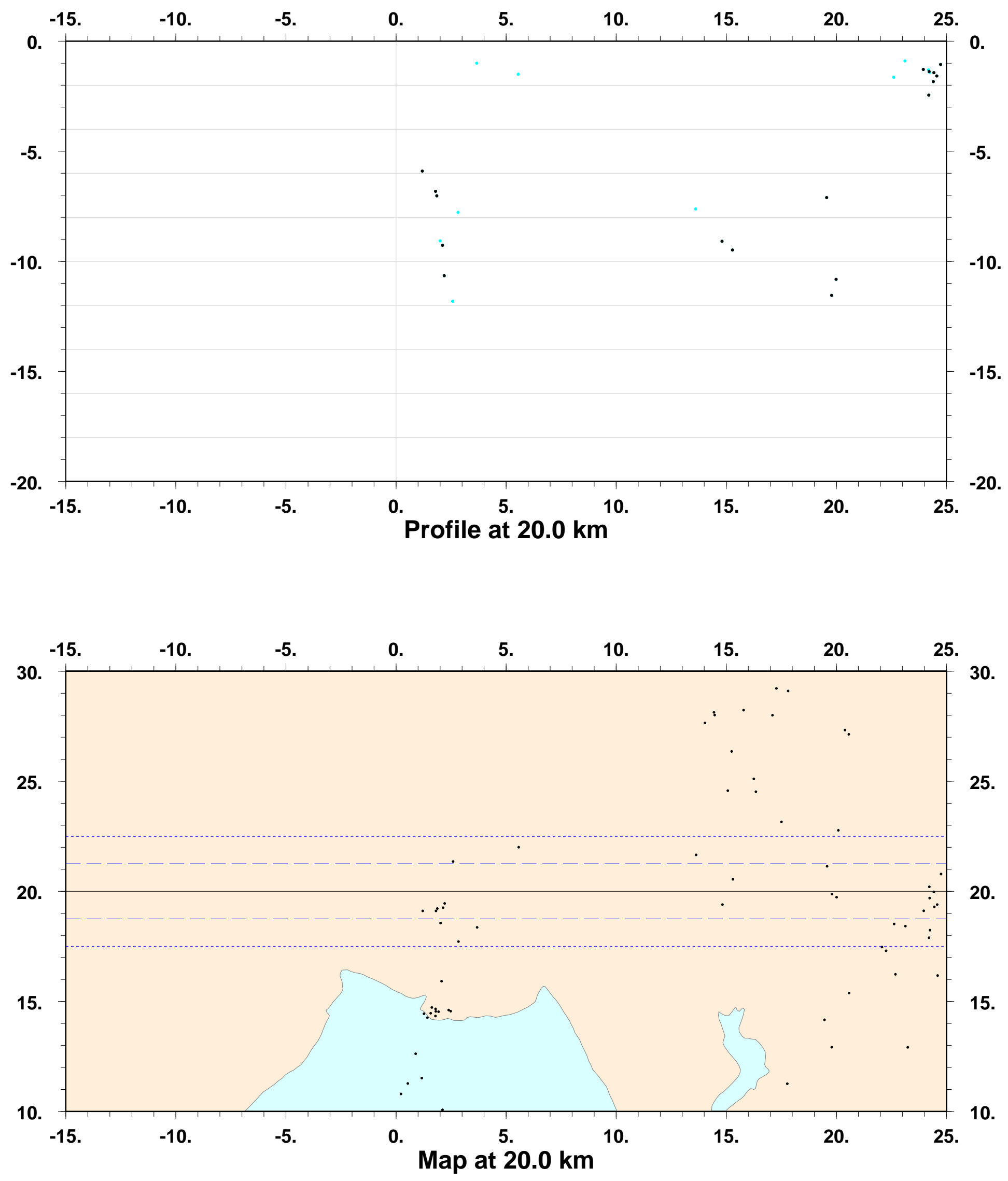

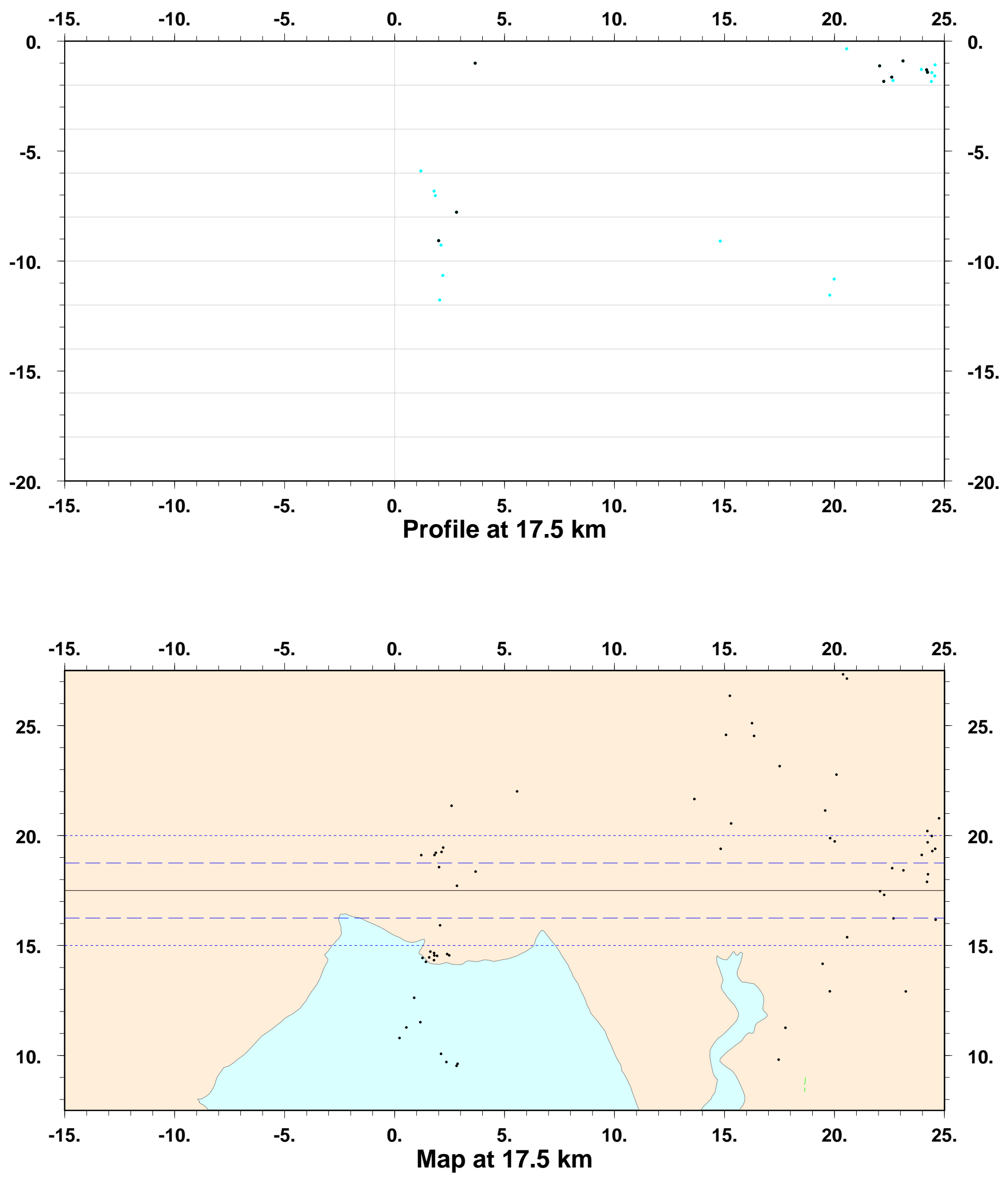

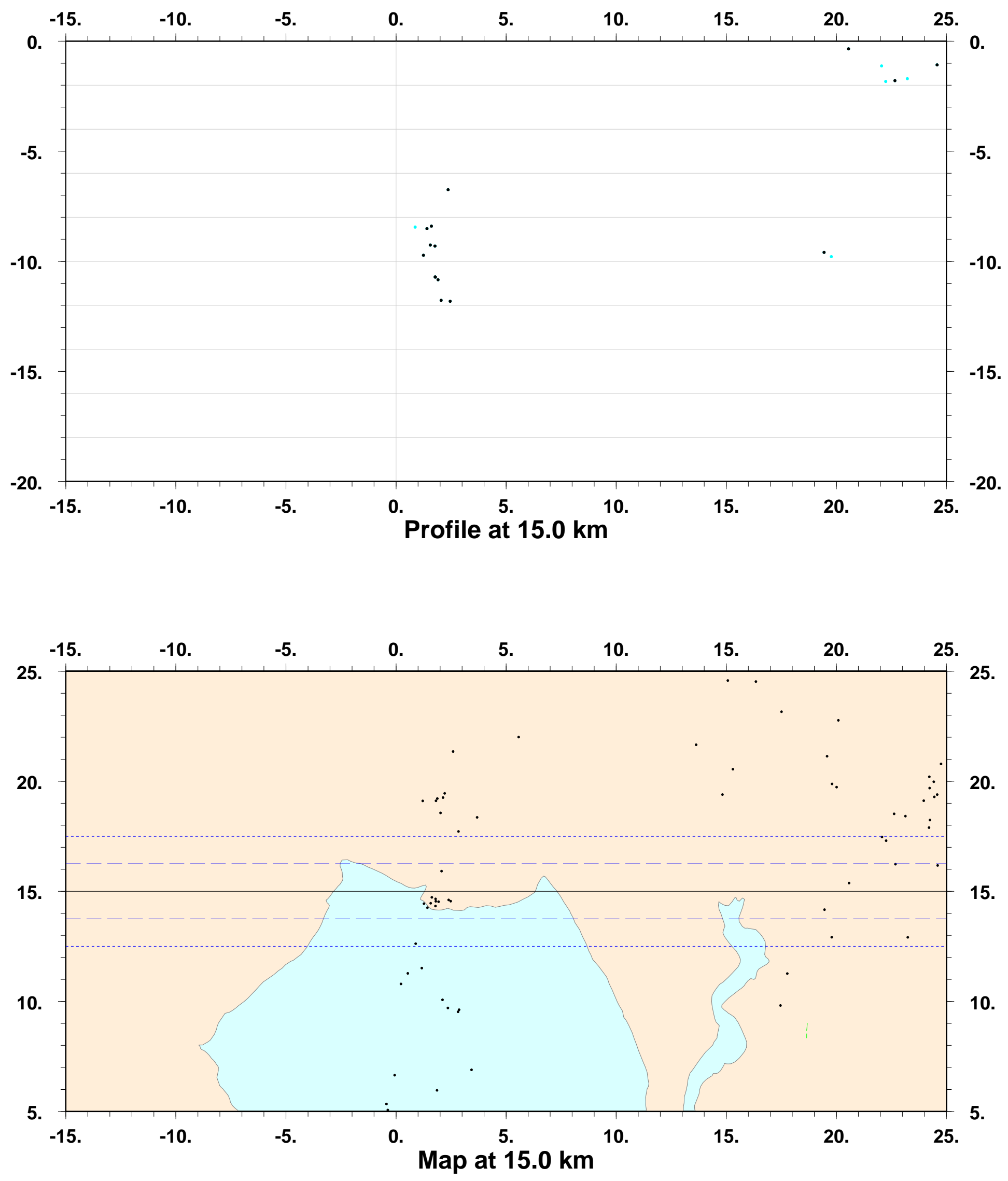

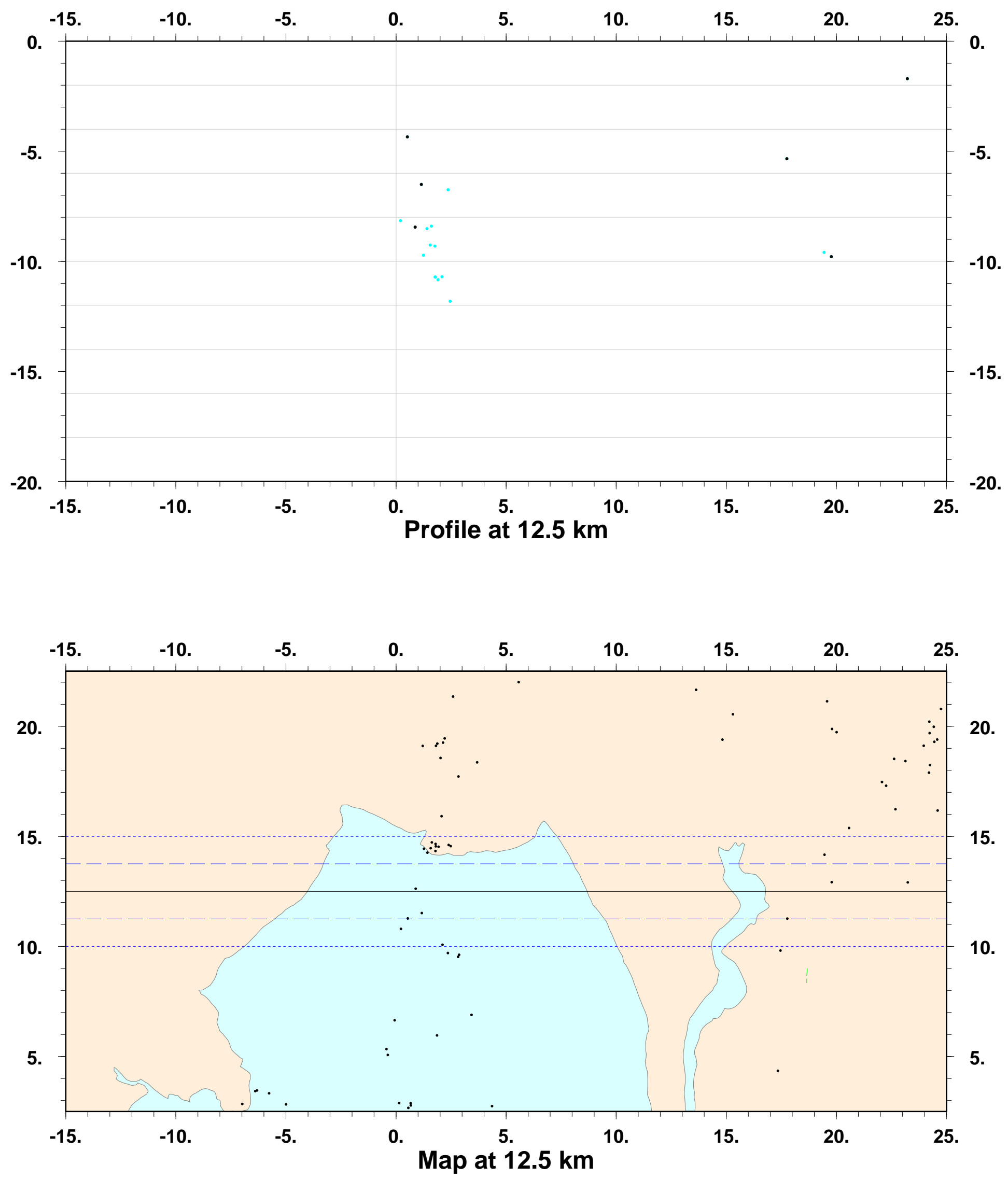

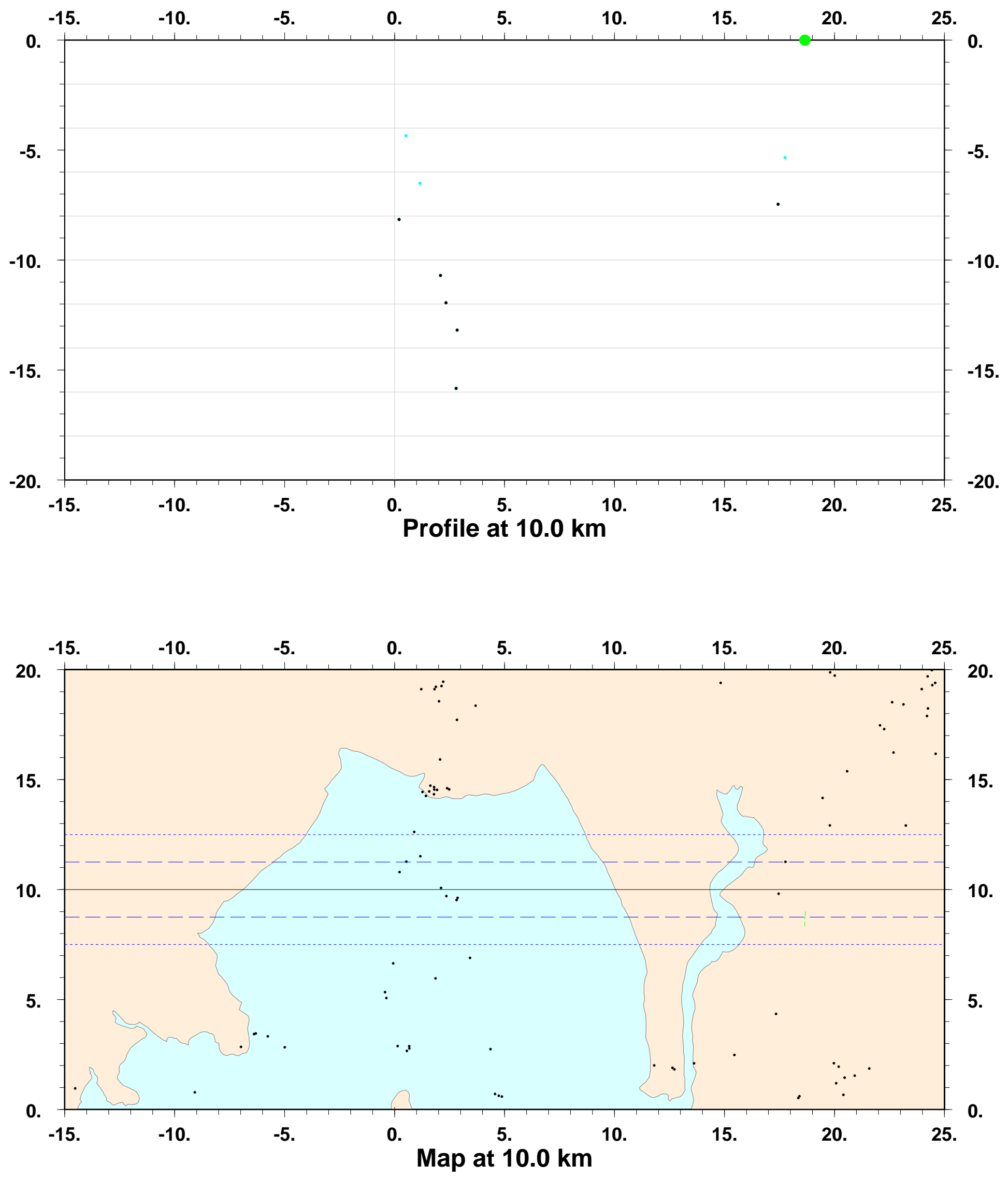

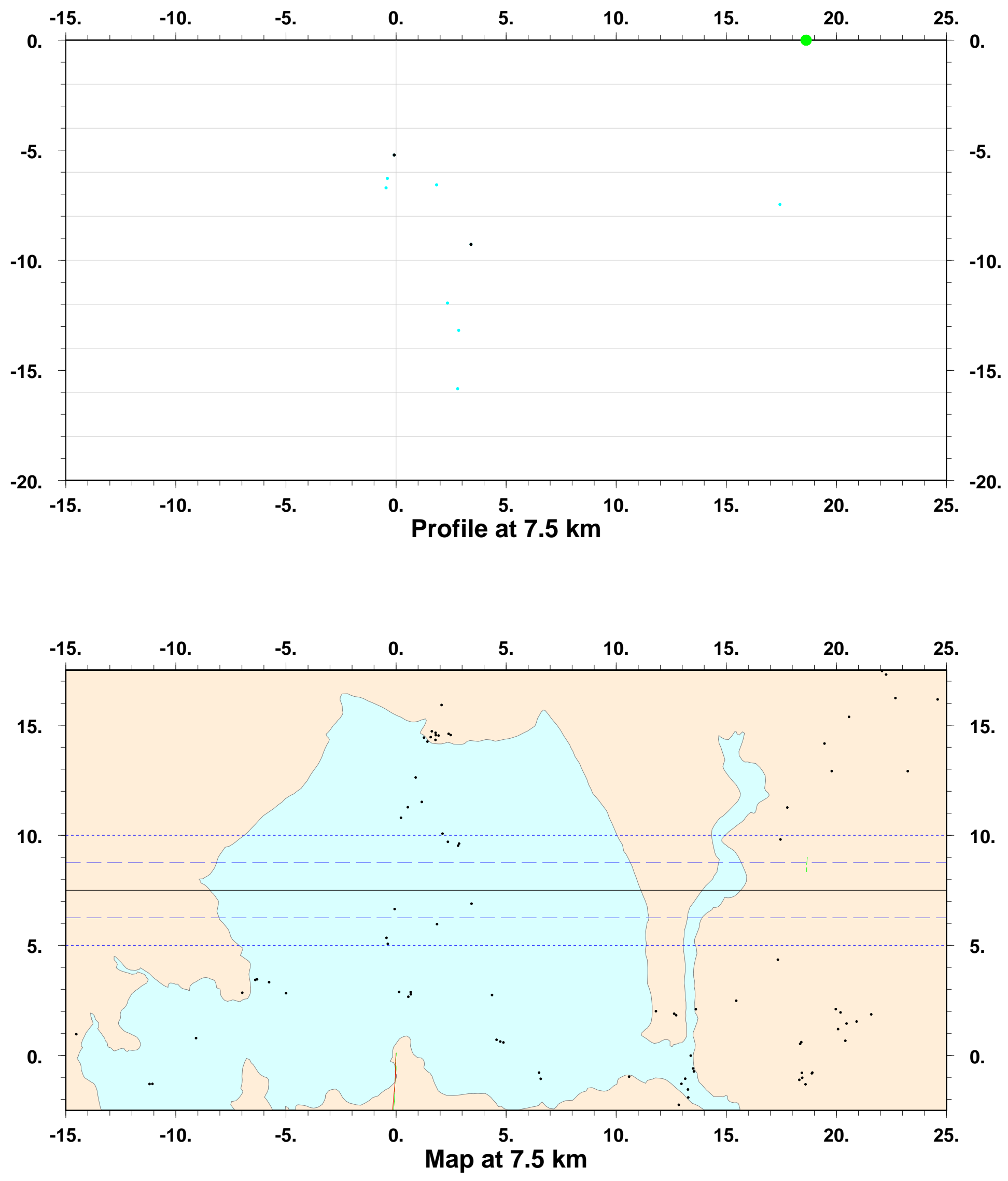

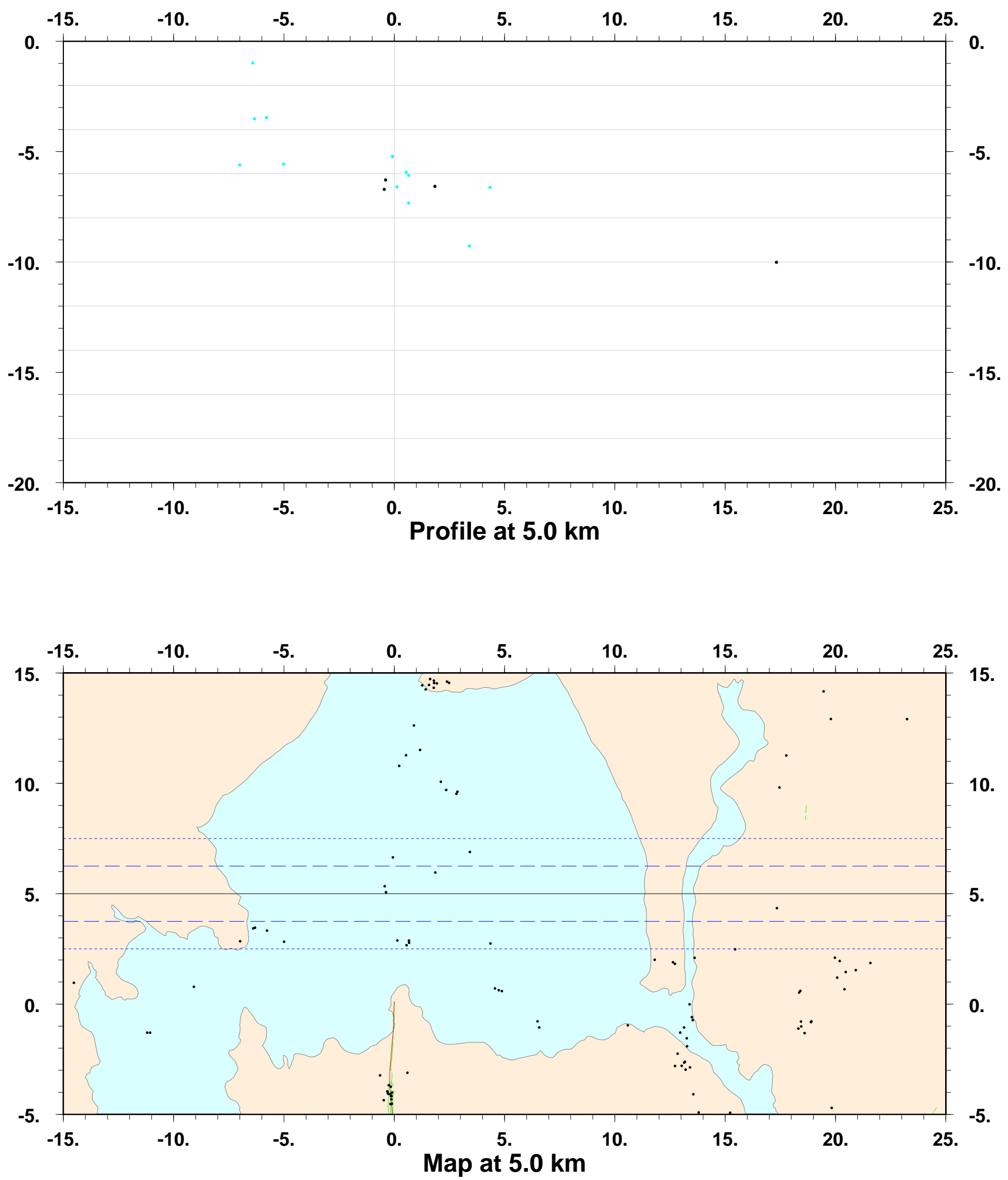

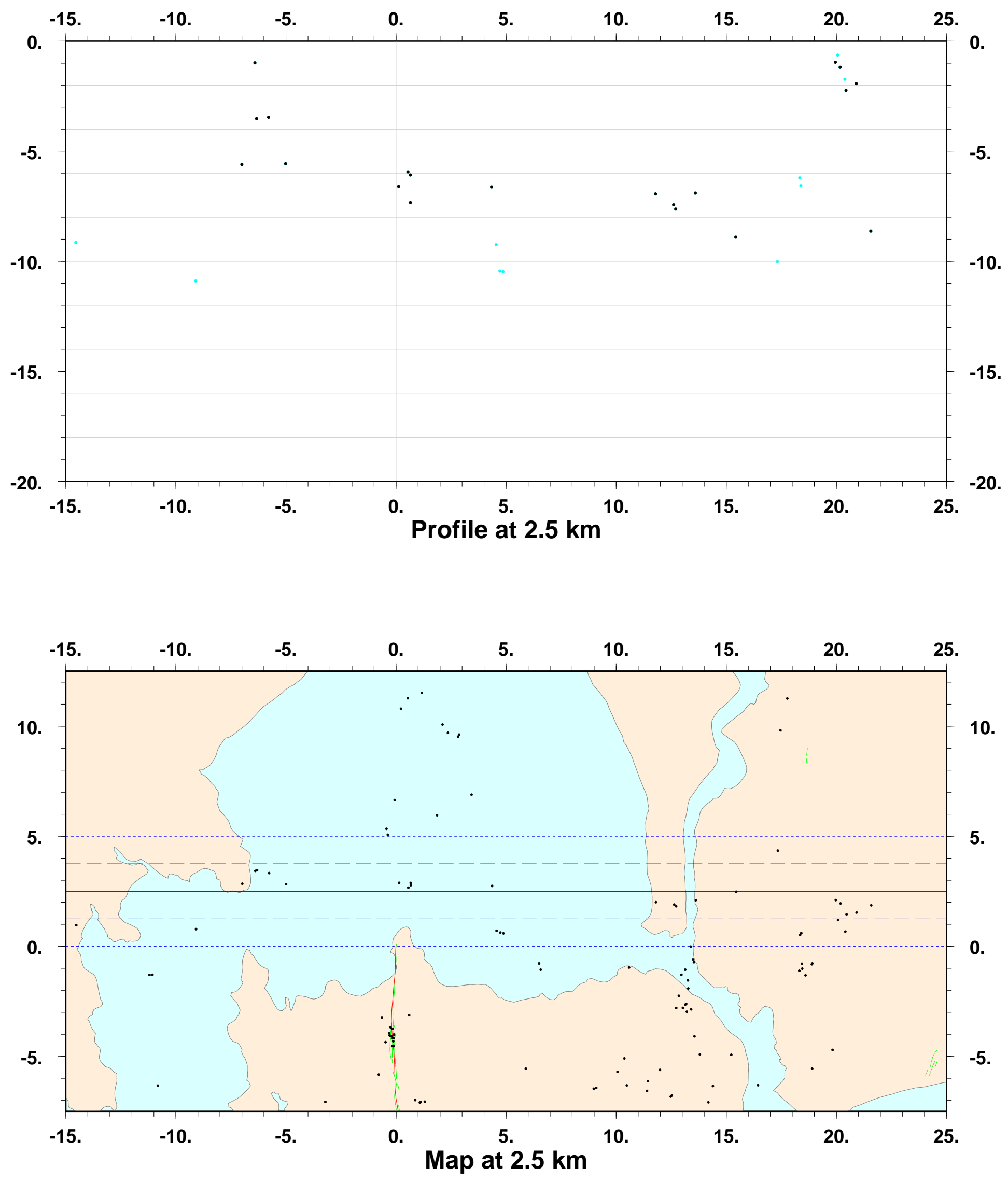

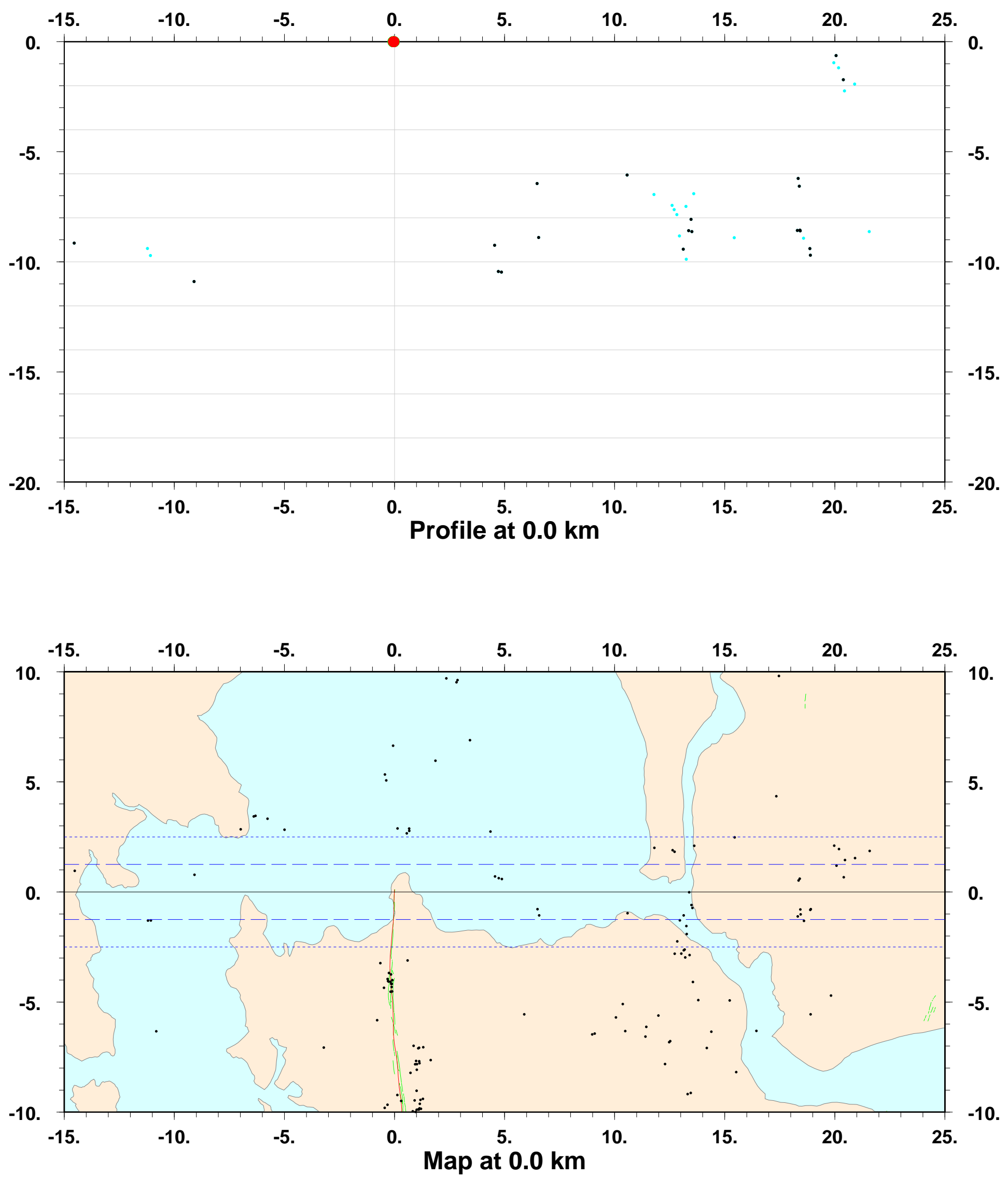

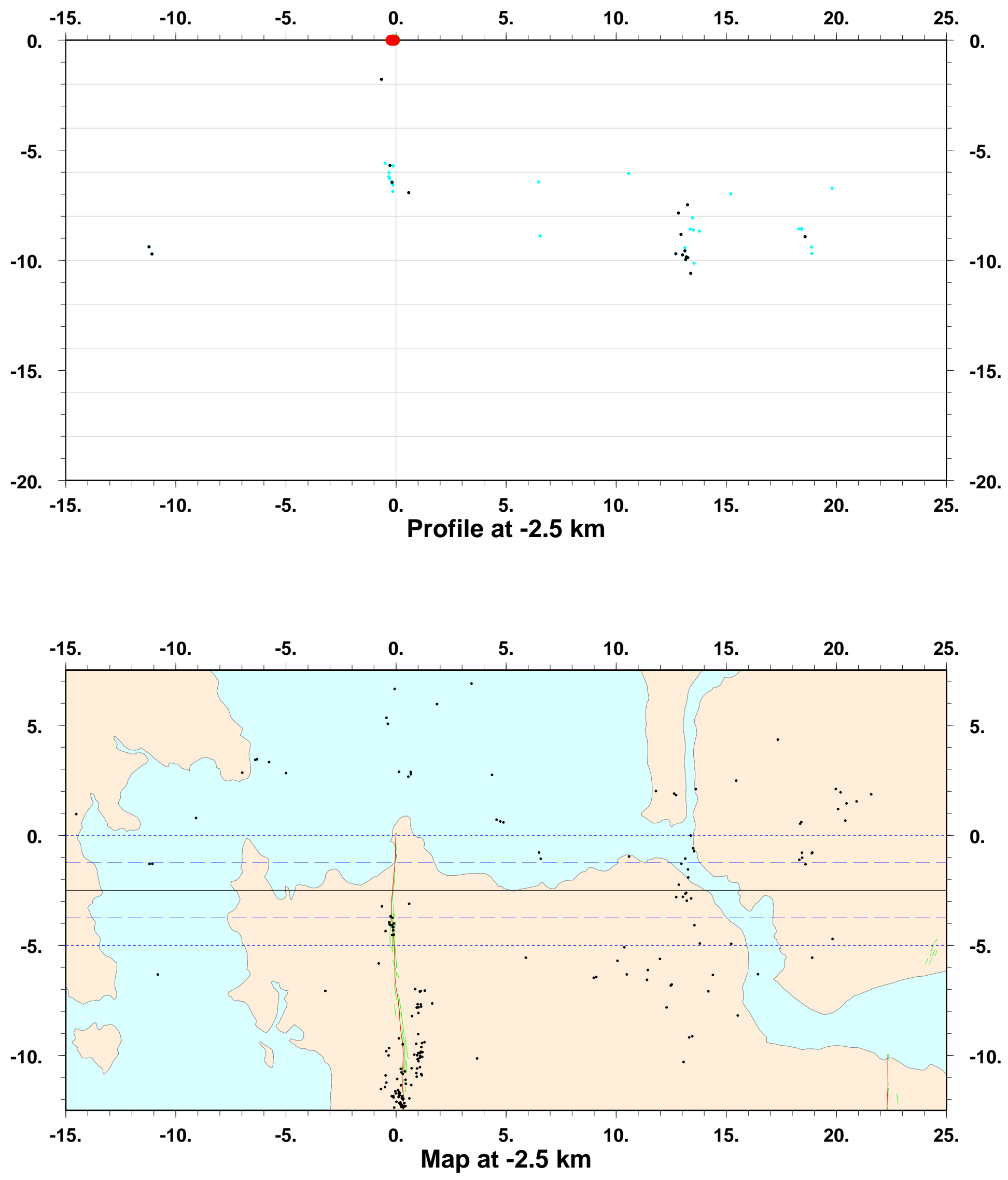

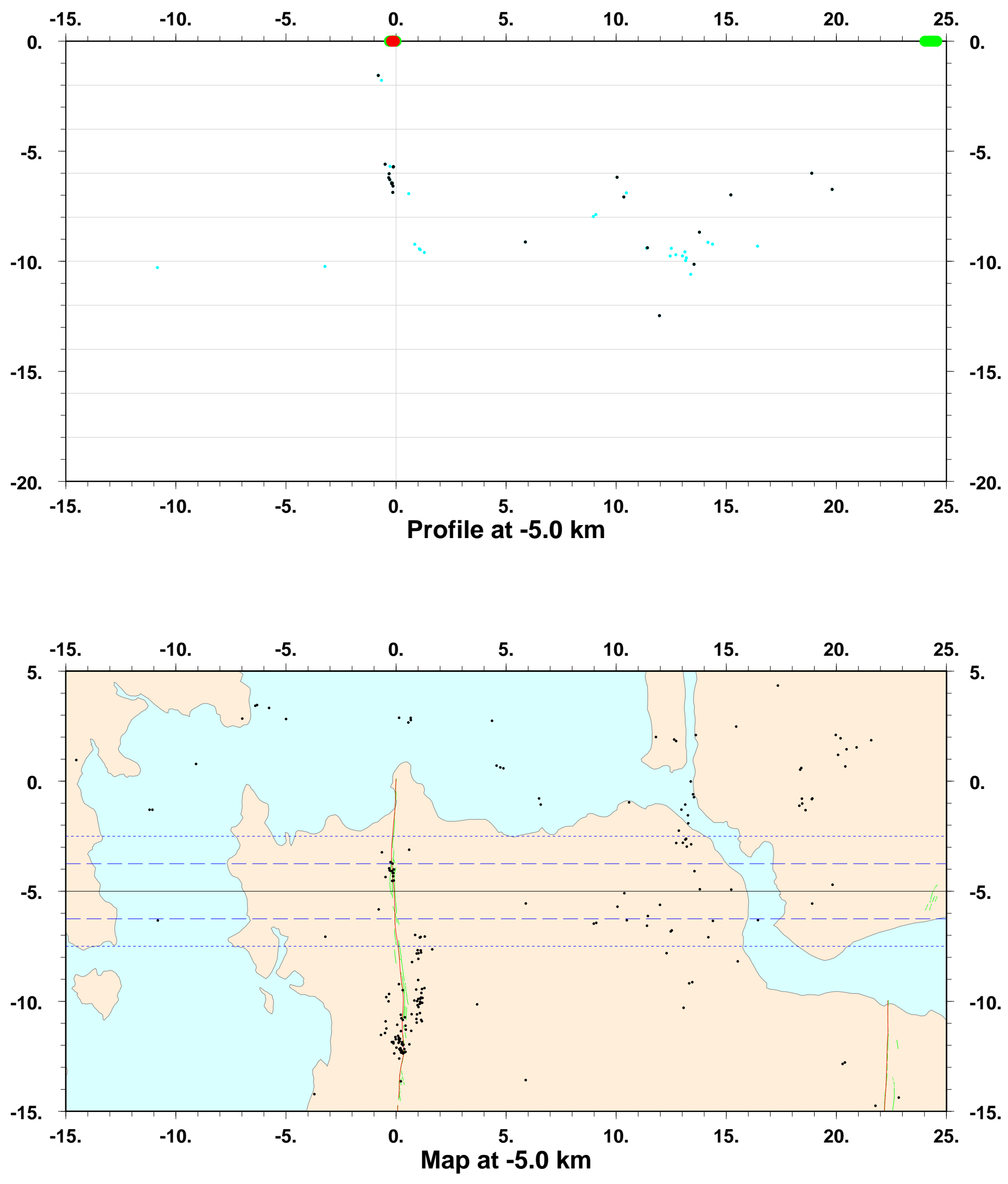

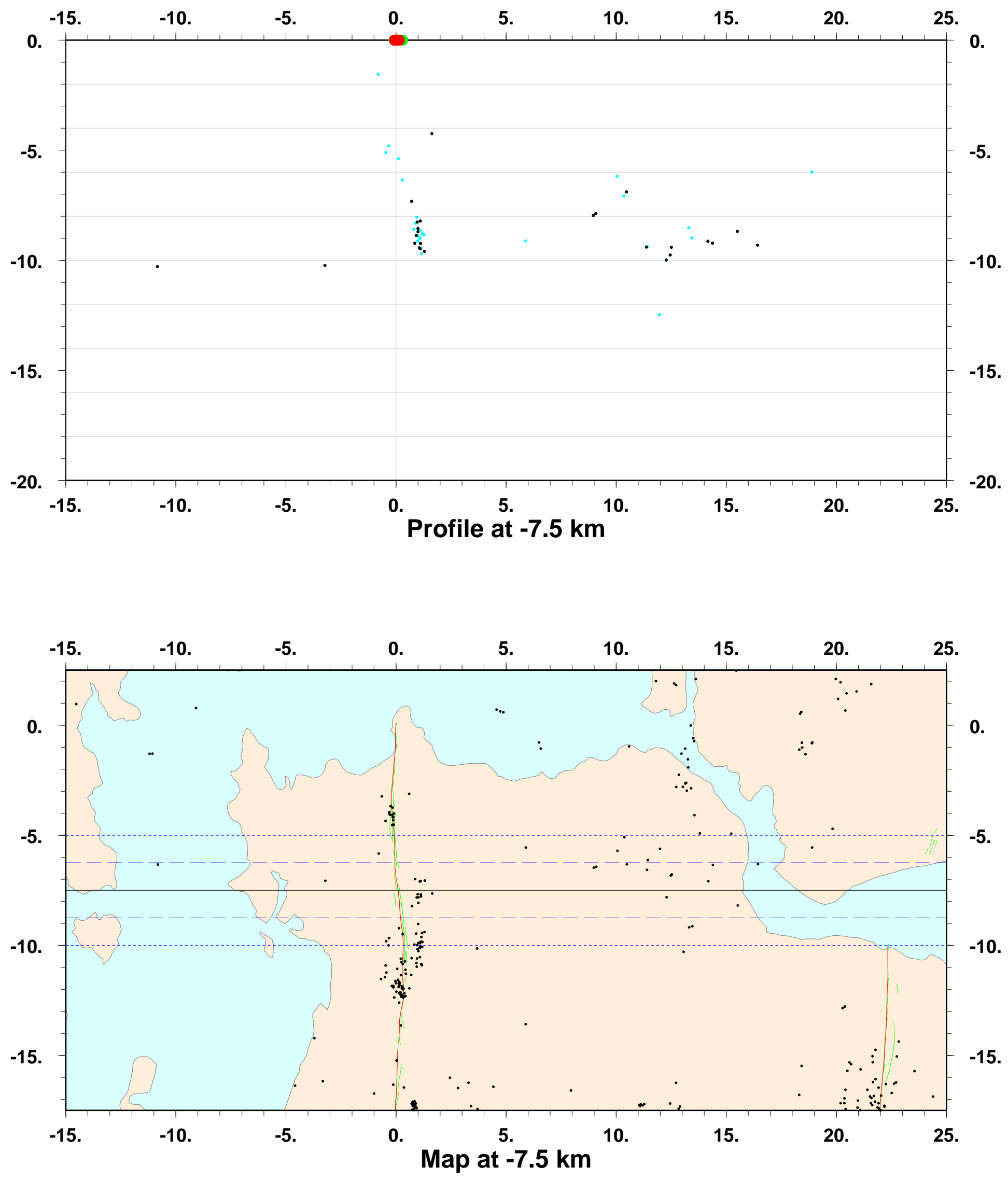

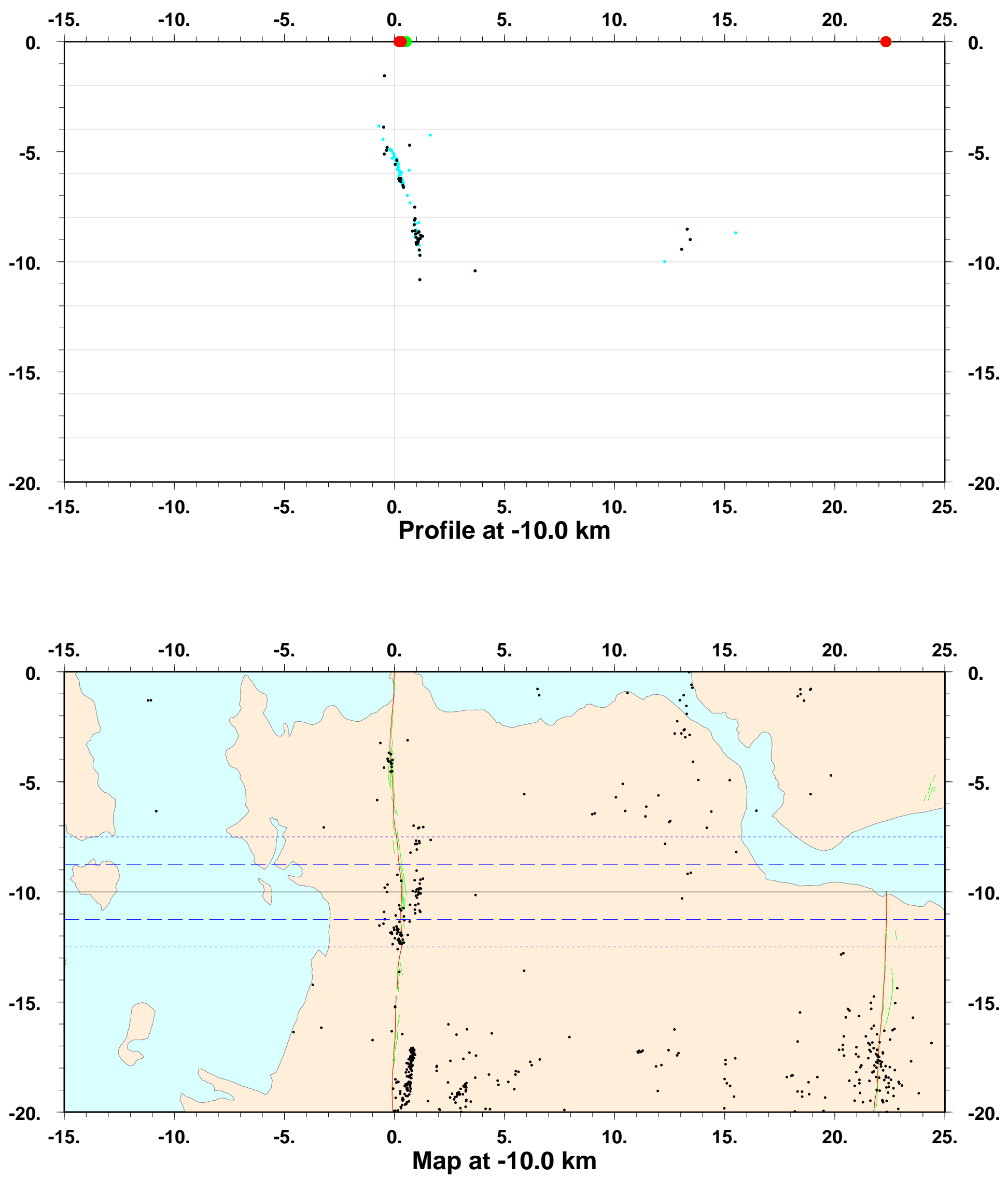

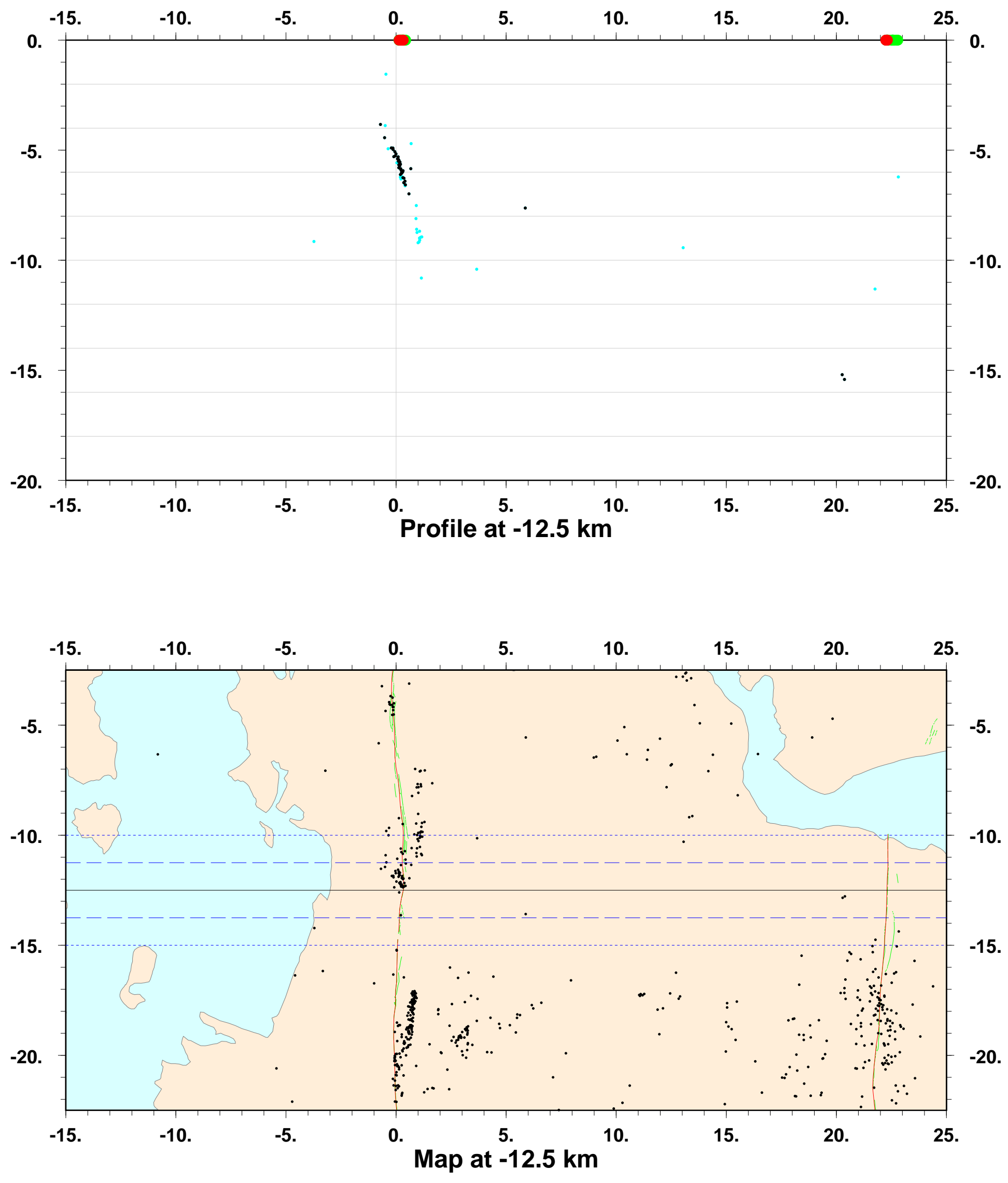

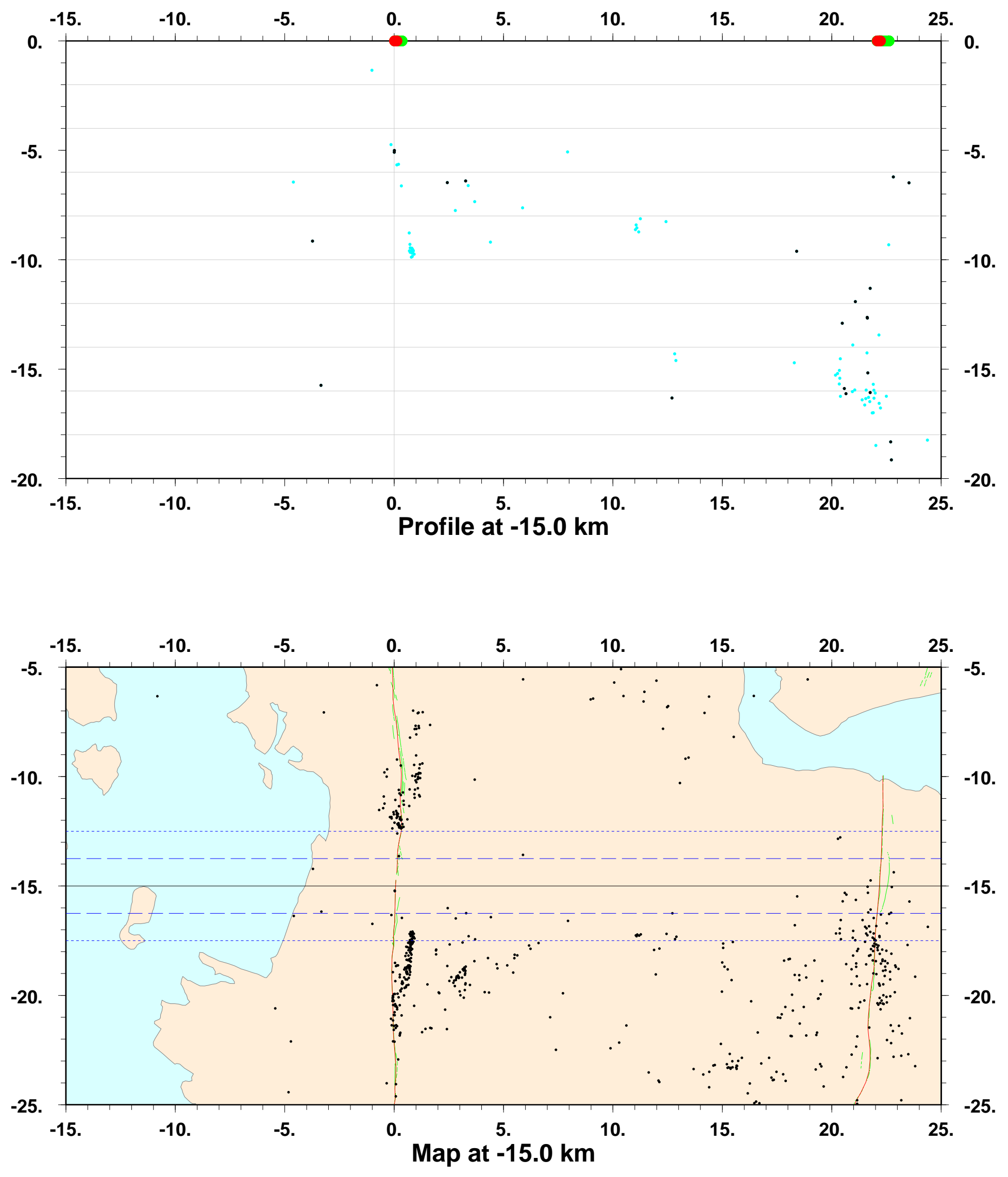


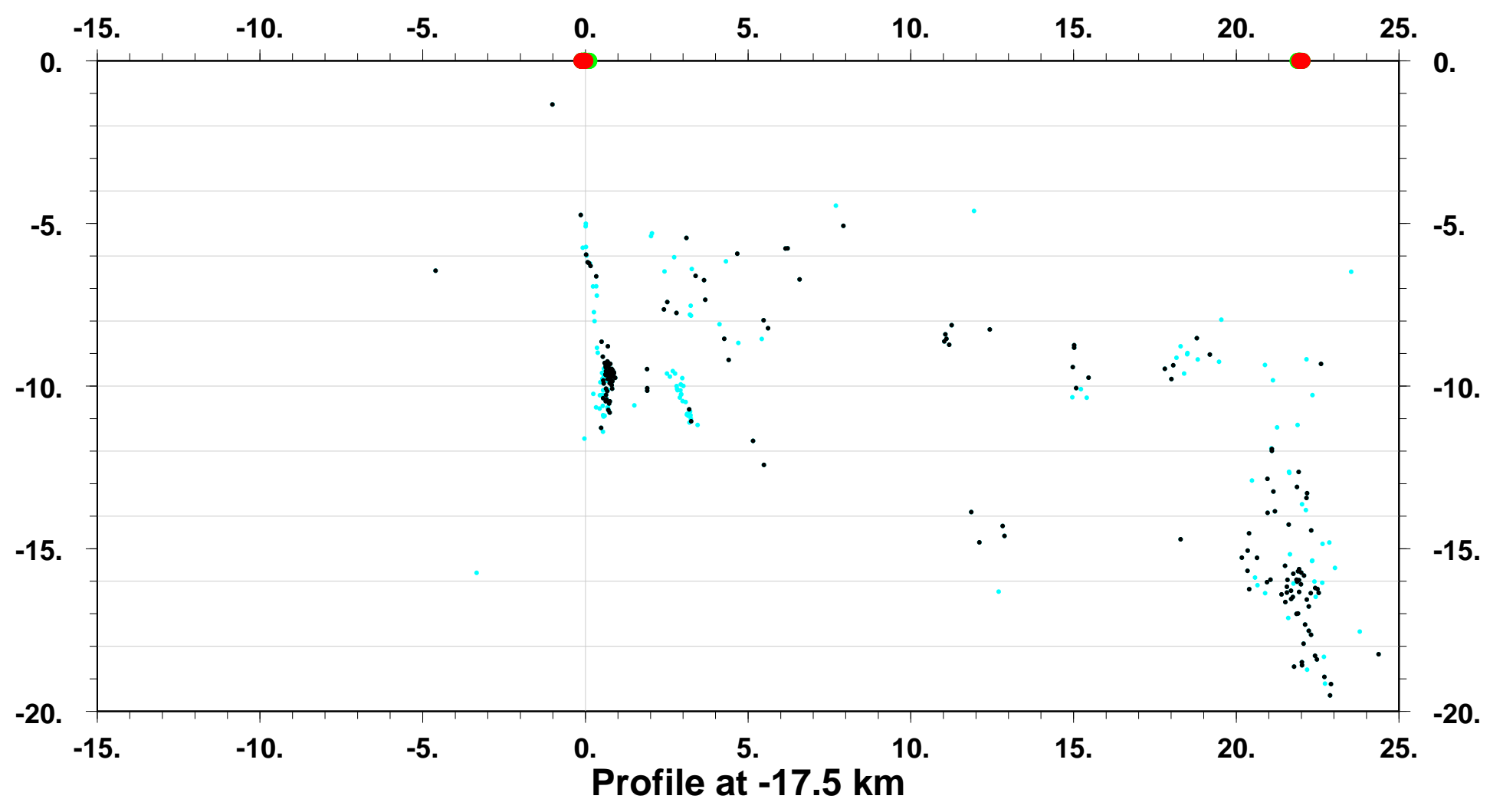

$\begin{array}{llllllll}-15 . & -10 . & -5 . & 0 . & 5 . & 10 . & 15 . & 20 .\end{array}$

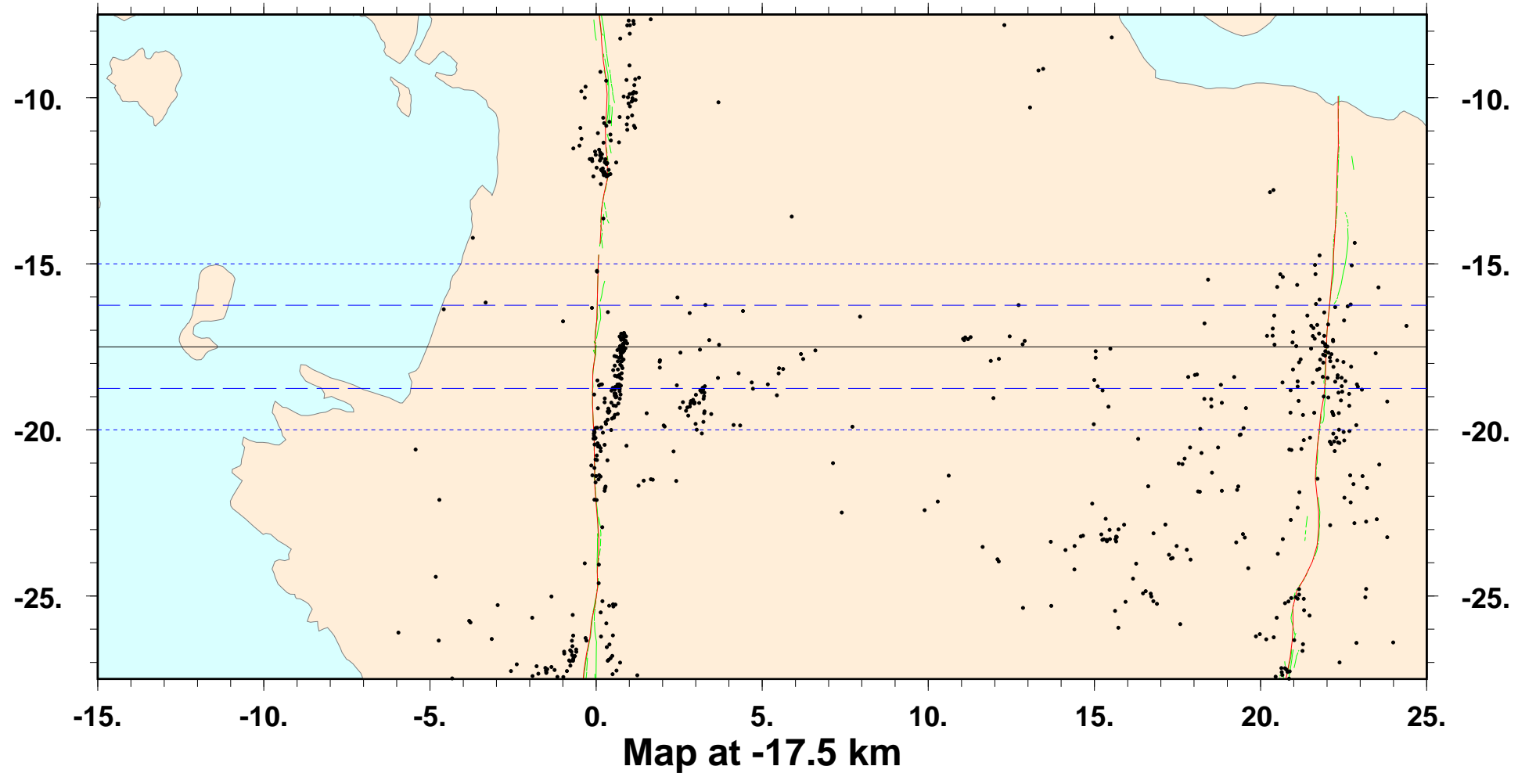



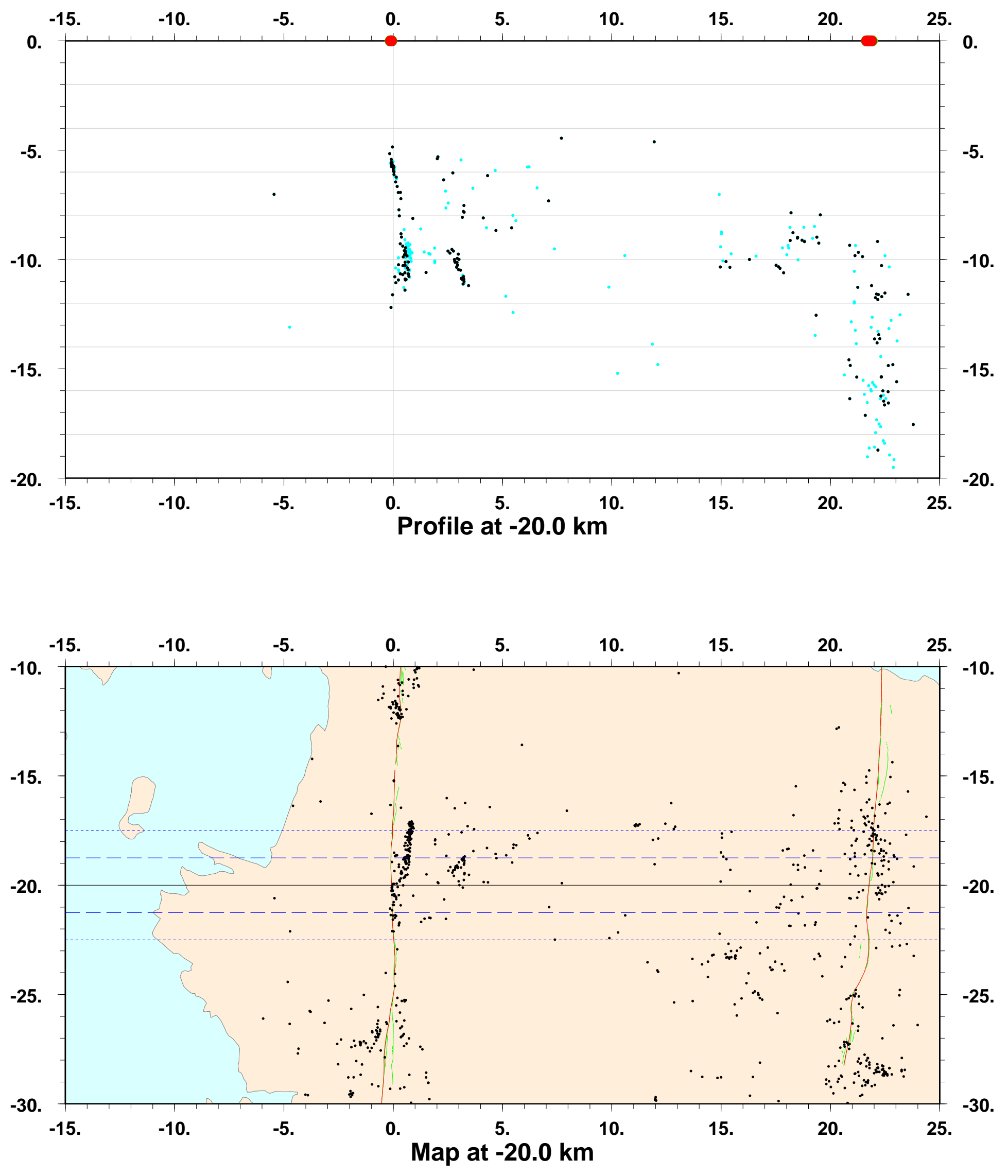


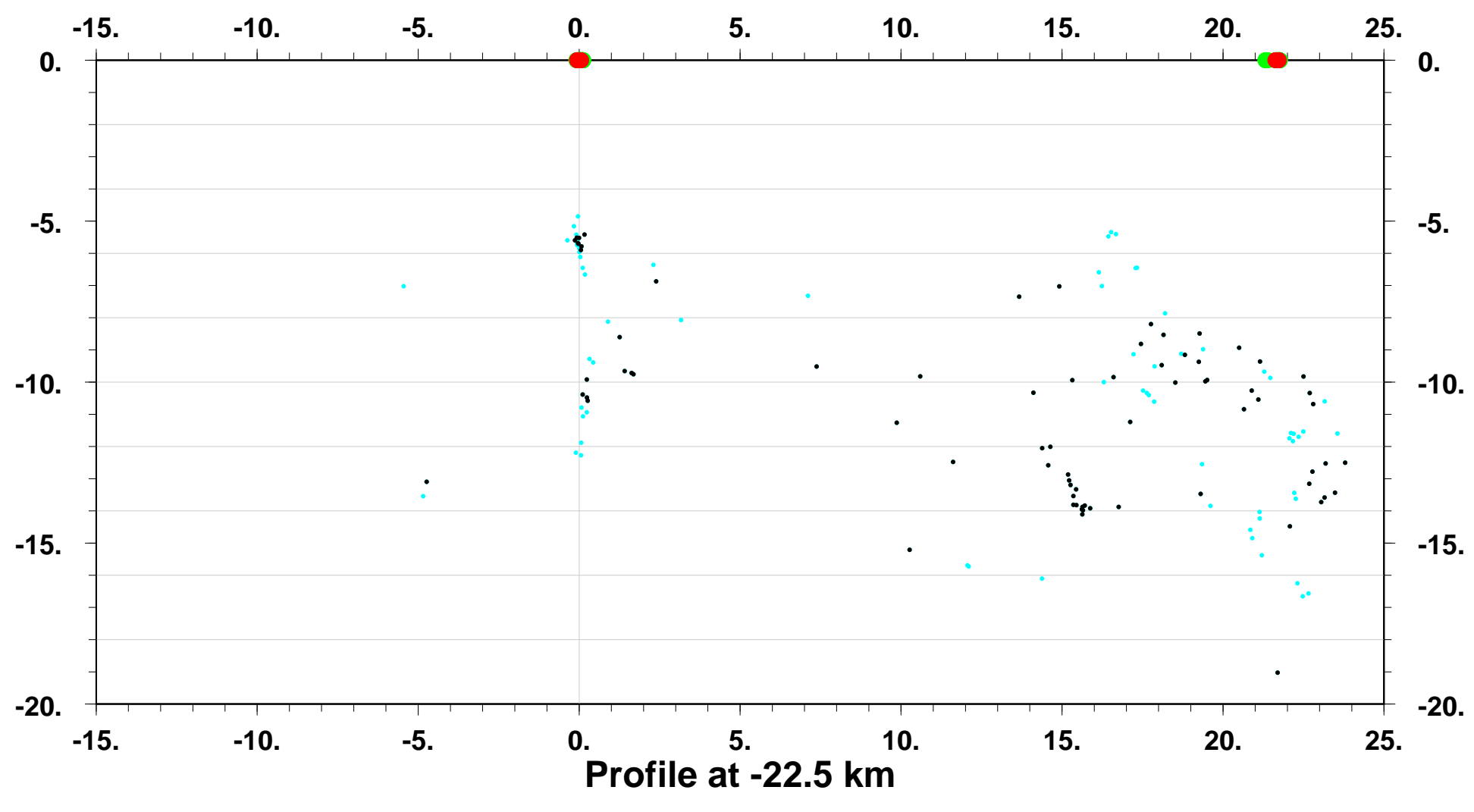

$\begin{array}{llllllll}-15 . & -10 . & -5 . & 0 . & 5 . & 10 . & 15 . & 20 .\end{array}$

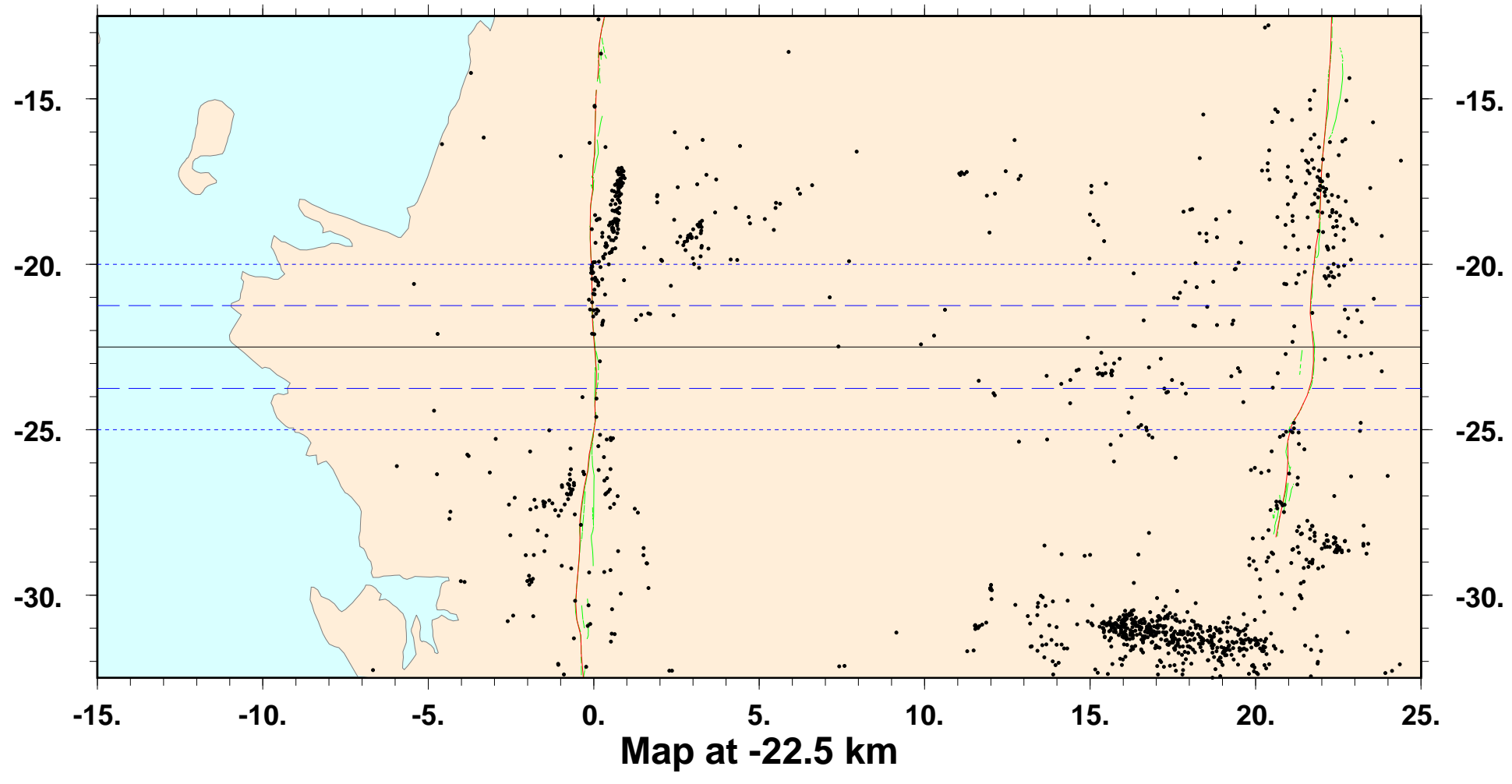



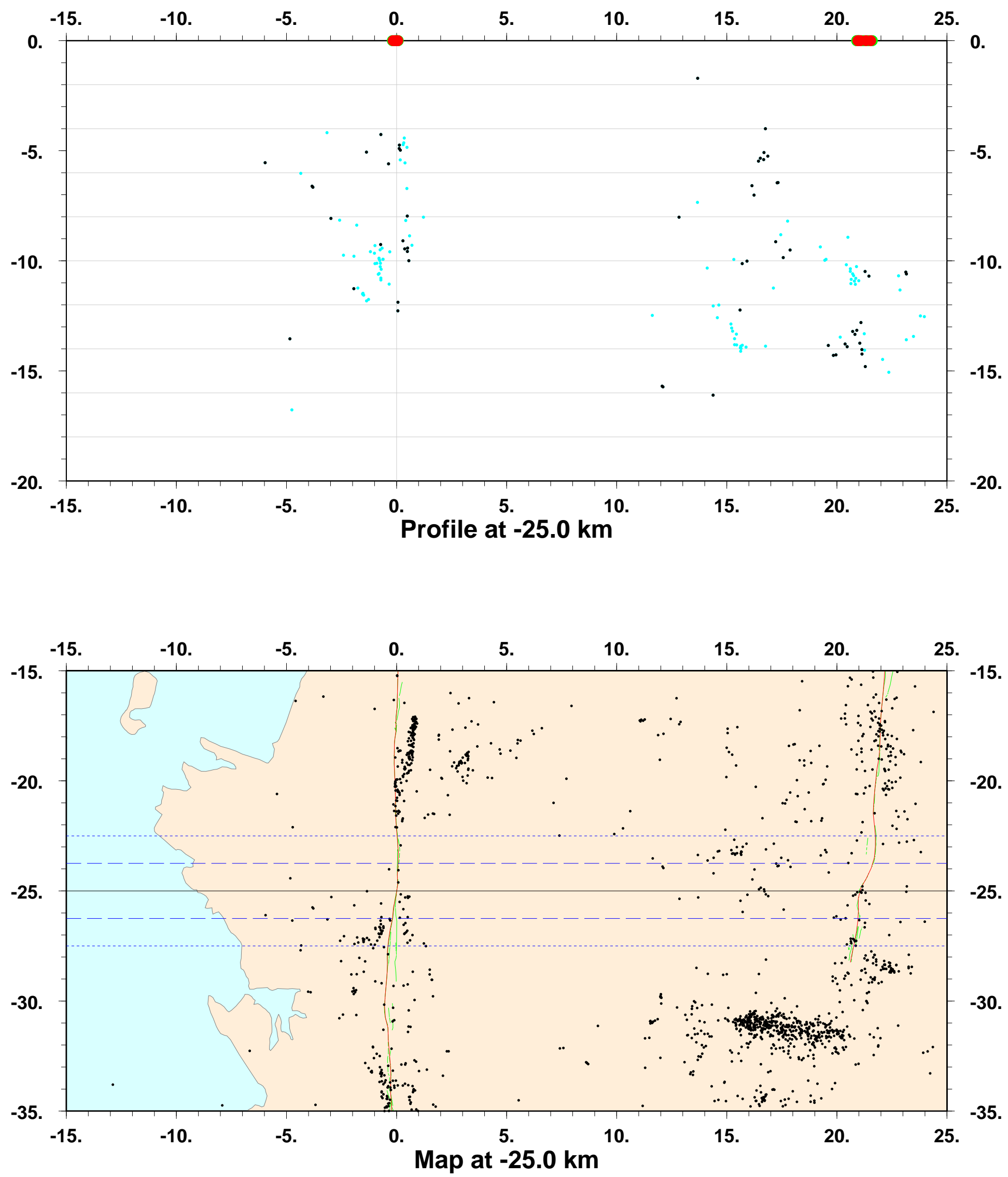


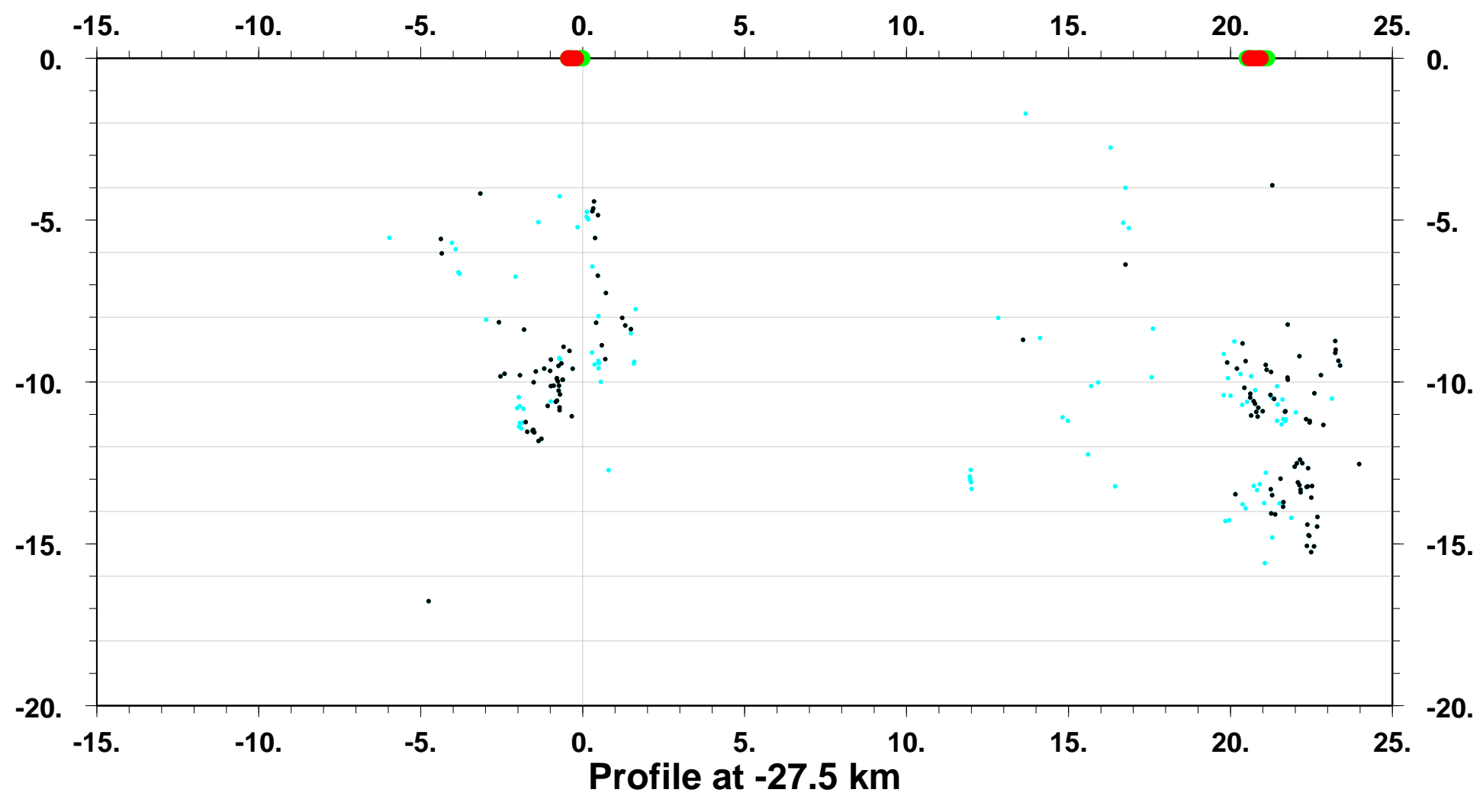

$\begin{array}{llllllll}-15 . & -10 . & -5 . & 0 . & 5 . & 10 . & 15 . & 20 .\end{array}$

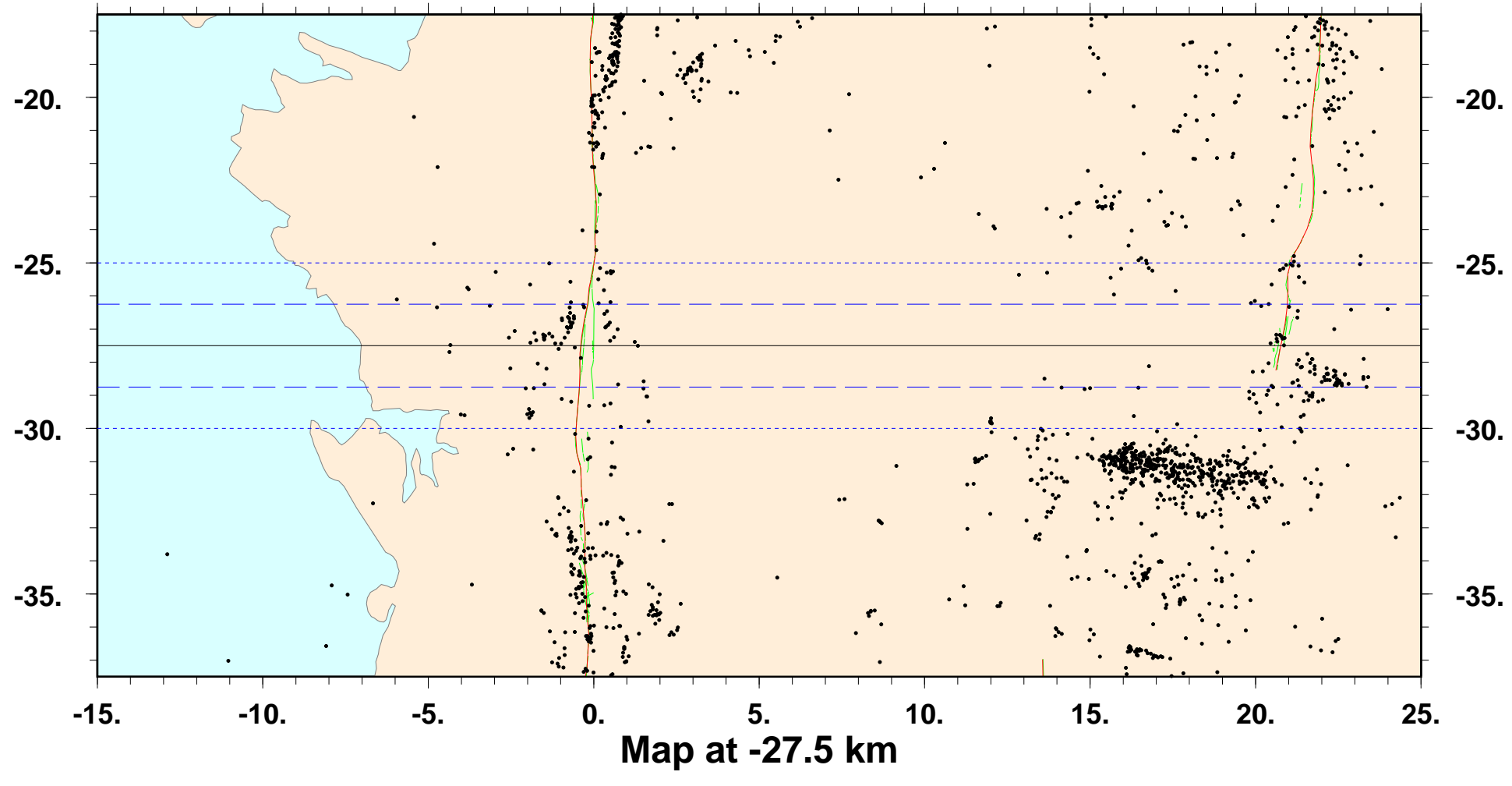



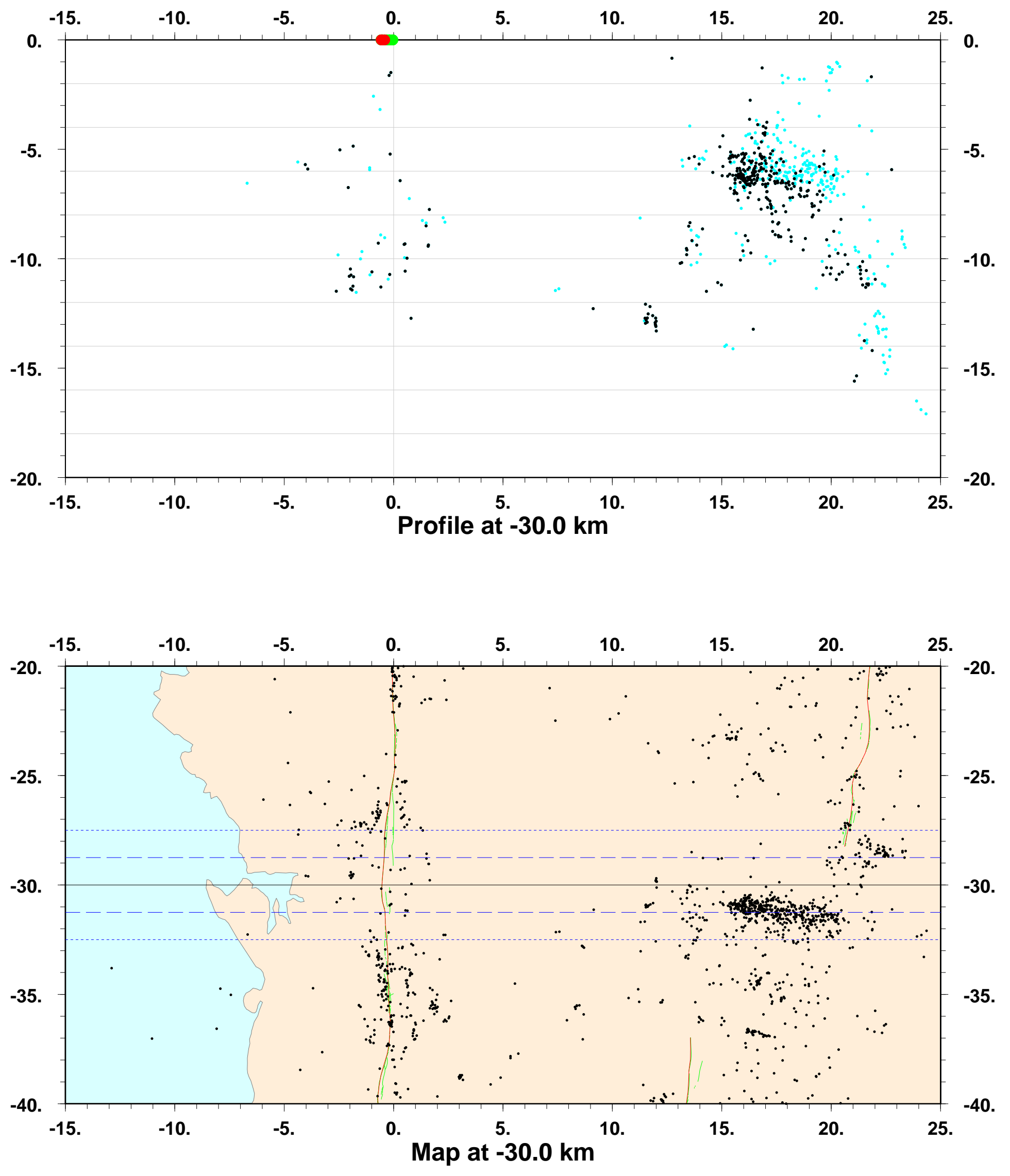


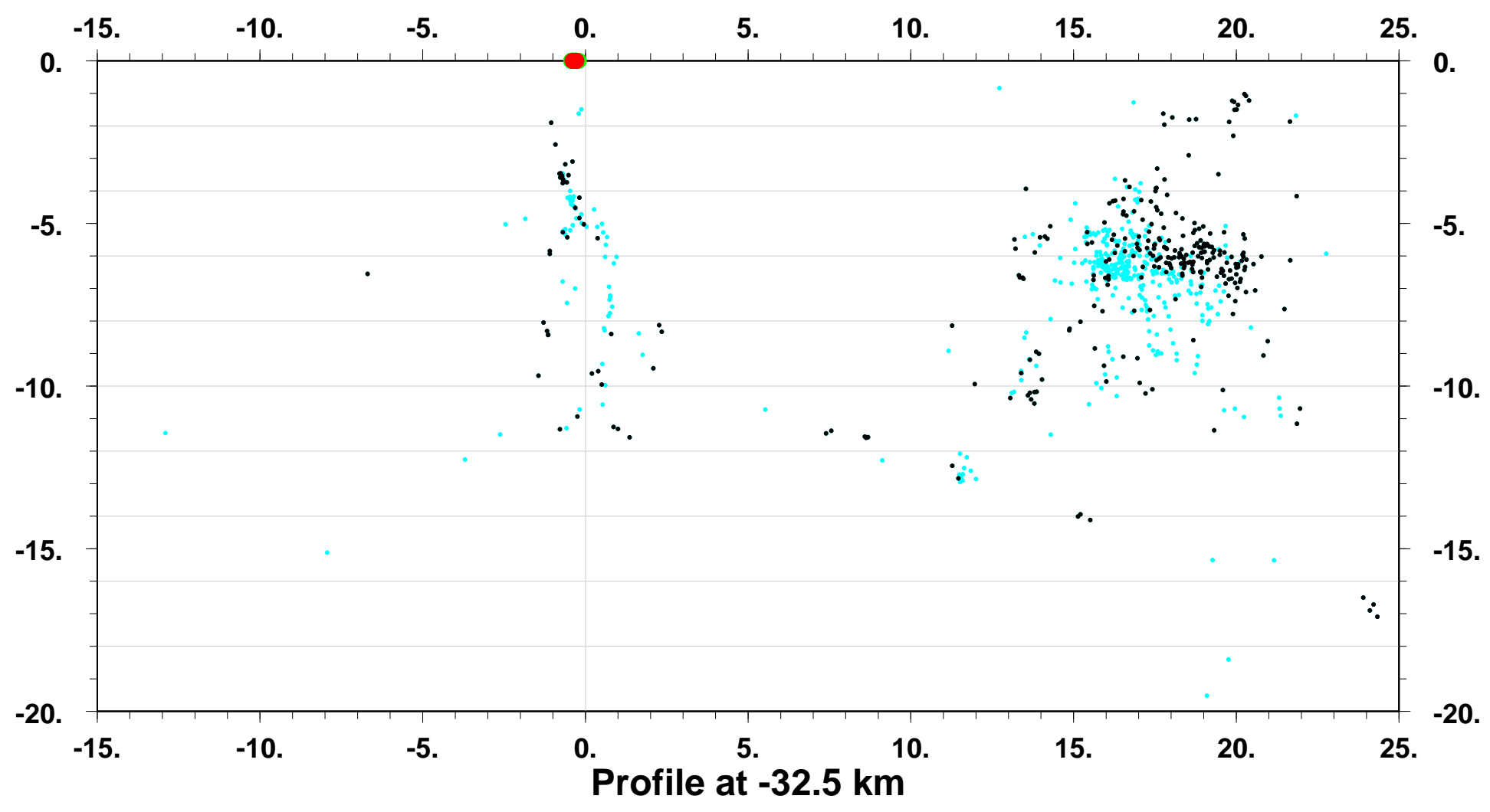

$\begin{array}{llllllll}-15 . & -10 . & -5 . & 0 . & 5 . & 10 . & 15 . & 20 .\end{array}$

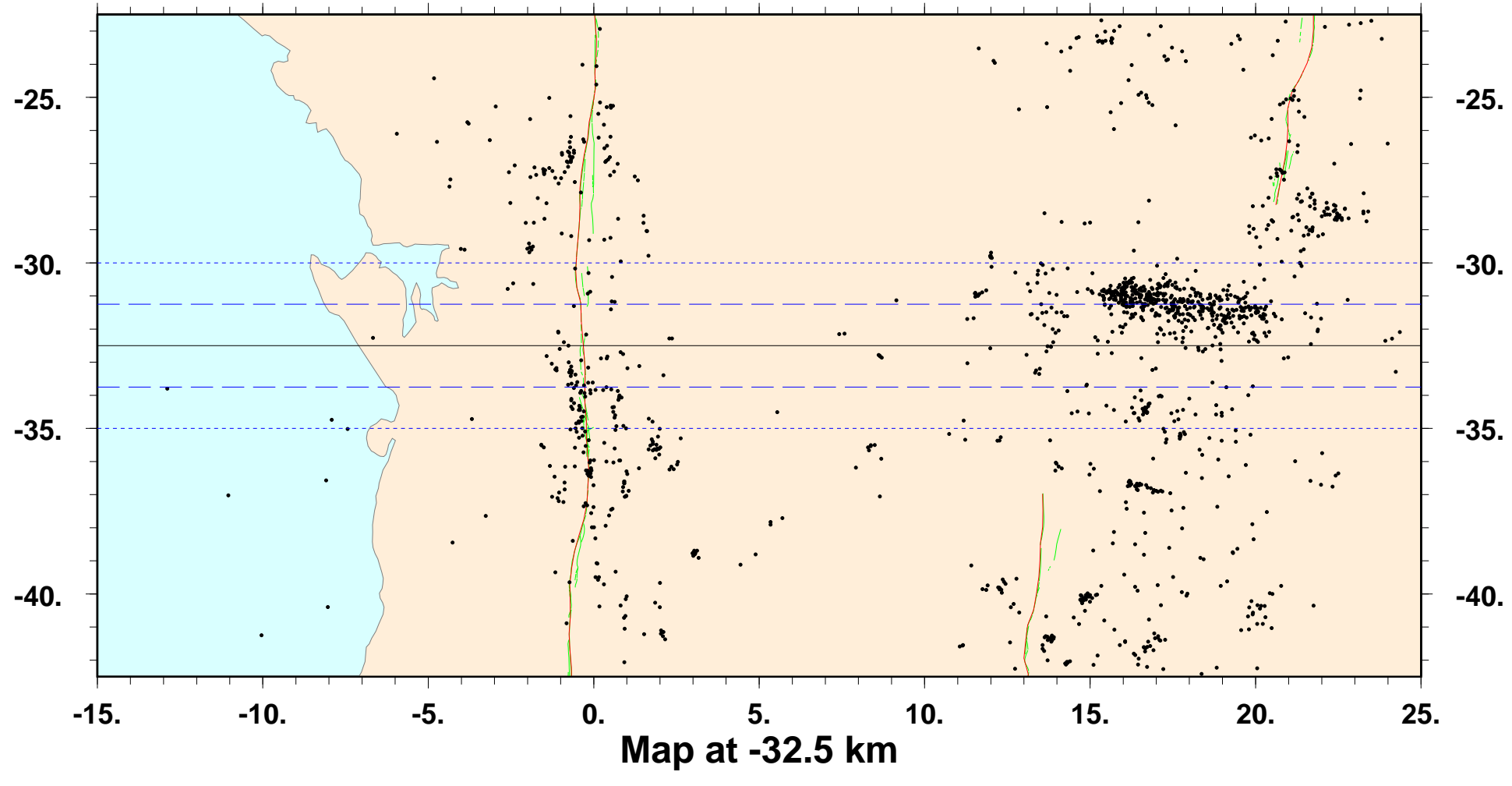




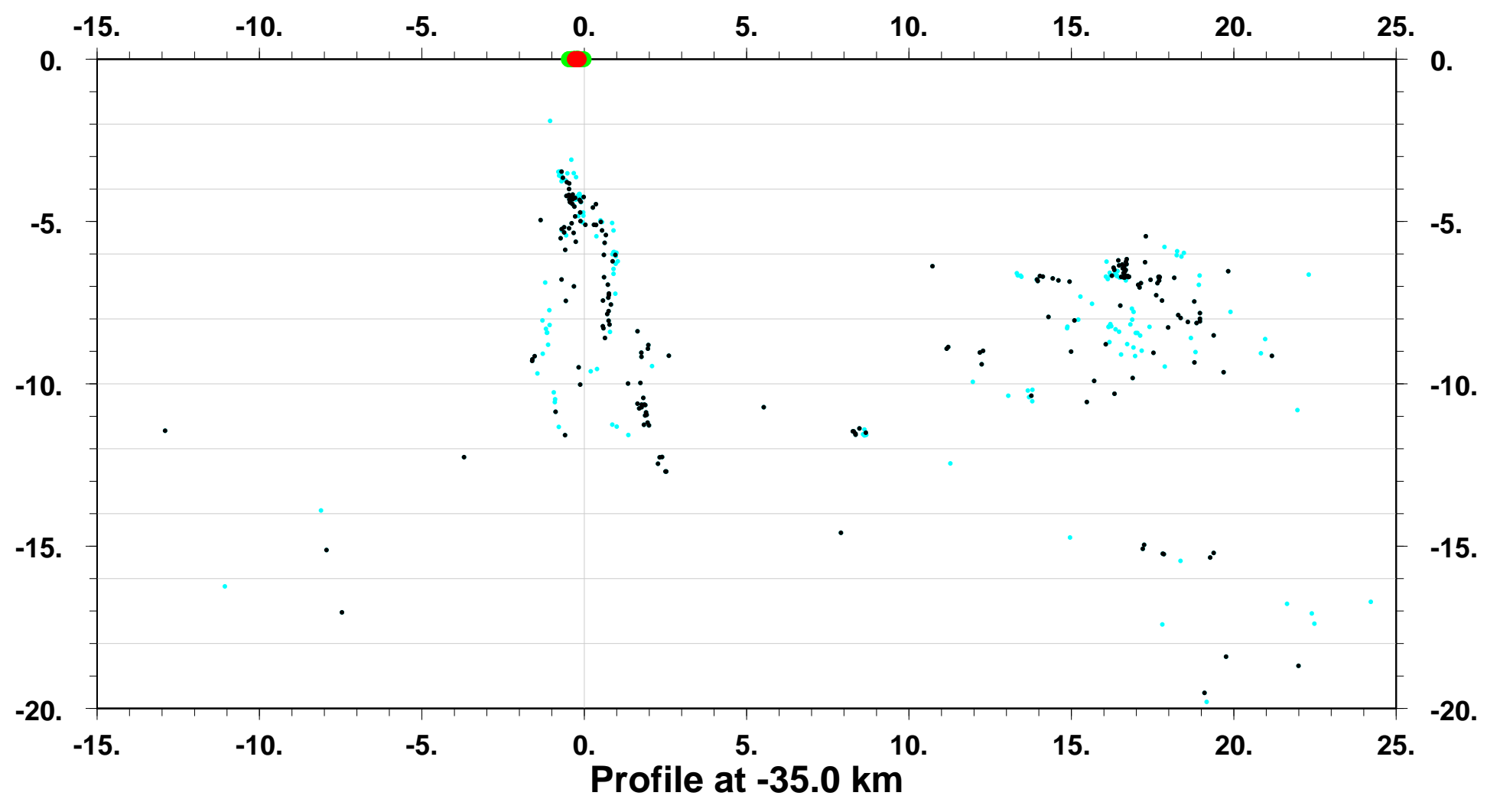

$\begin{array}{llllllll}-15 . & -10 . & -5 . & 0 . & 5 . & 10 . & 15 . & 20 .\end{array}$

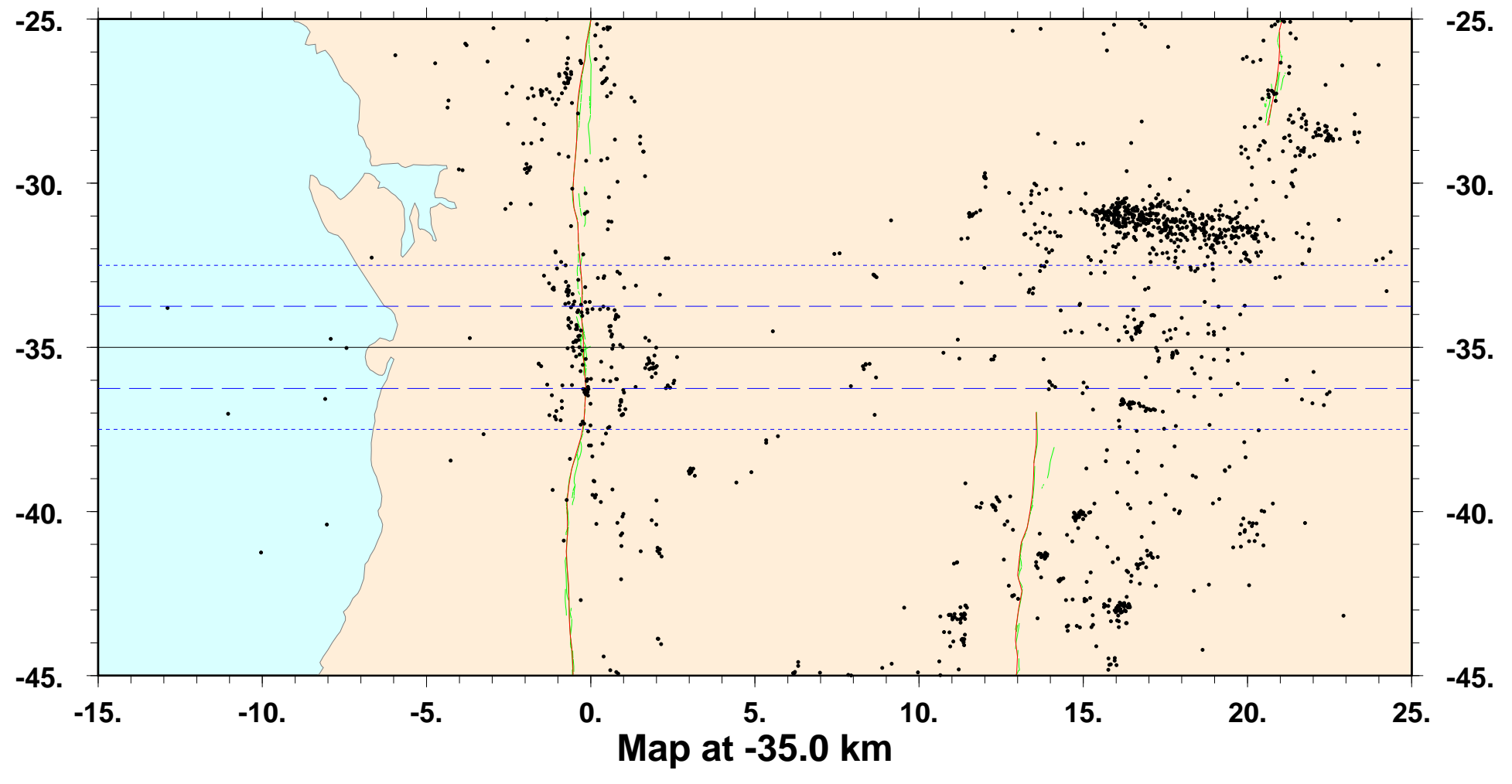




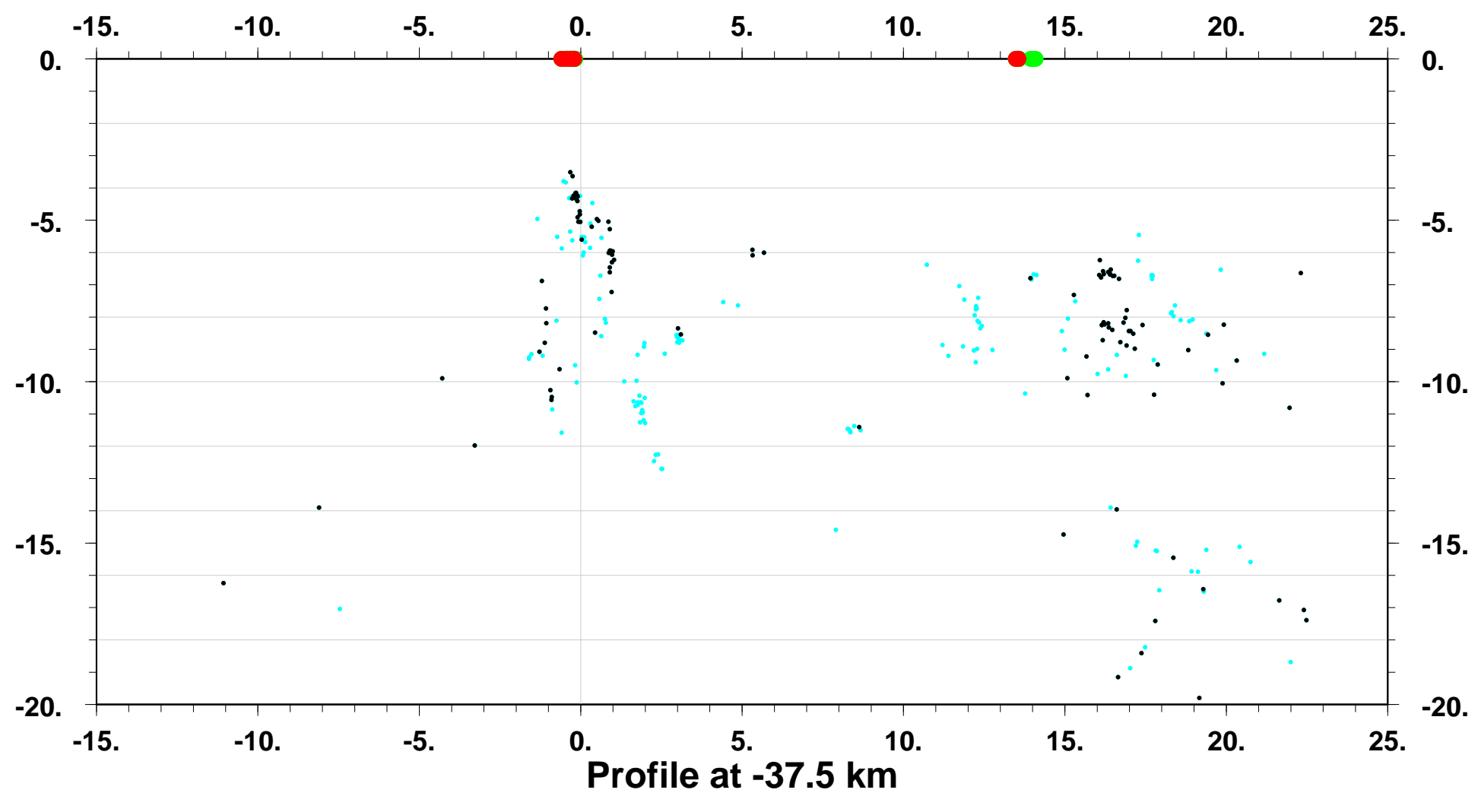

$\begin{array}{rrrrrrrrr}-15 . & -10 . & -5 . & 0 . & 5 . & 10 . & 15 . & 20 . & 25 .\end{array}$

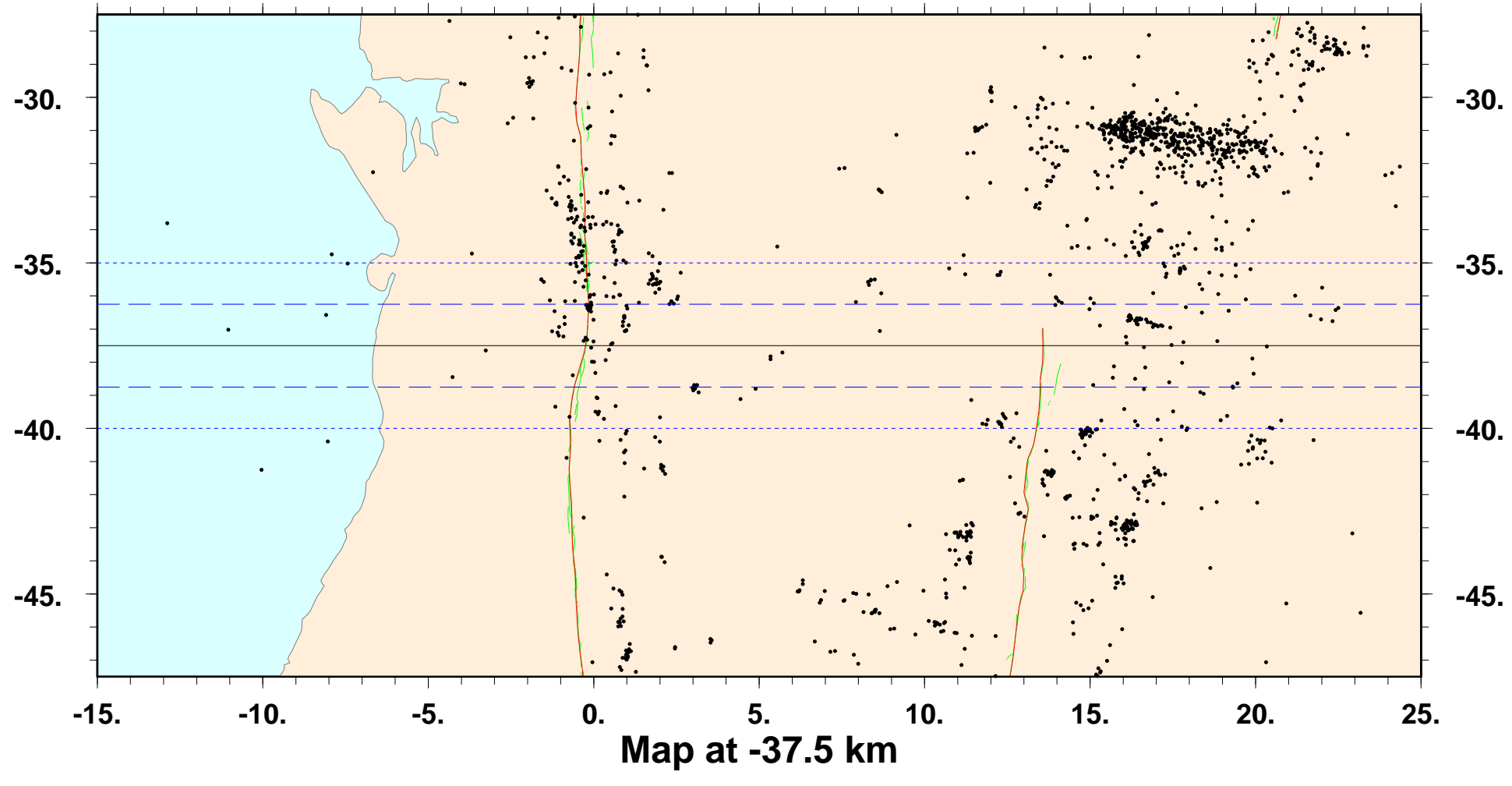



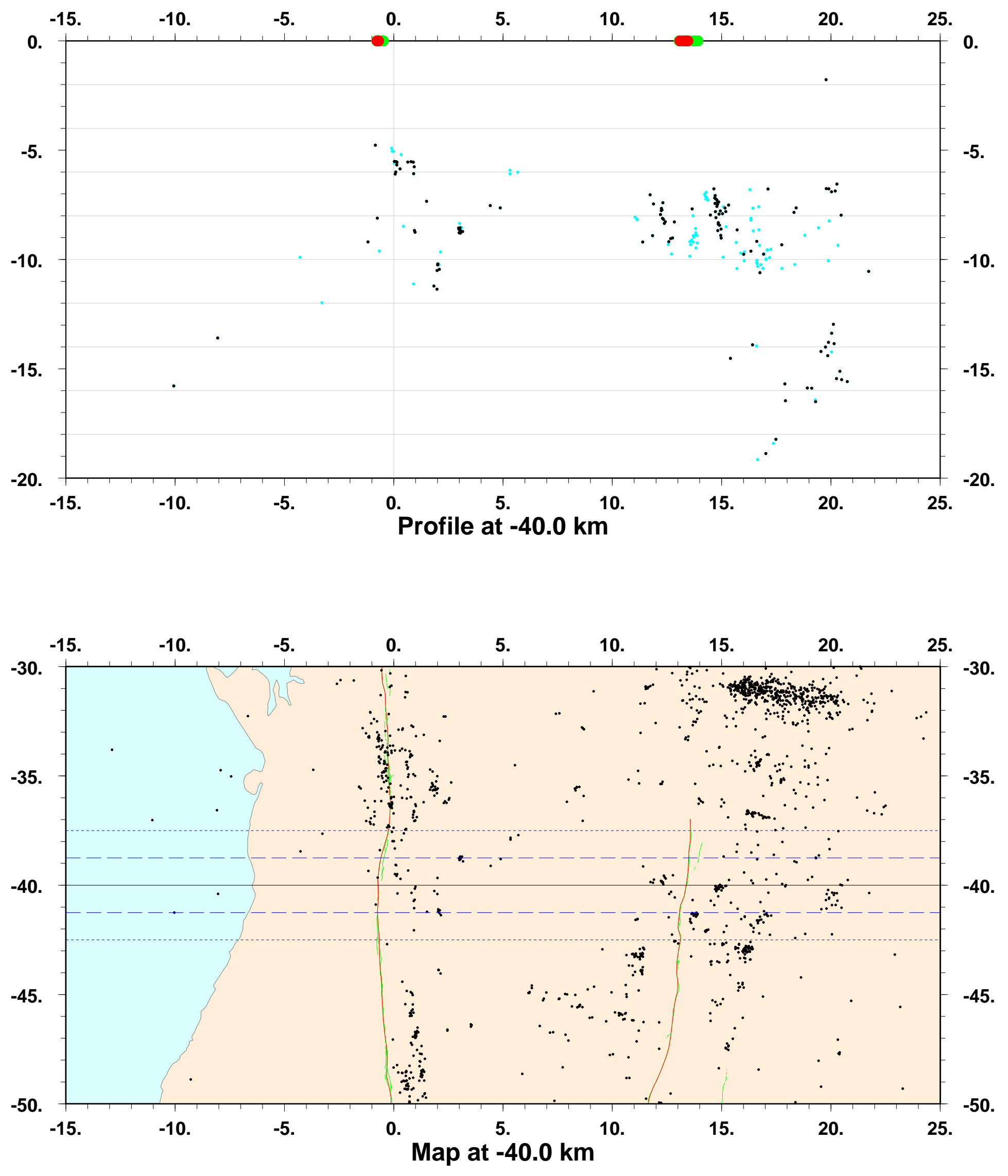

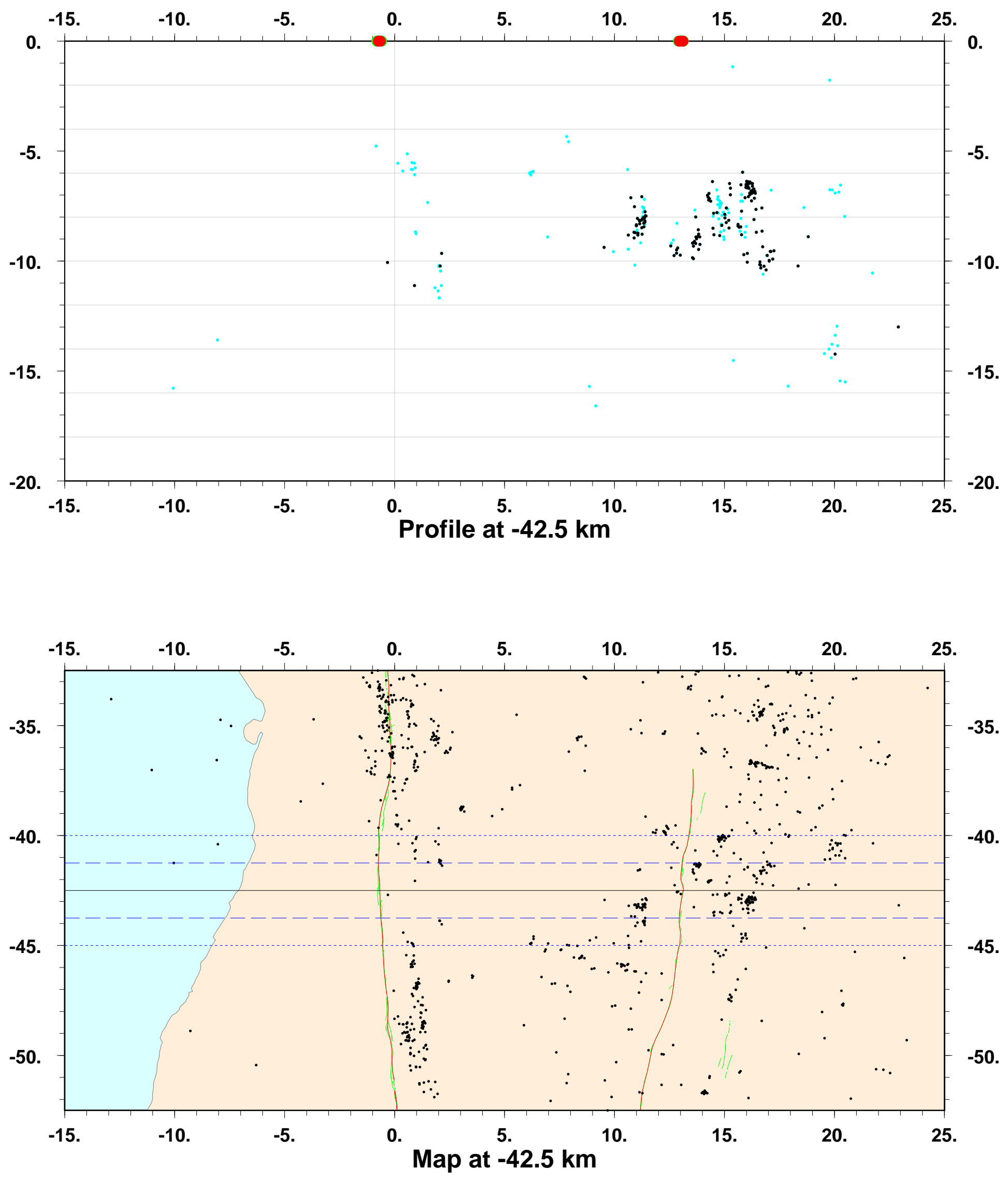

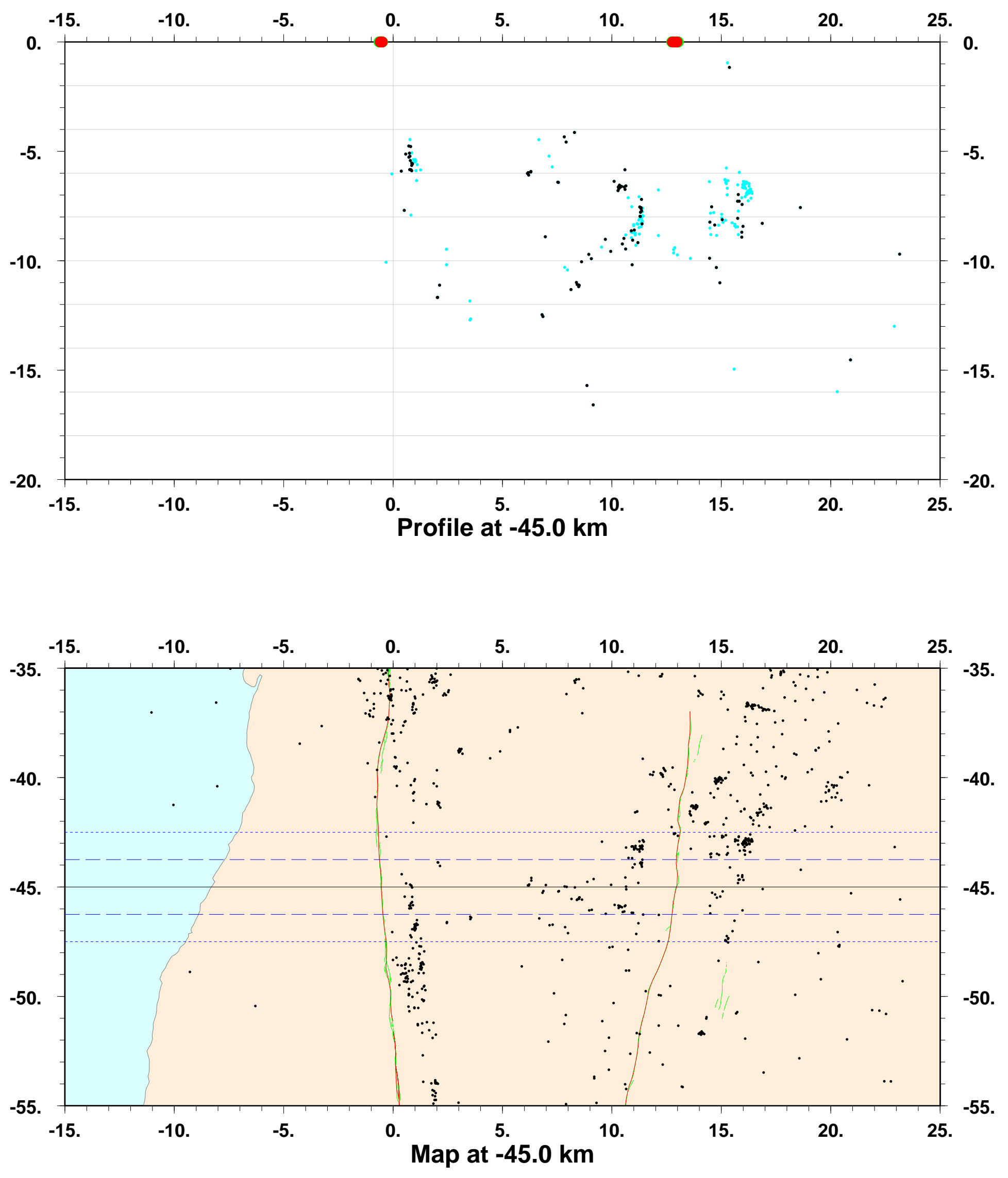


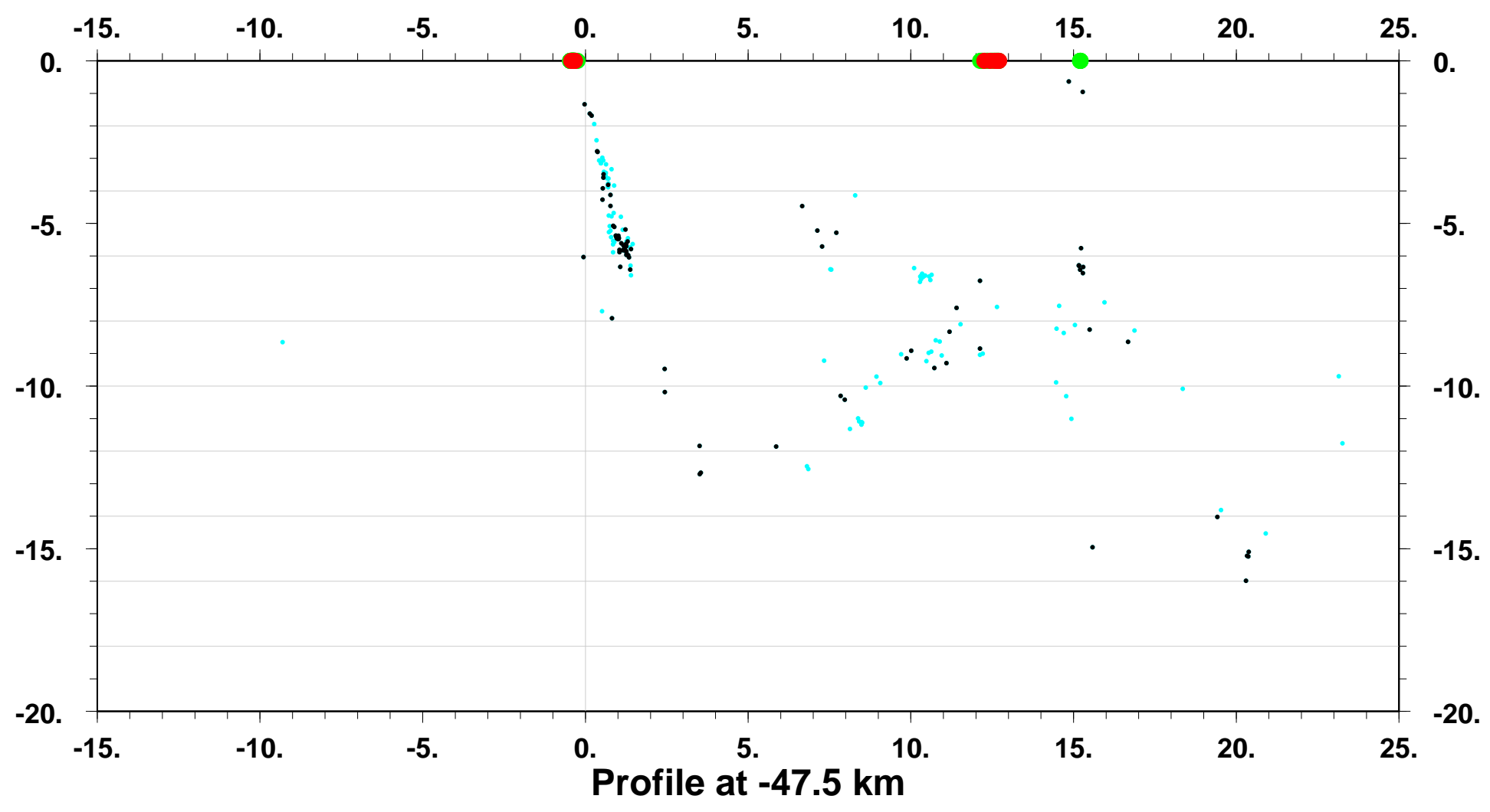

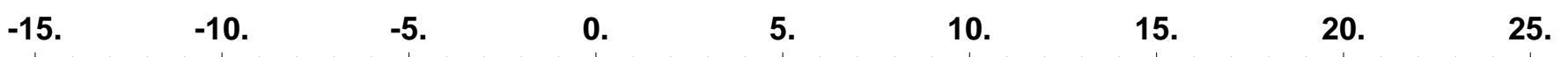

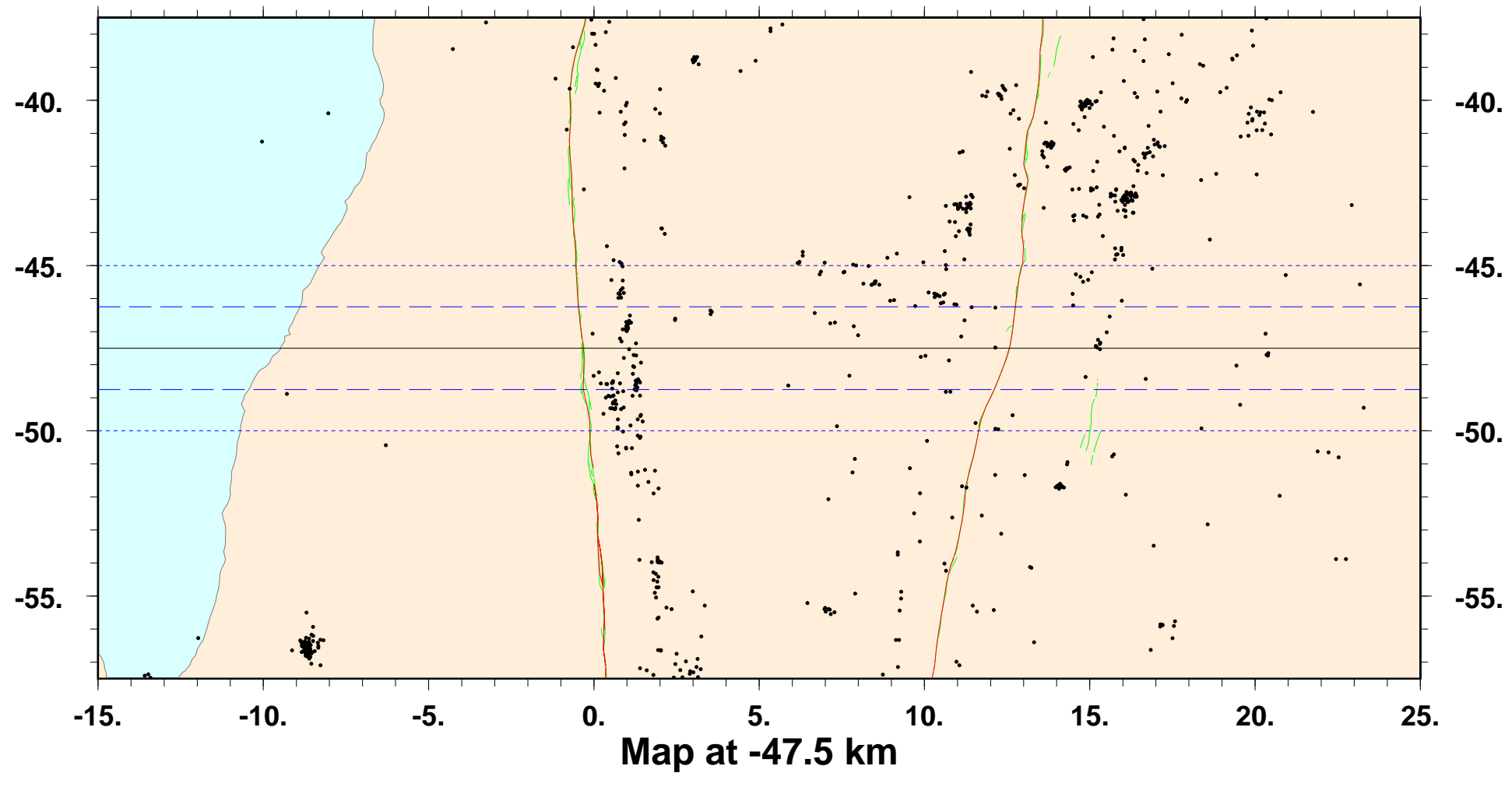



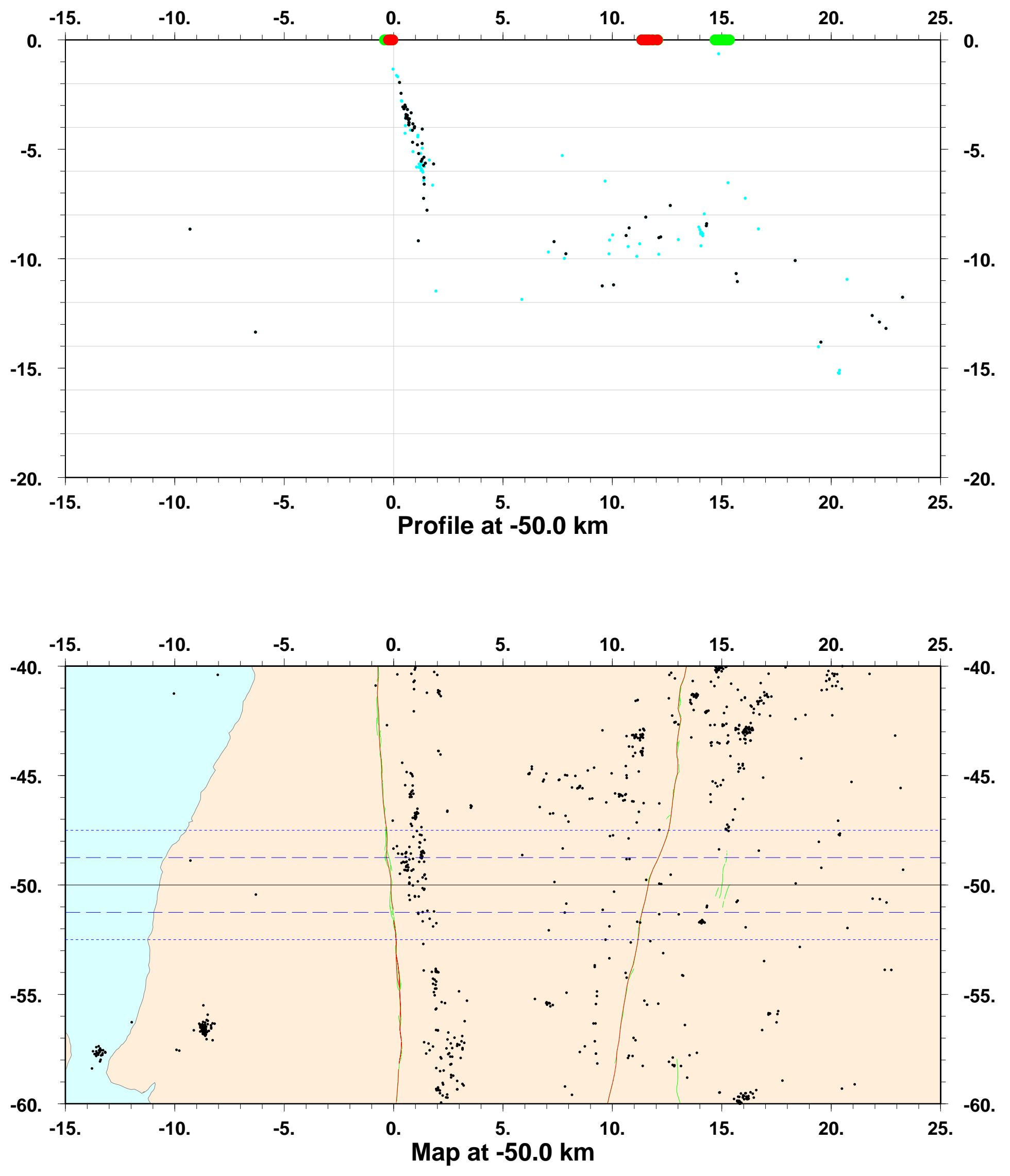

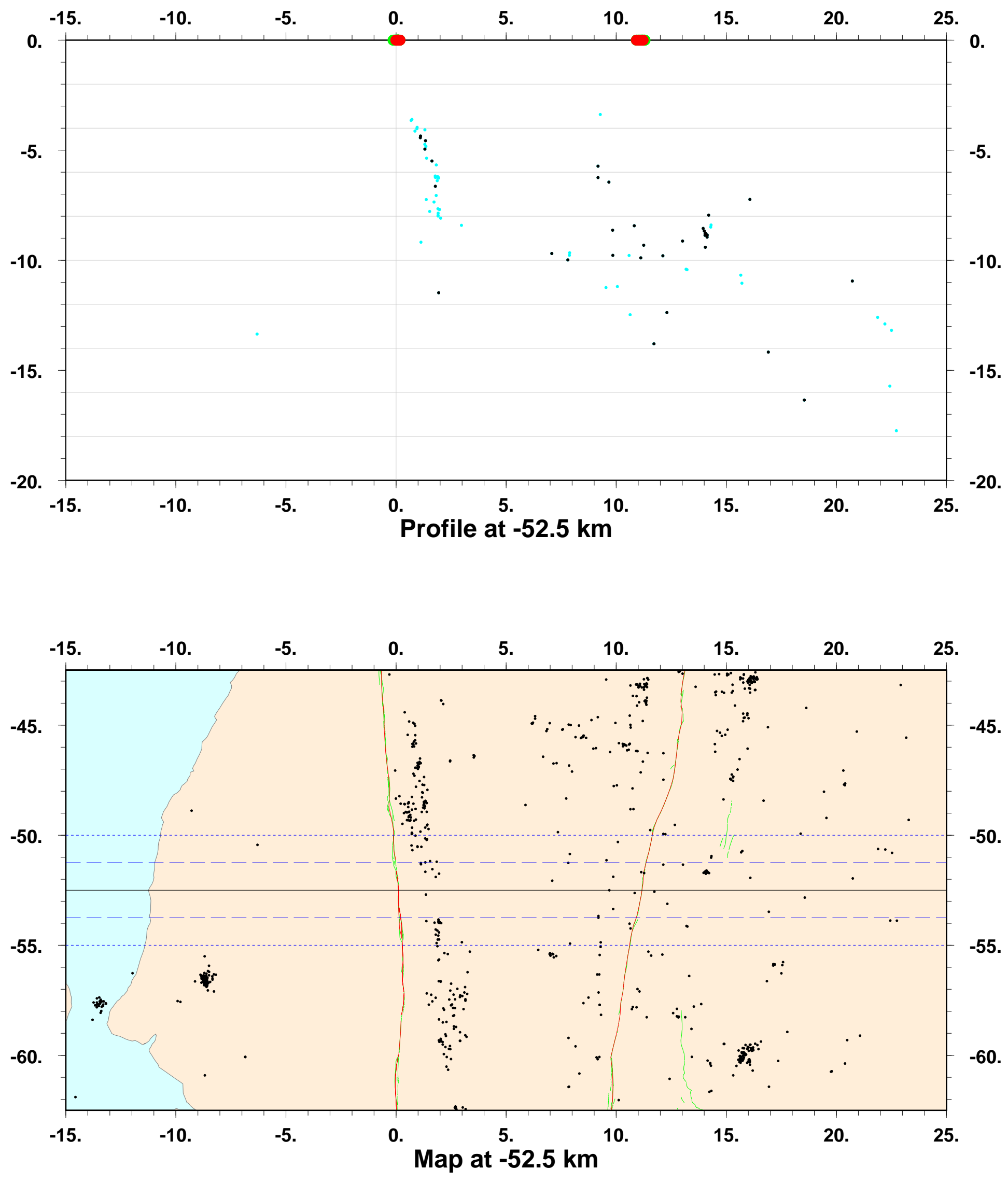

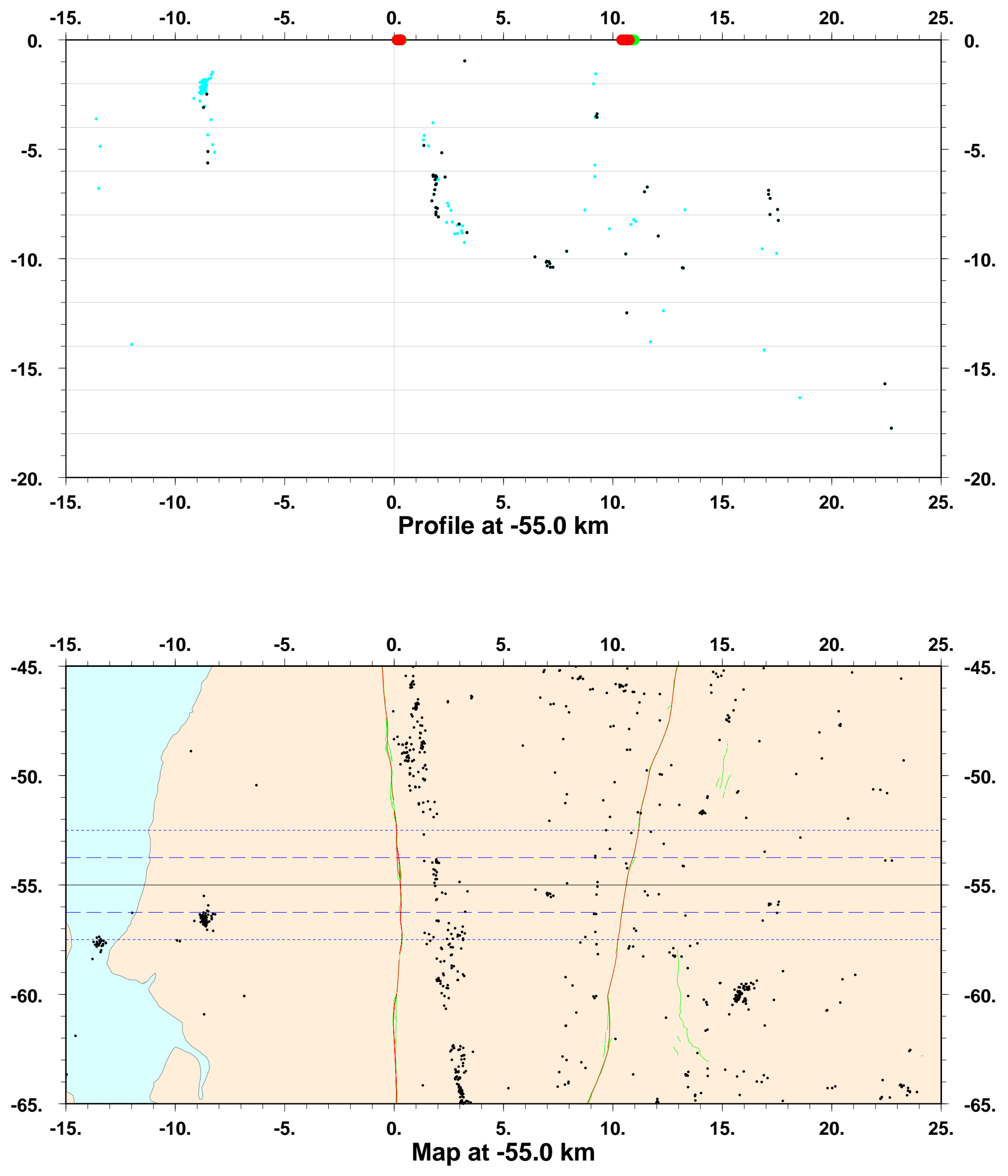

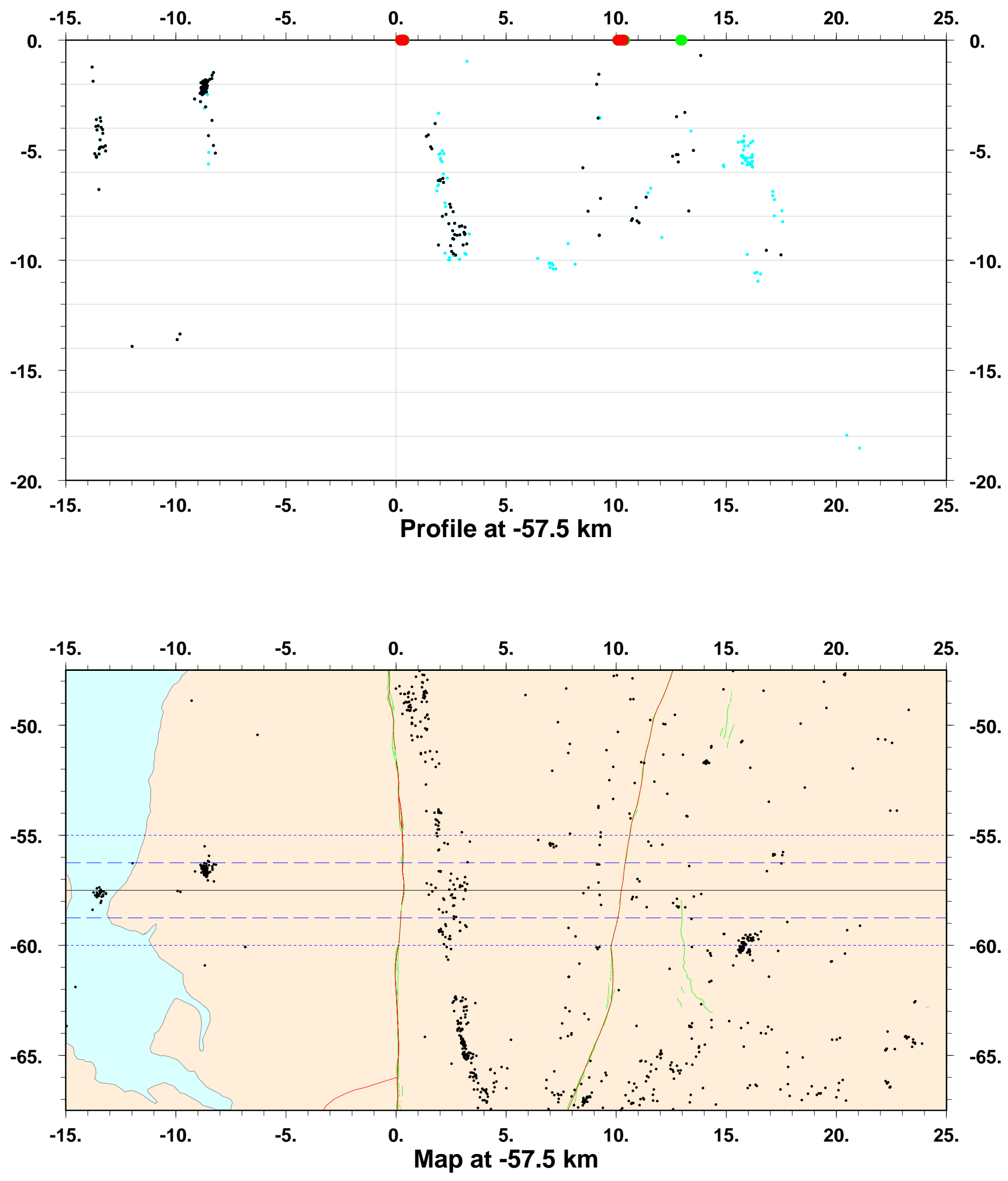

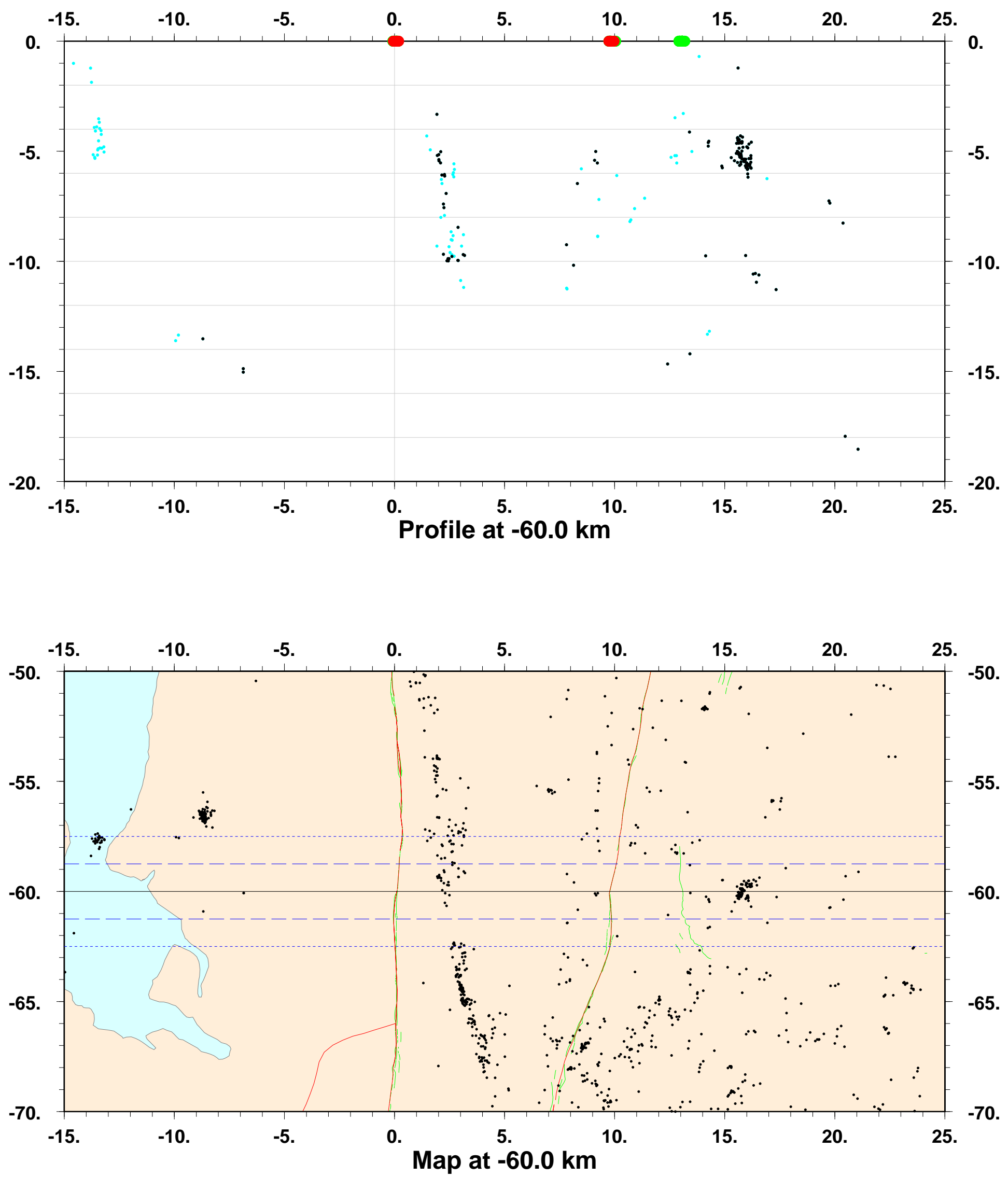


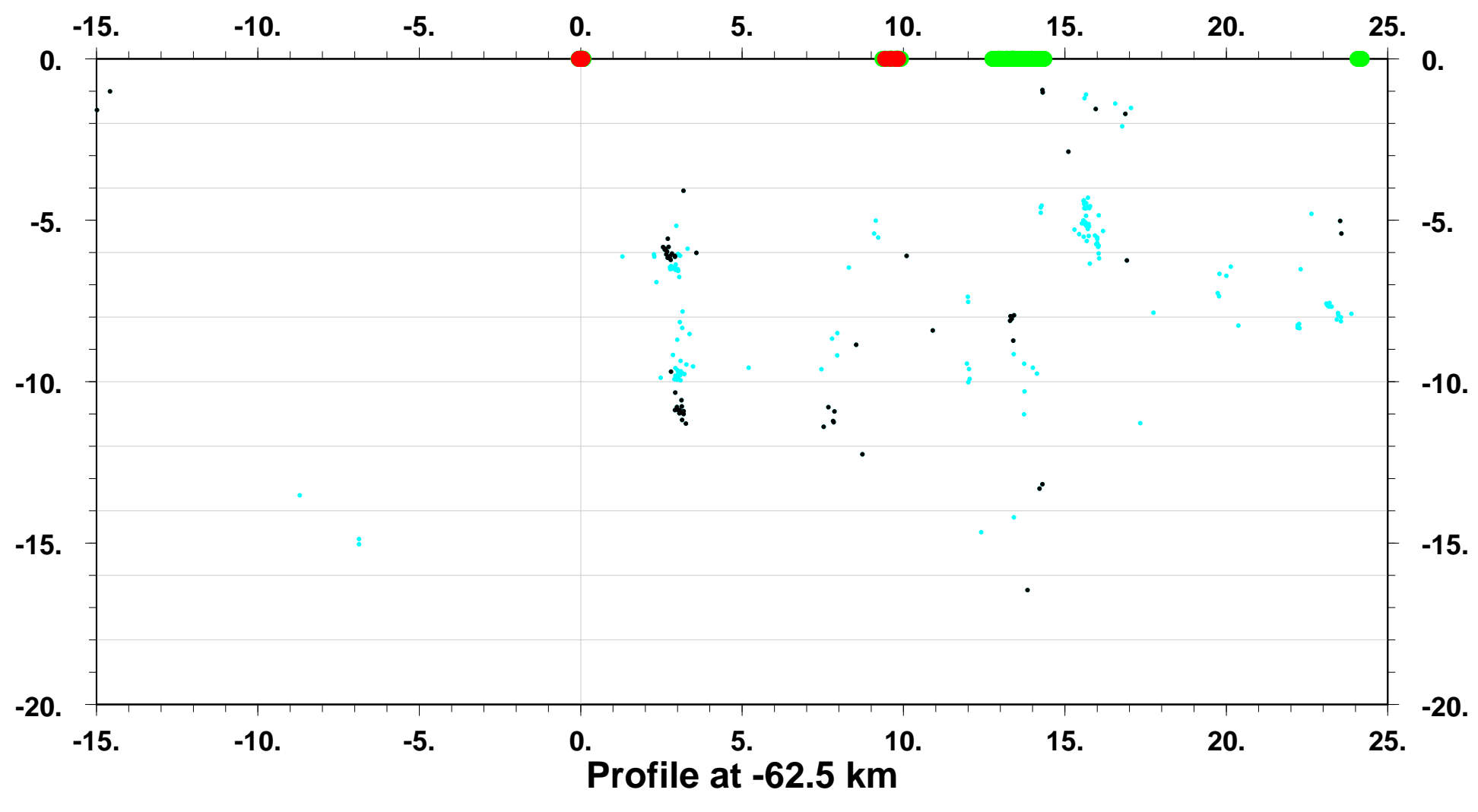

$\begin{array}{llllllll}-15 . & -10 & -5 . & 0 . & 5 . & 10 . & 15 . & 20 .\end{array}$

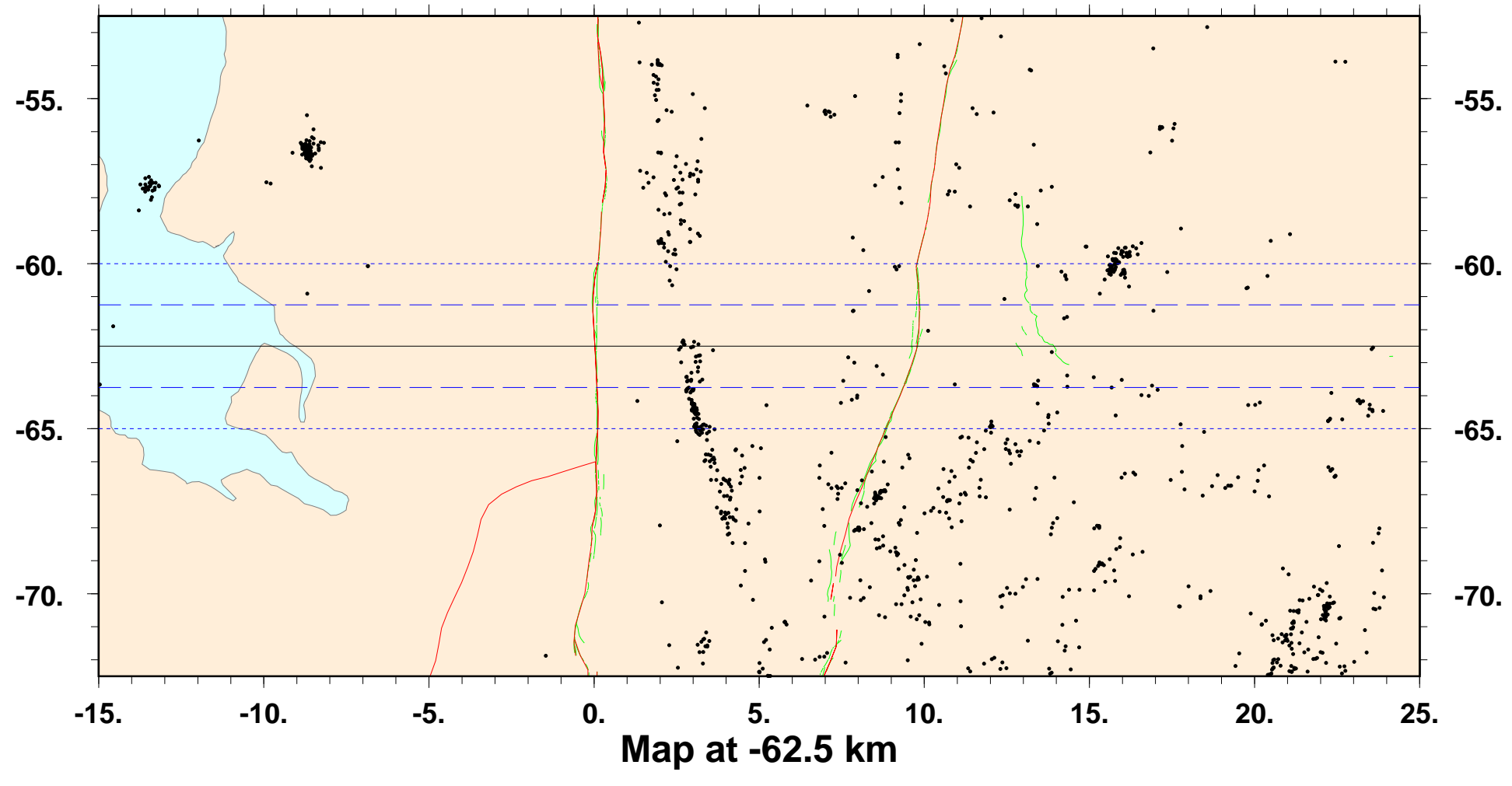




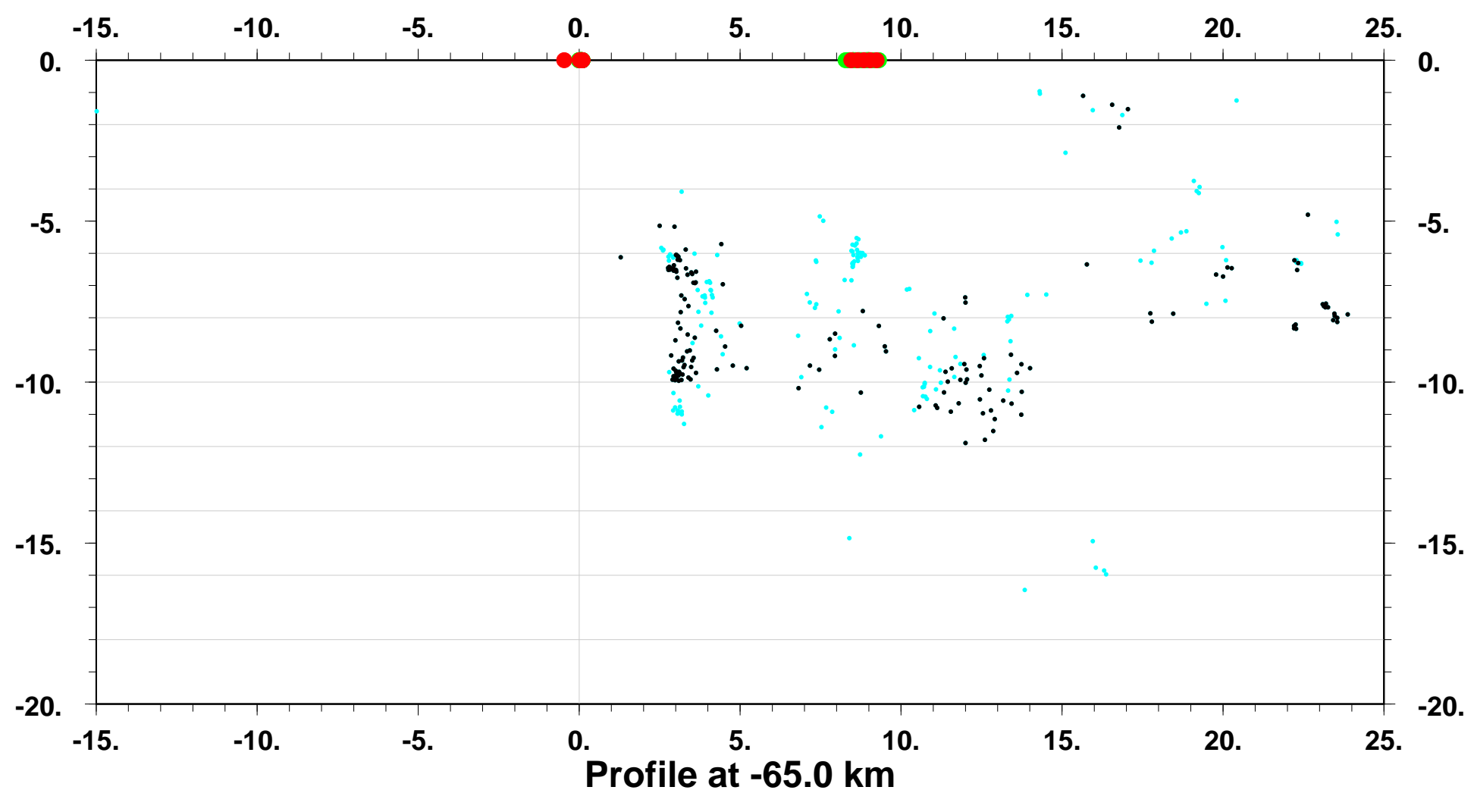

$\begin{array}{rrrrrrrrr}-15 . & -10 . & -5 . & 0 . & 5 . & 10 . & 15 . & 20 . & 25 .\end{array}$

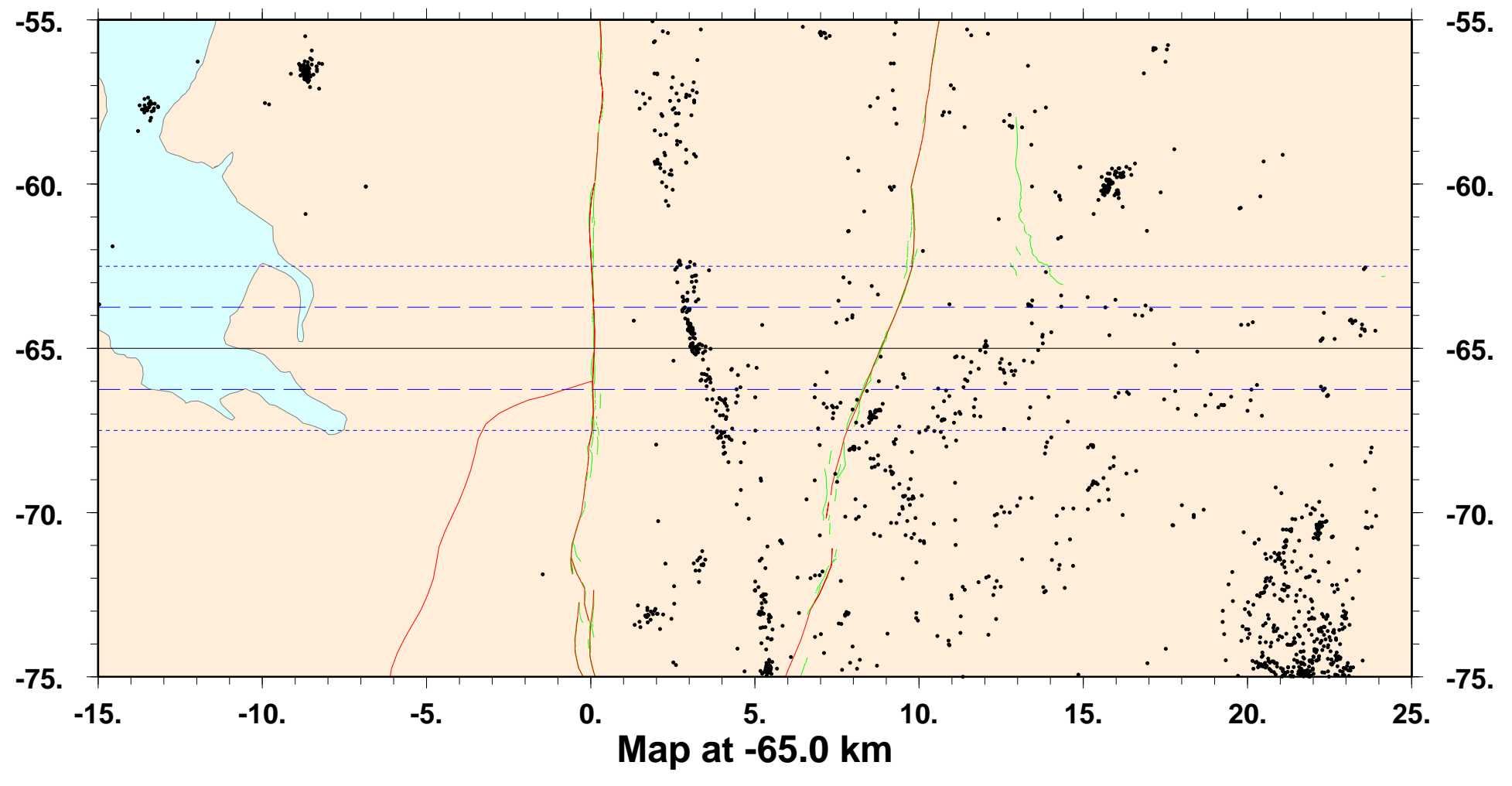




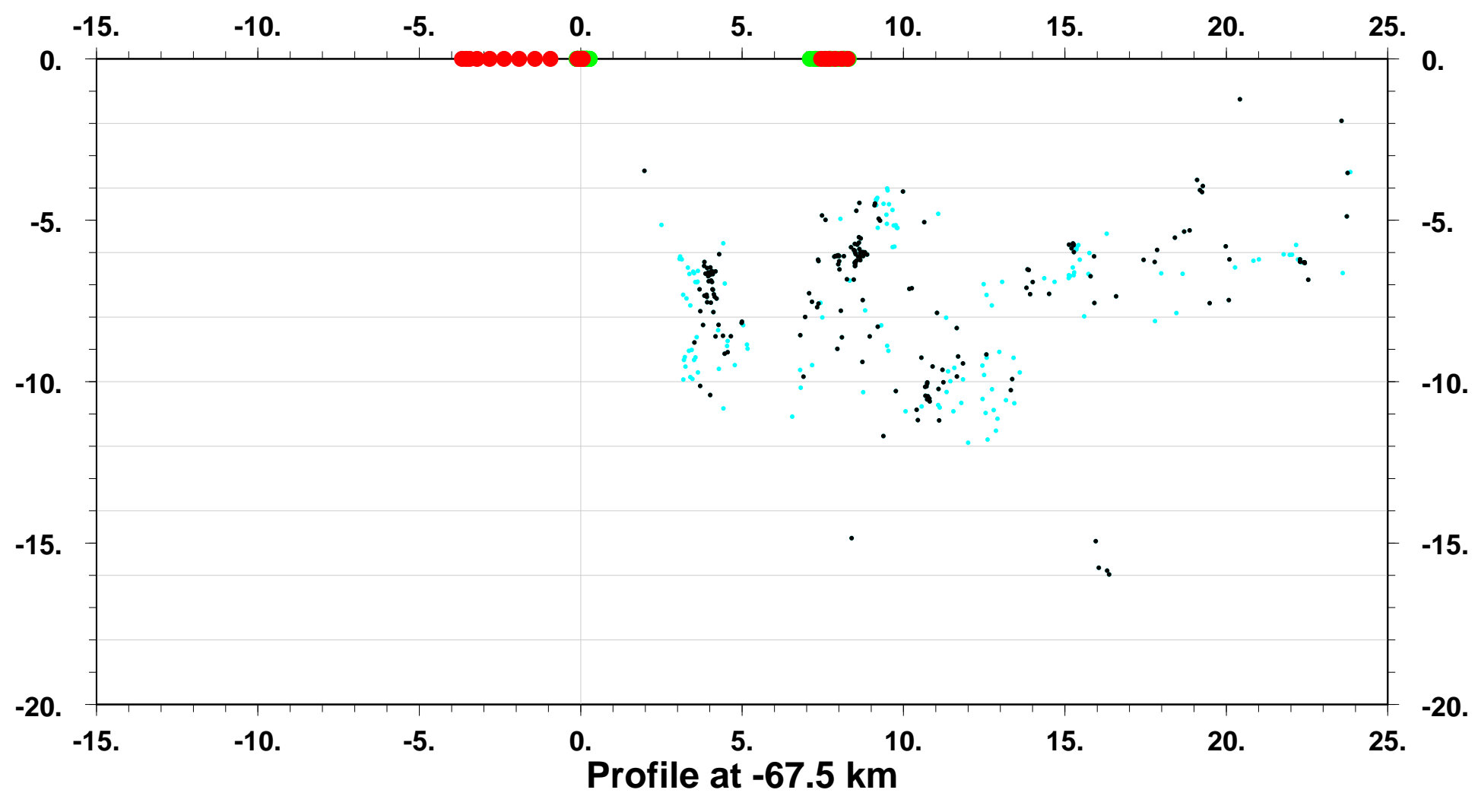

$\begin{array}{llllllll}-15 . & -10 . & -5 . & 0 . & 5 . & 10 . & 15 . & 20 .\end{array}$

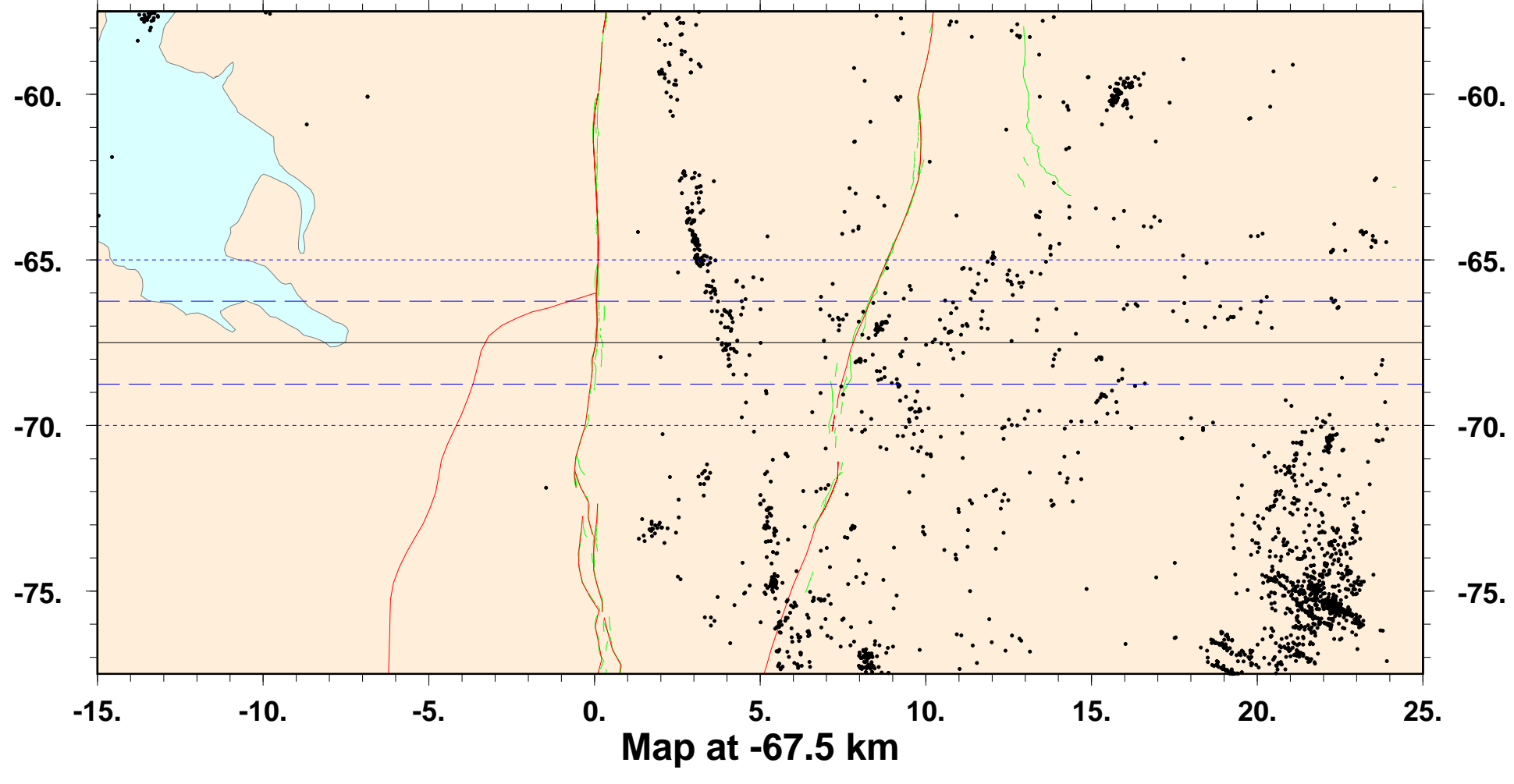



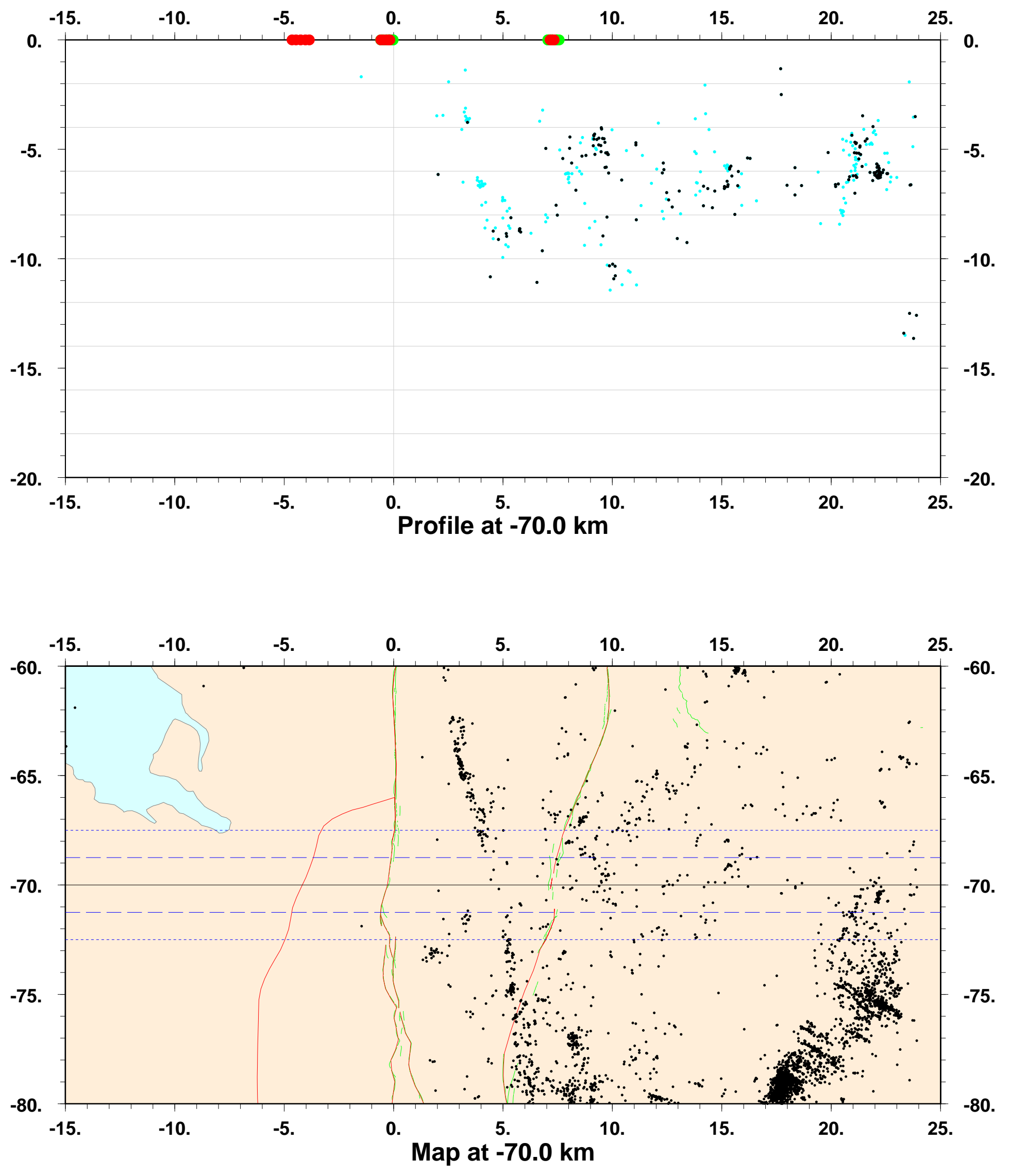


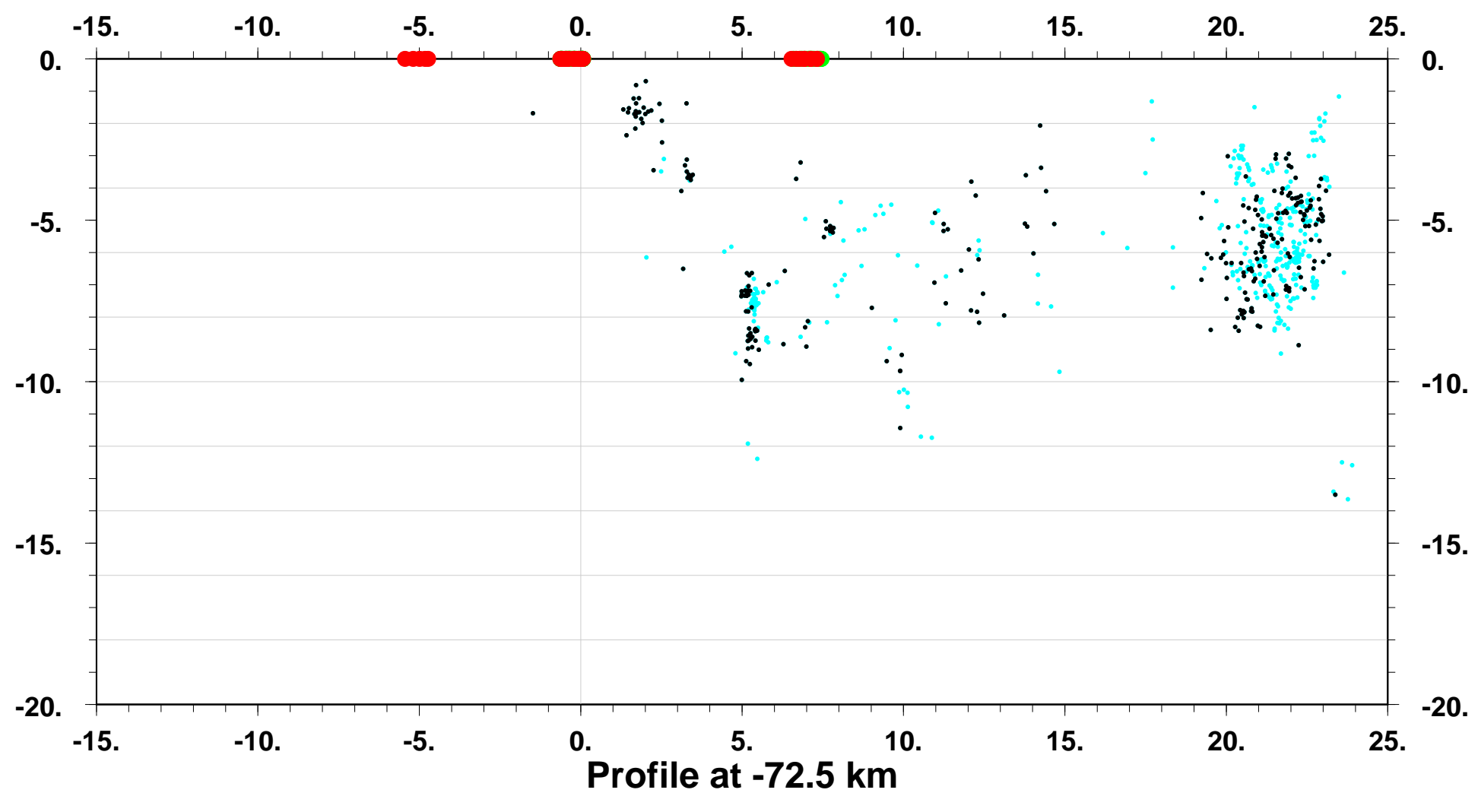

$\begin{array}{rrrrrrrrr}-15 . & -10 . & -5 . & 0 . & 5 . & 10 . & 15 . & 20 . & 25 .\end{array}$

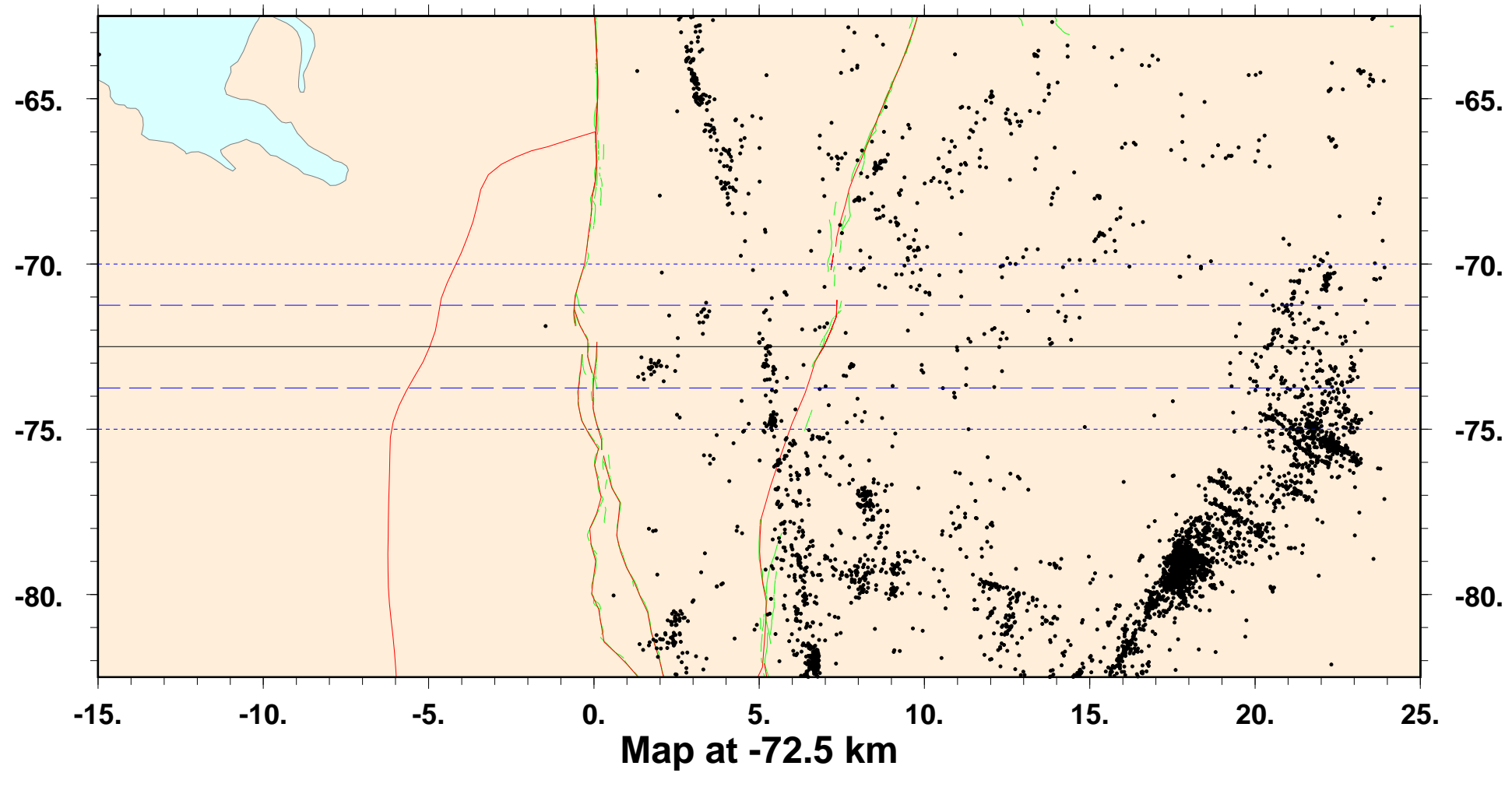



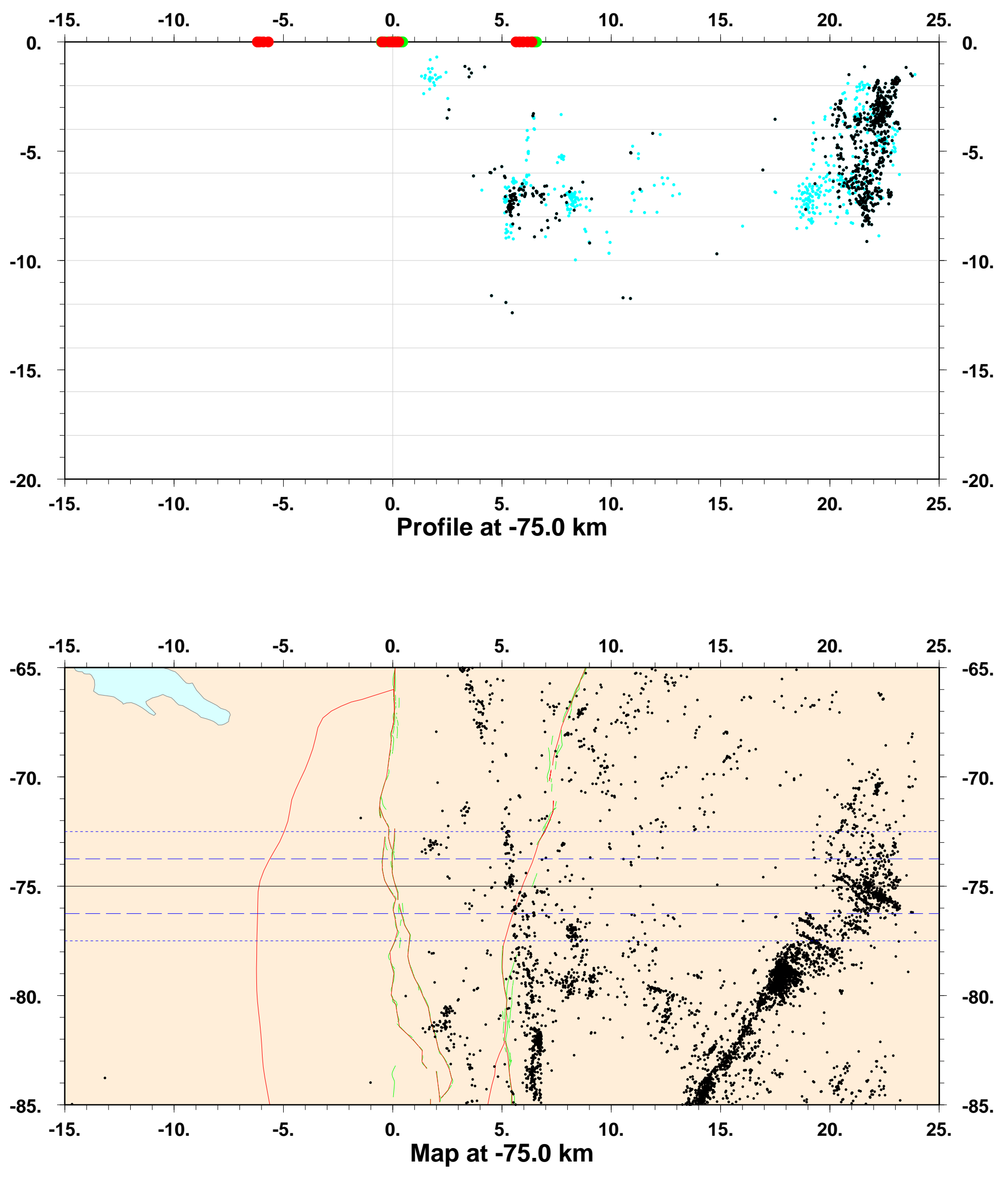


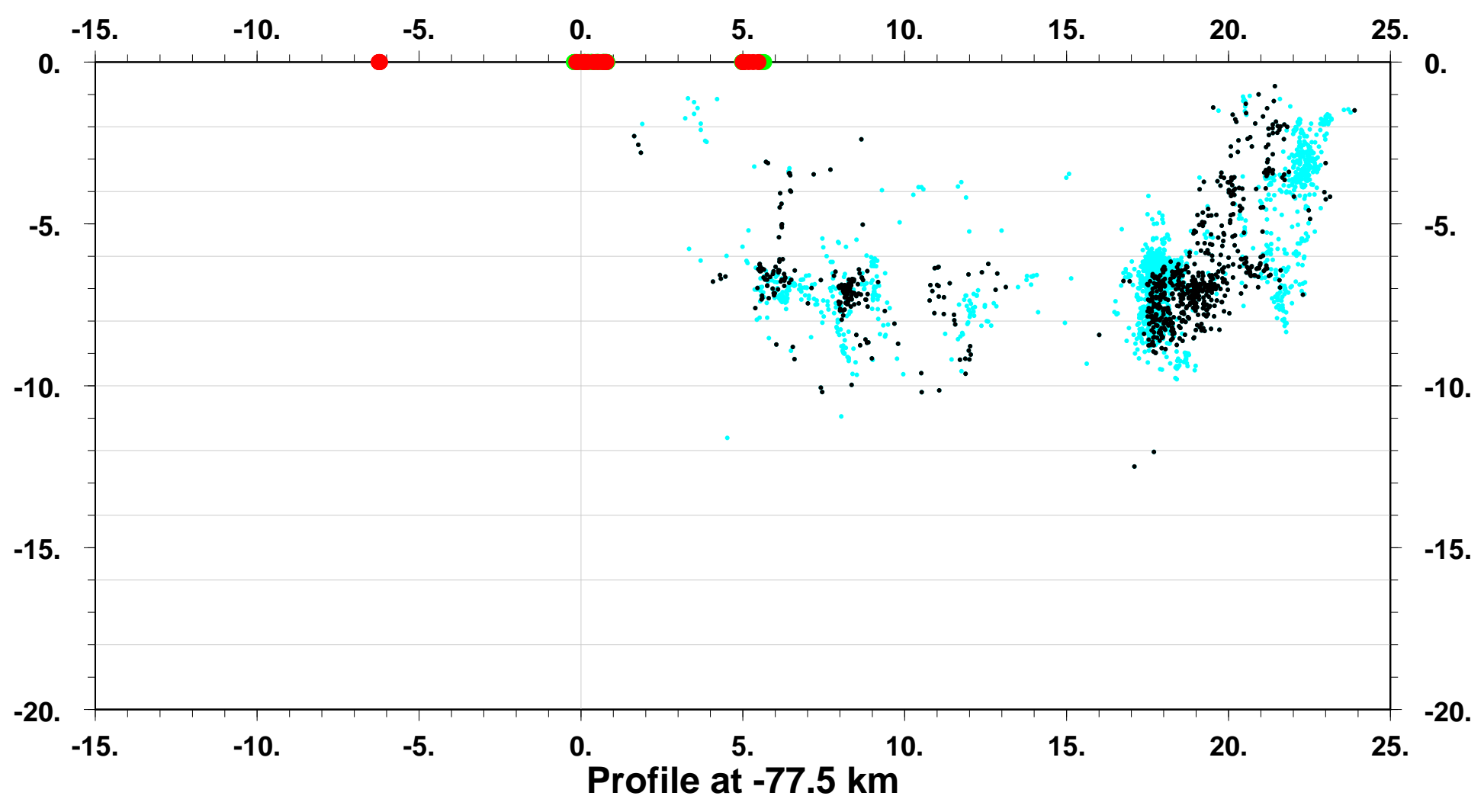

$\begin{array}{rrrrrrrr}-15 . & -10 . & -5 . & 0 . & 5 . & 10 . & 15 . & 20 .\end{array}$

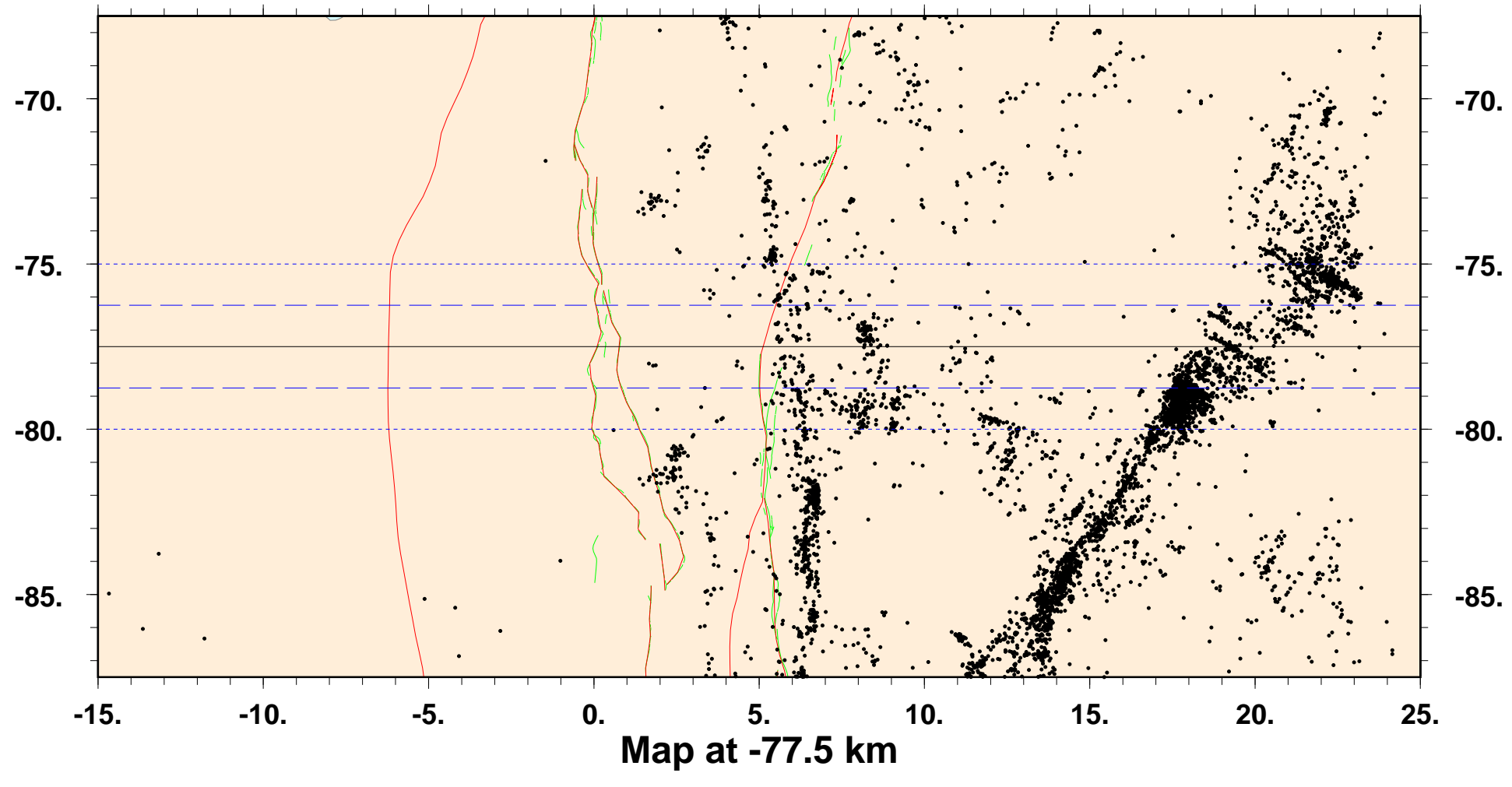



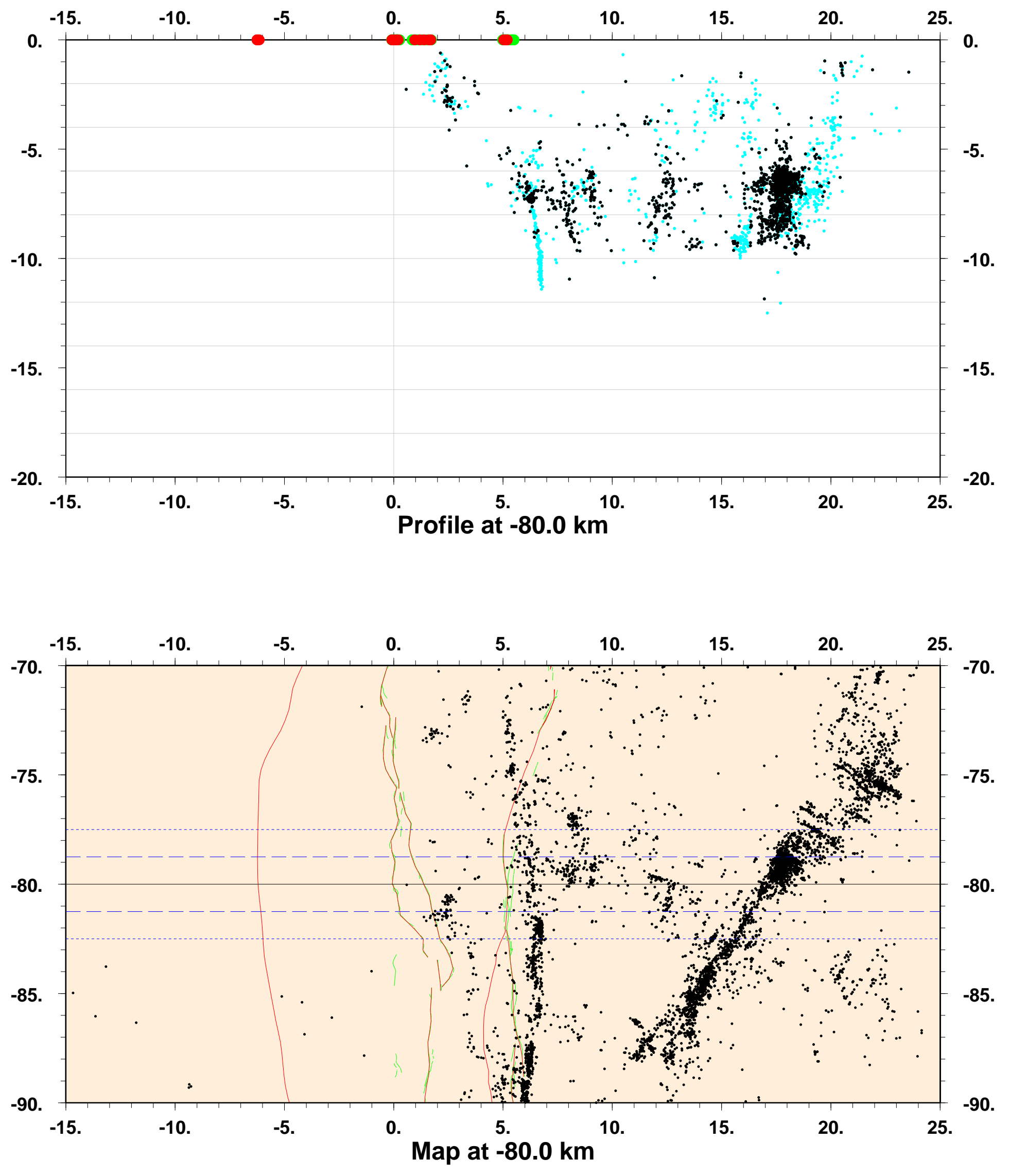


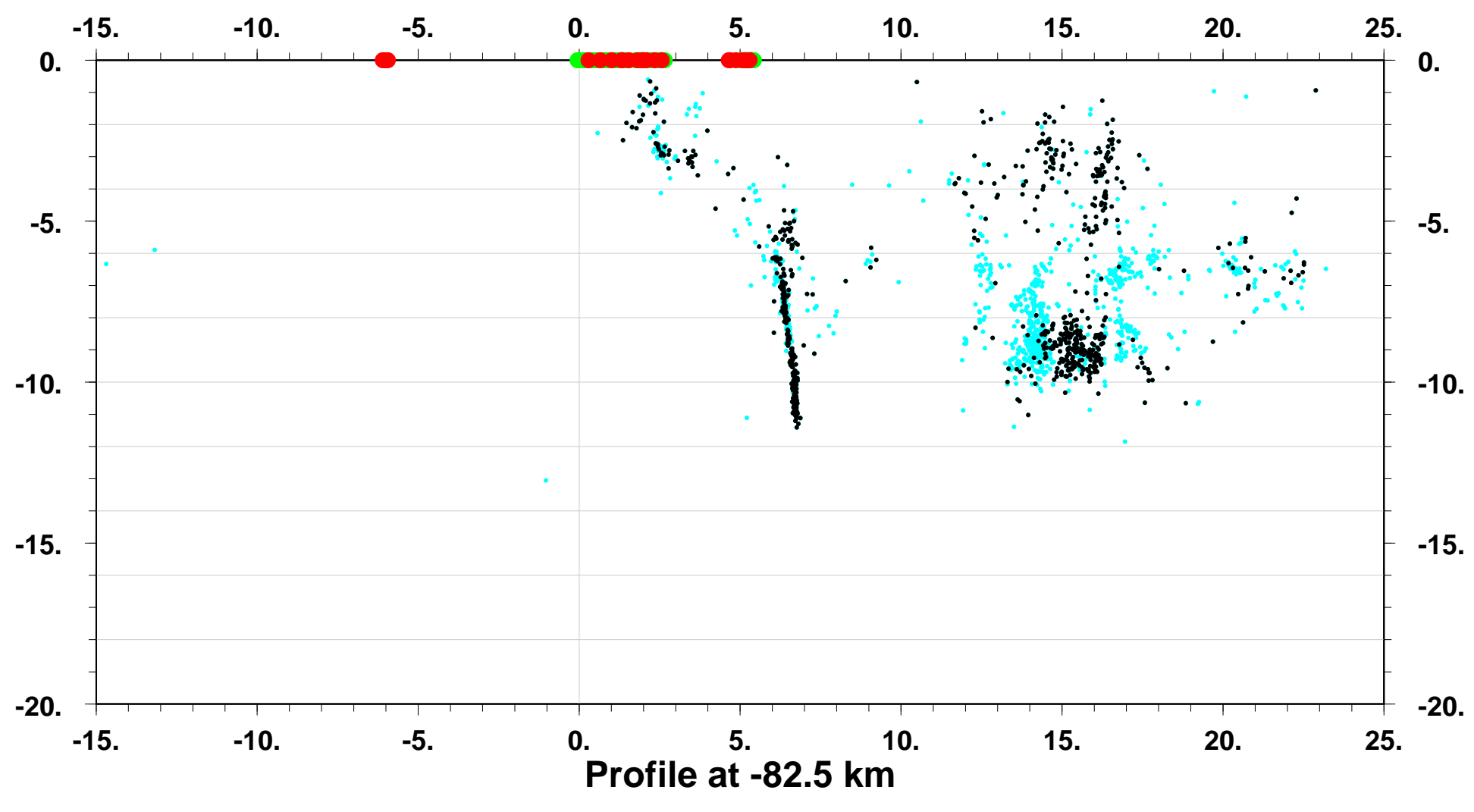

$\begin{array}{lllllllll}-15 . & -10 . & -5 . & 0 . & 5 . & 10 . & 15 . & 20 . & 25 .\end{array}$

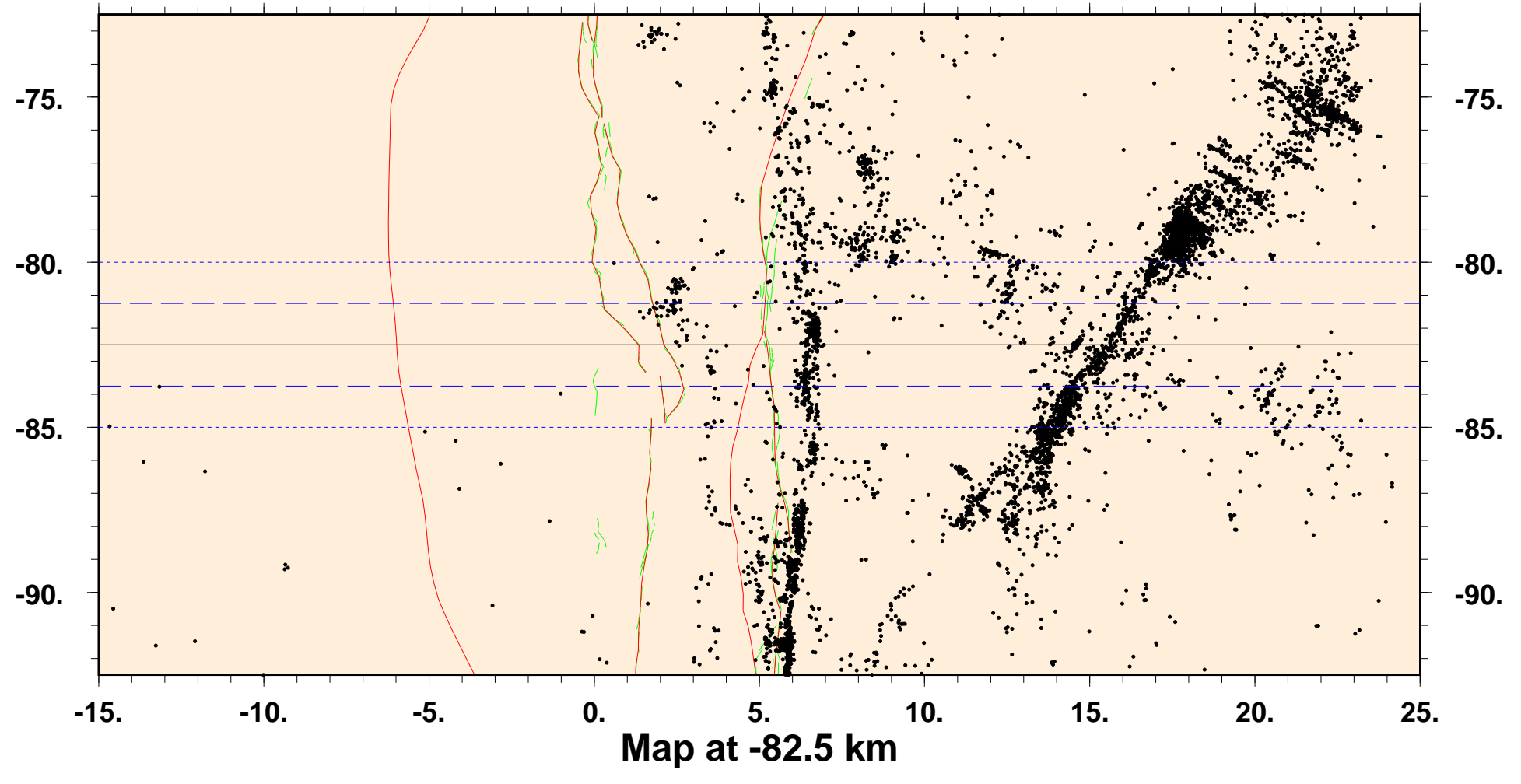




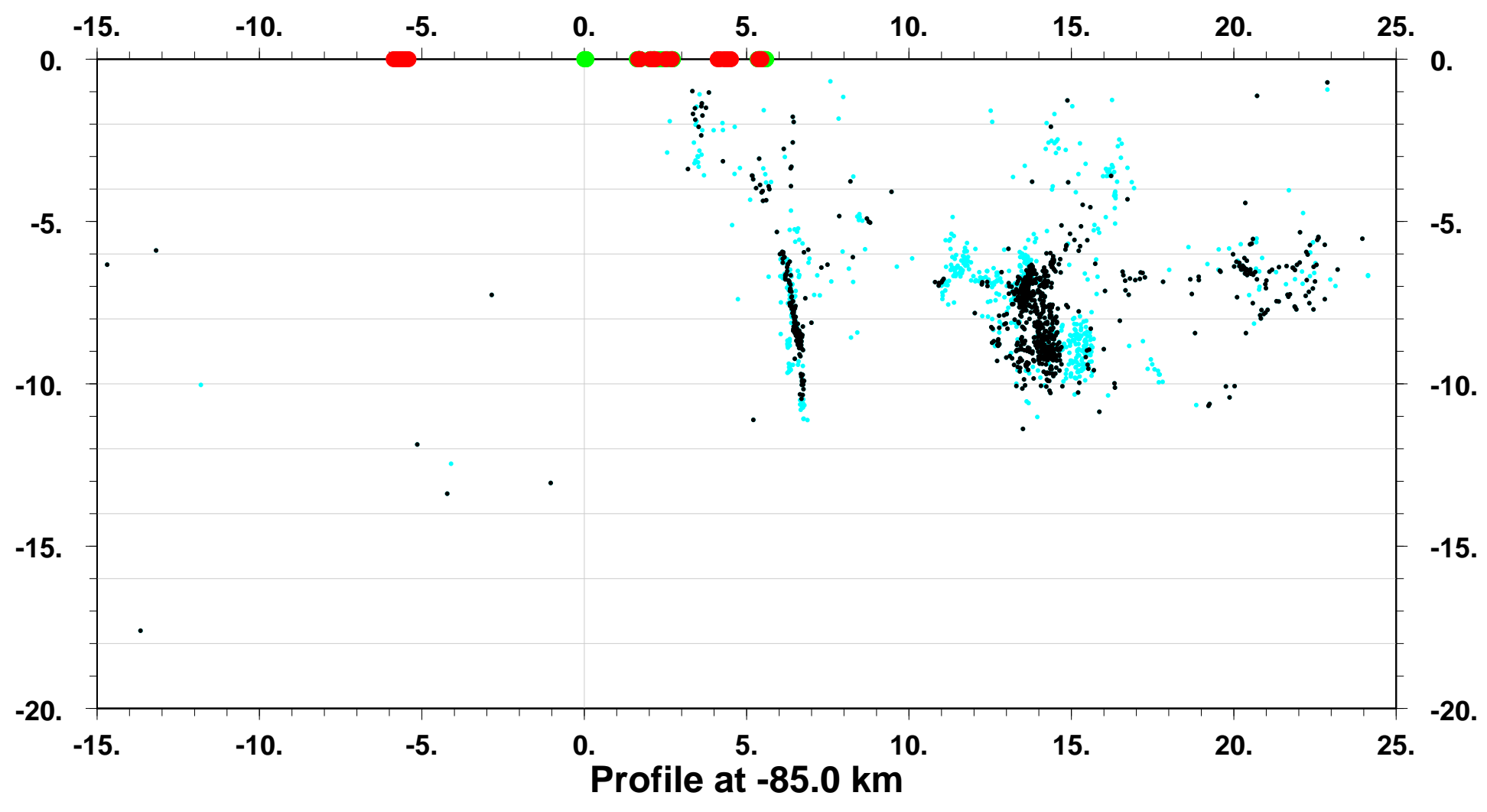

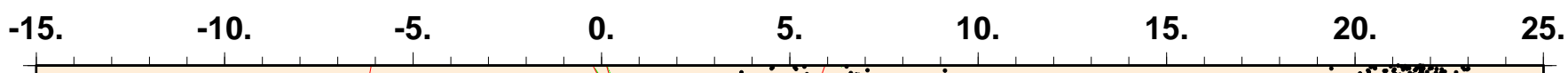

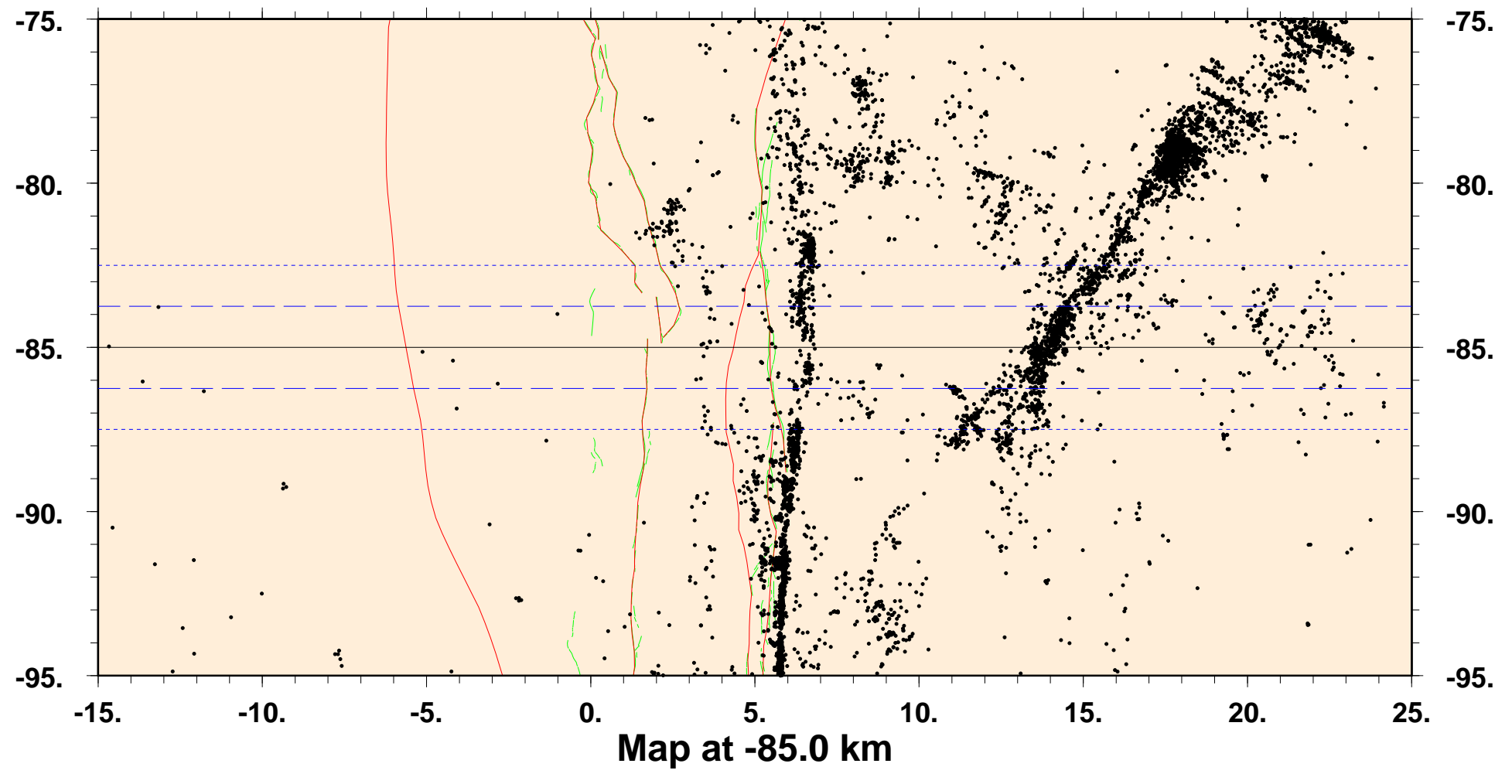



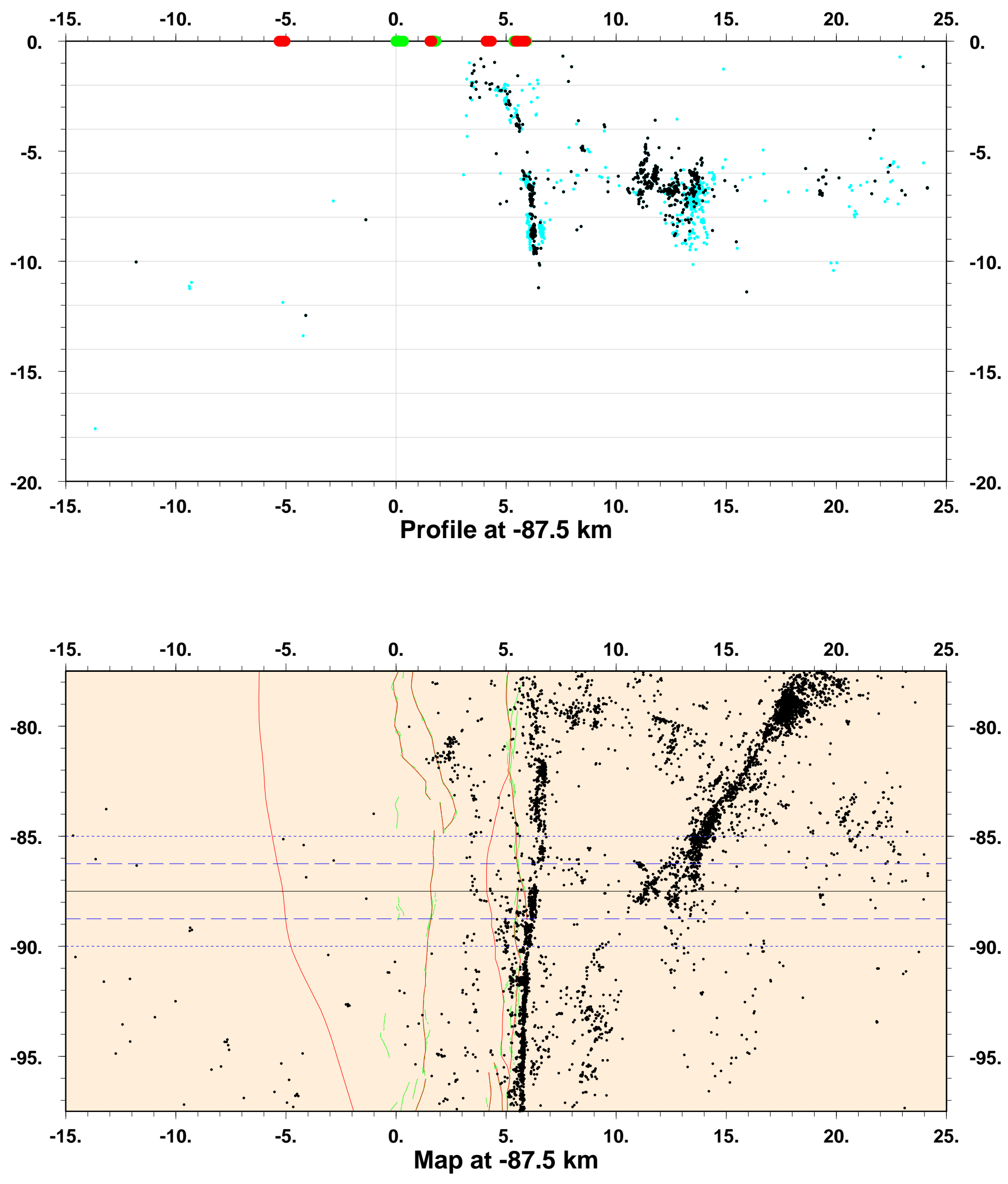

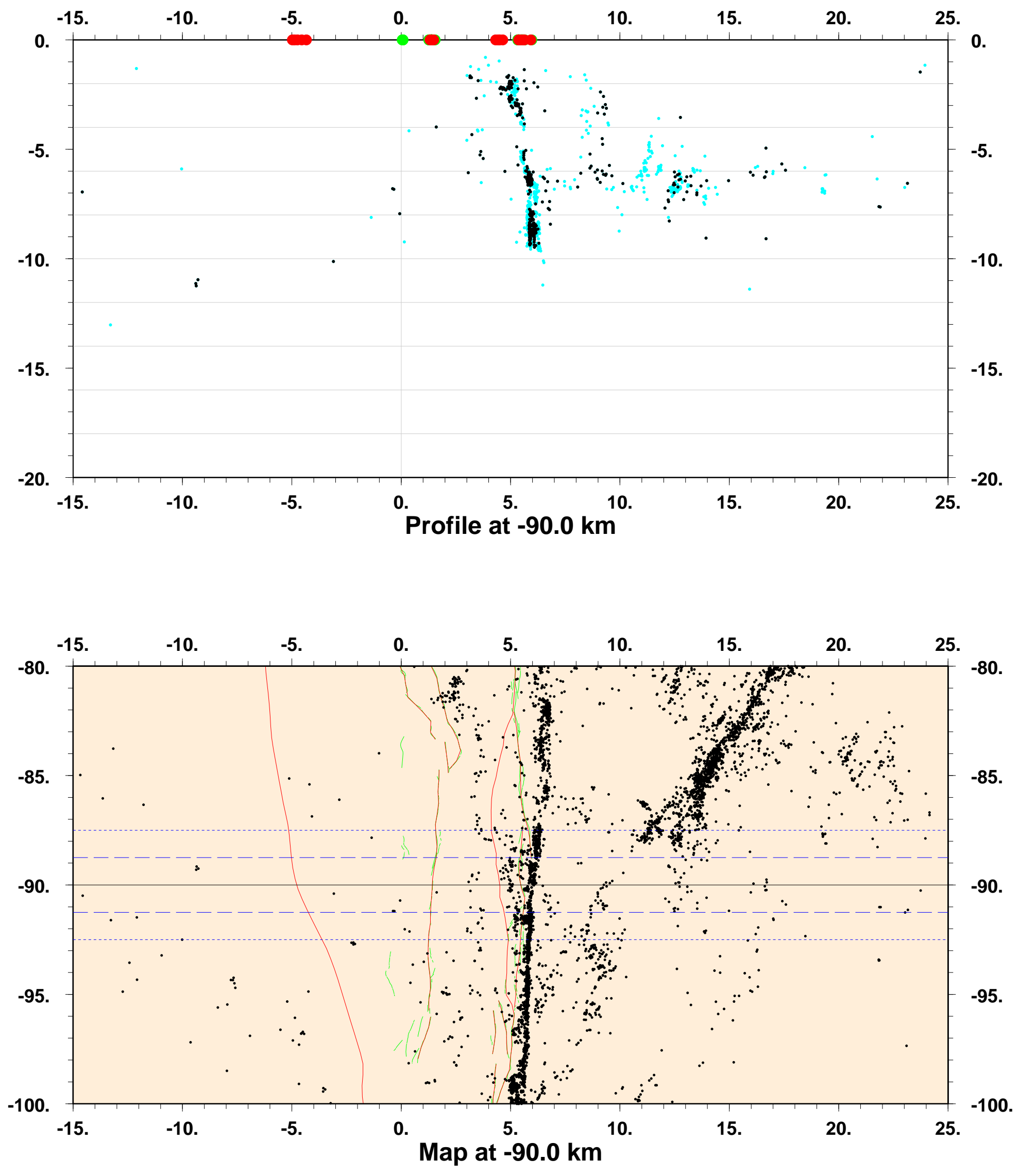

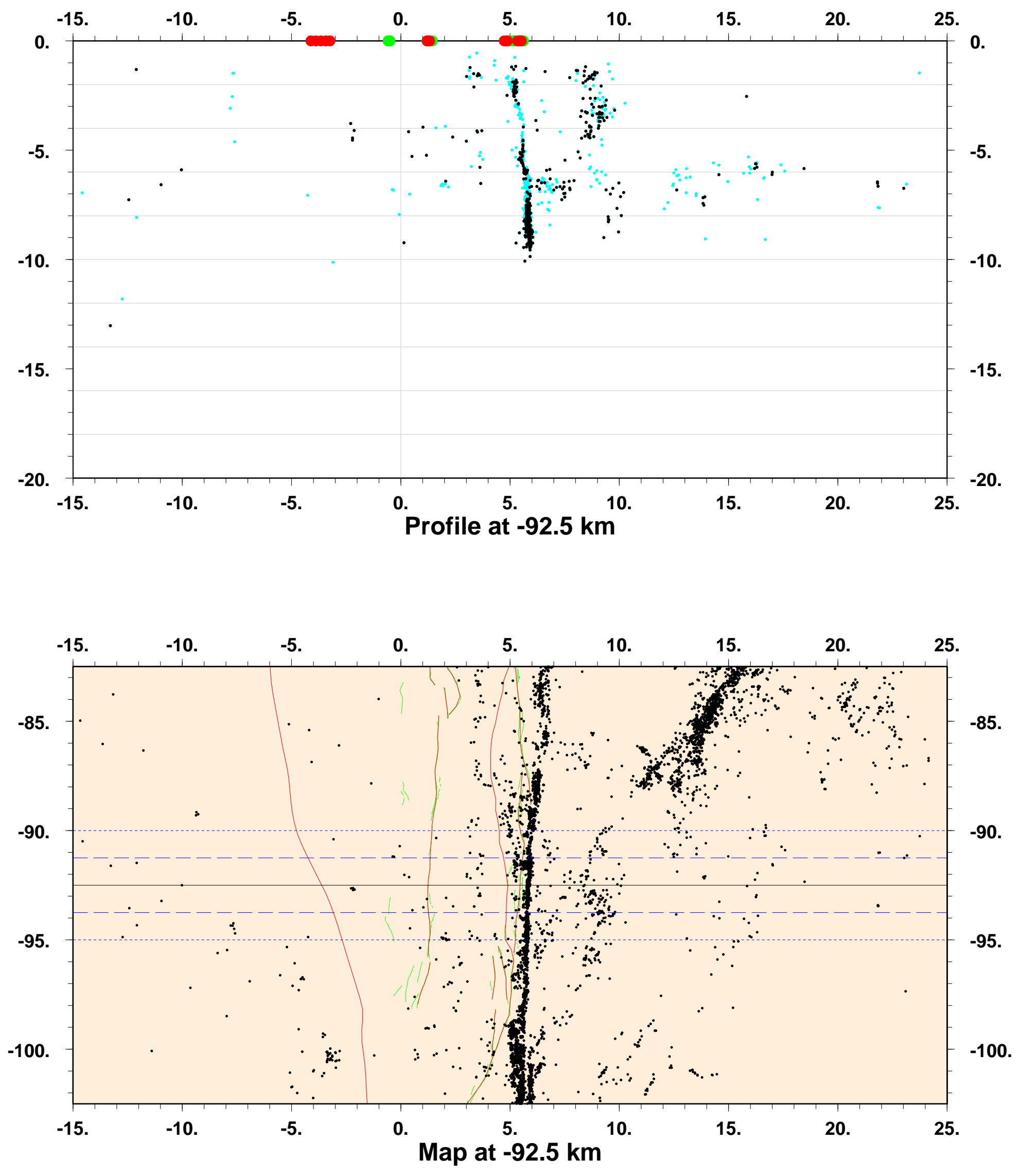

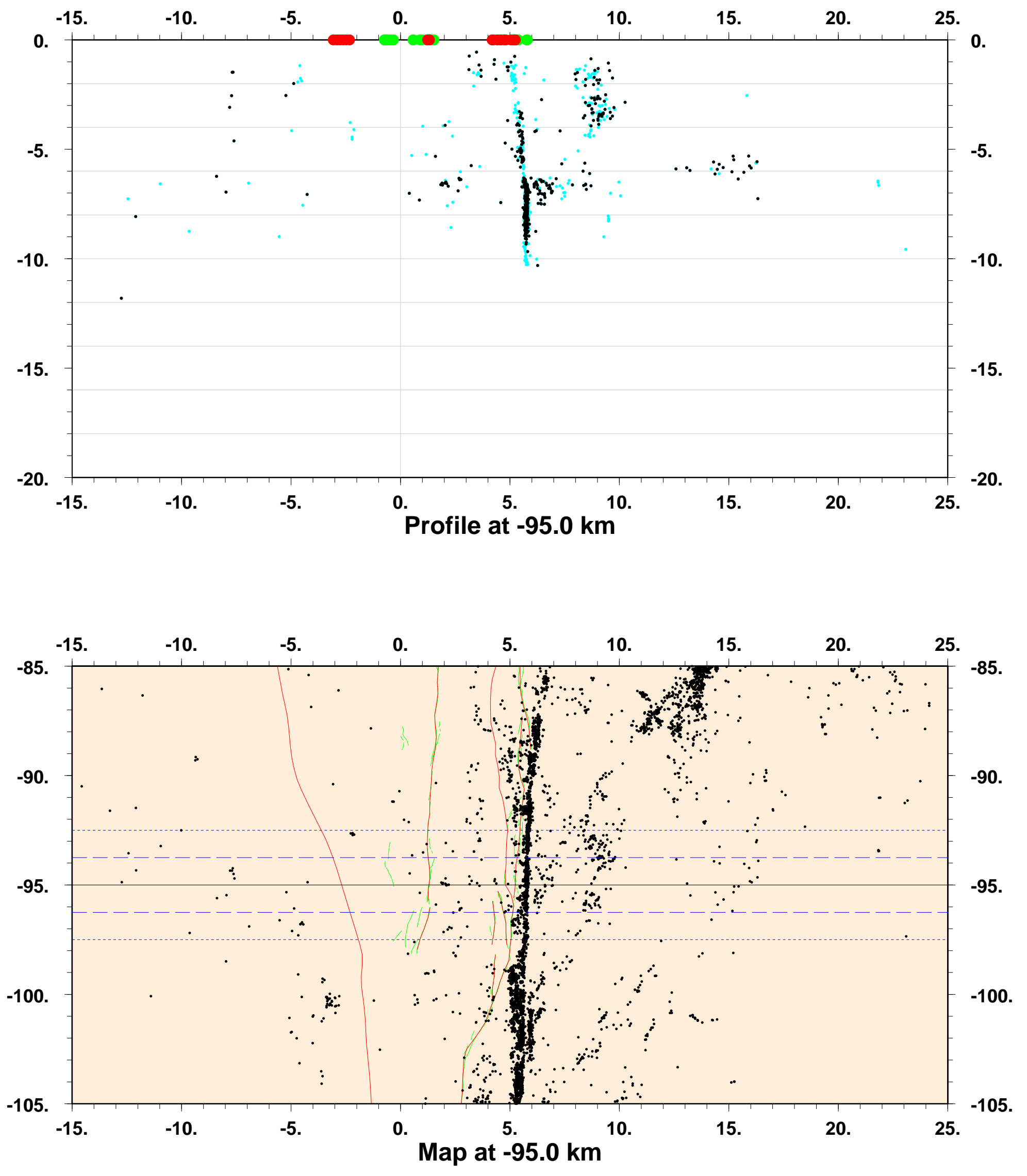

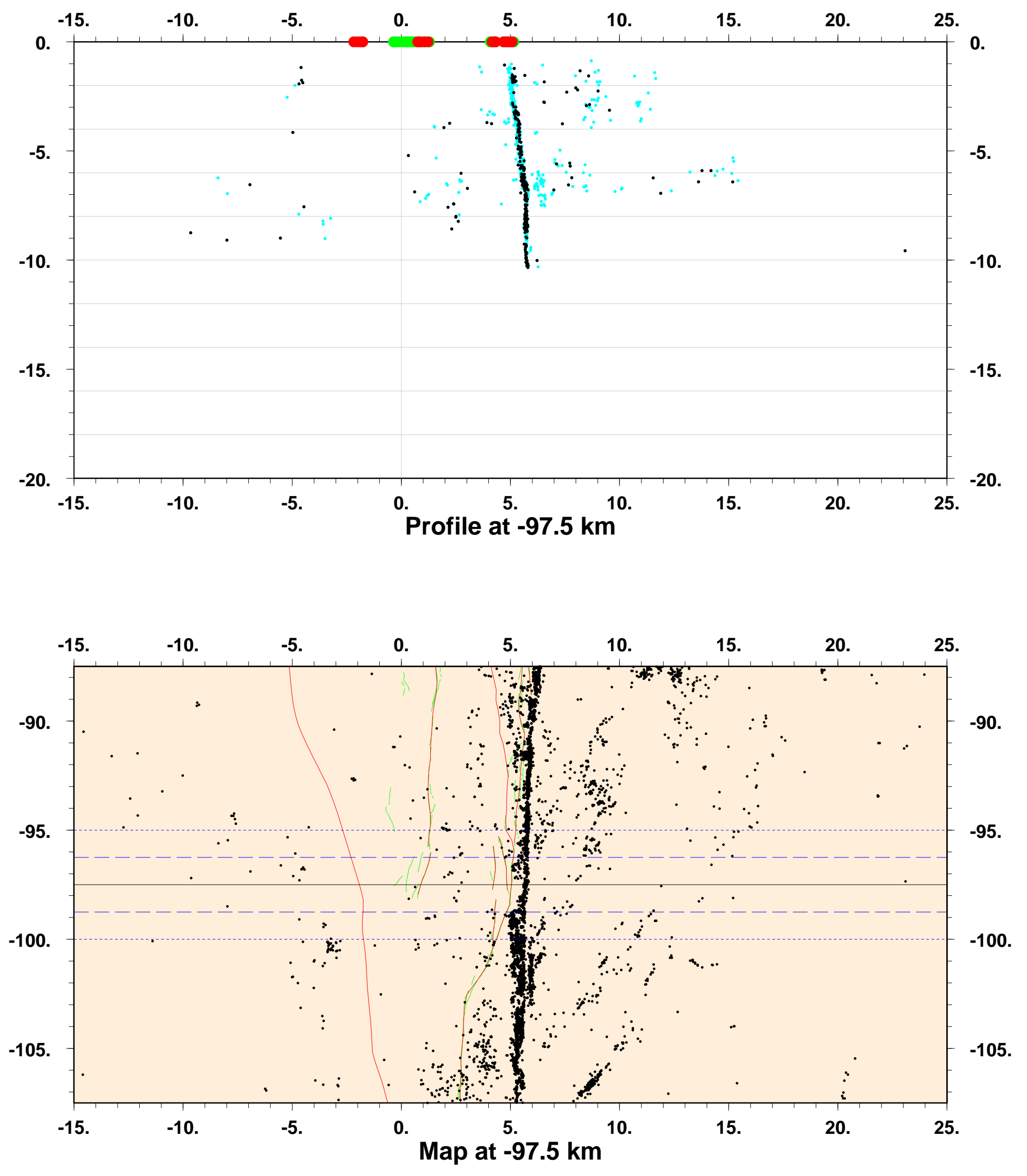

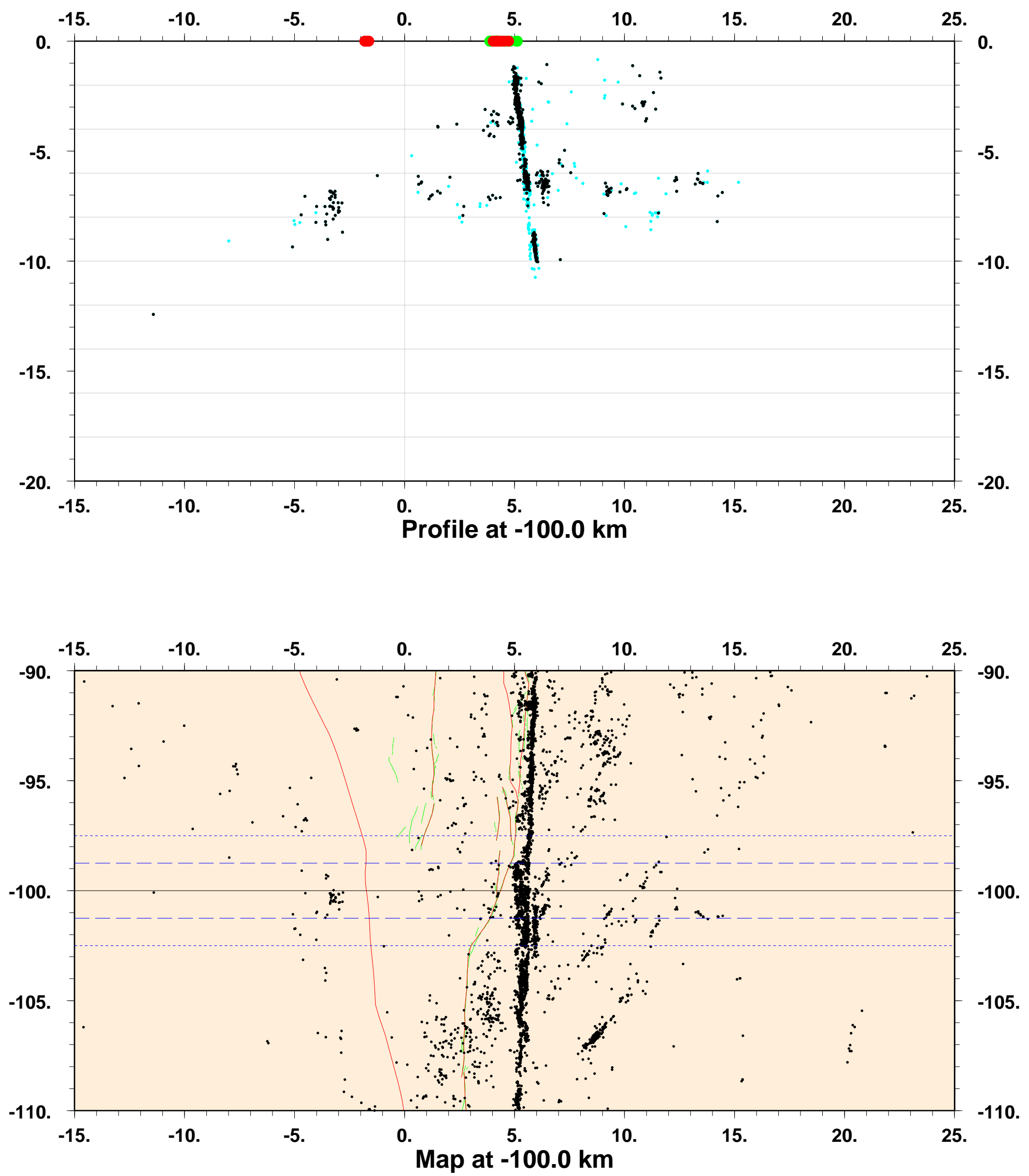

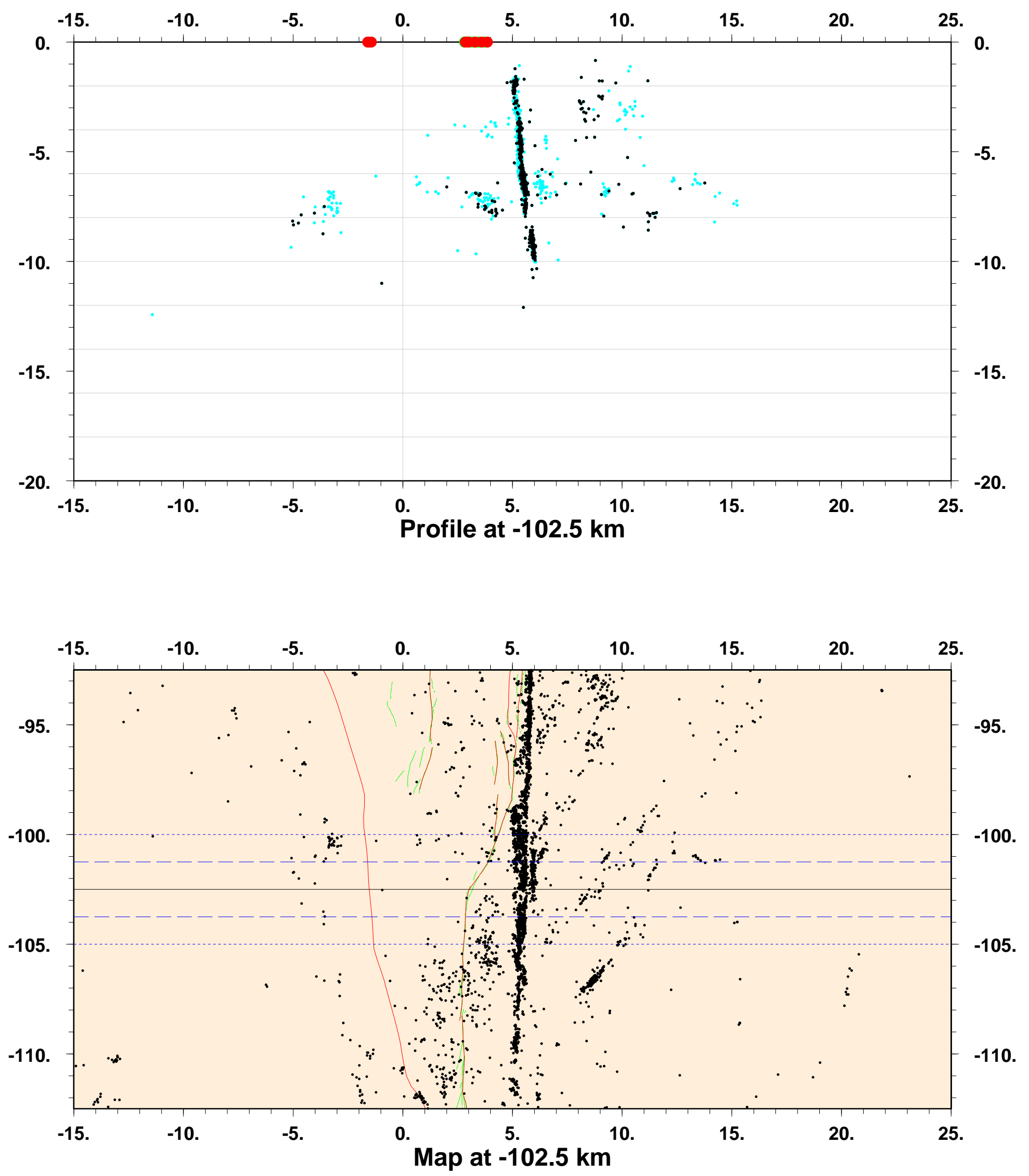

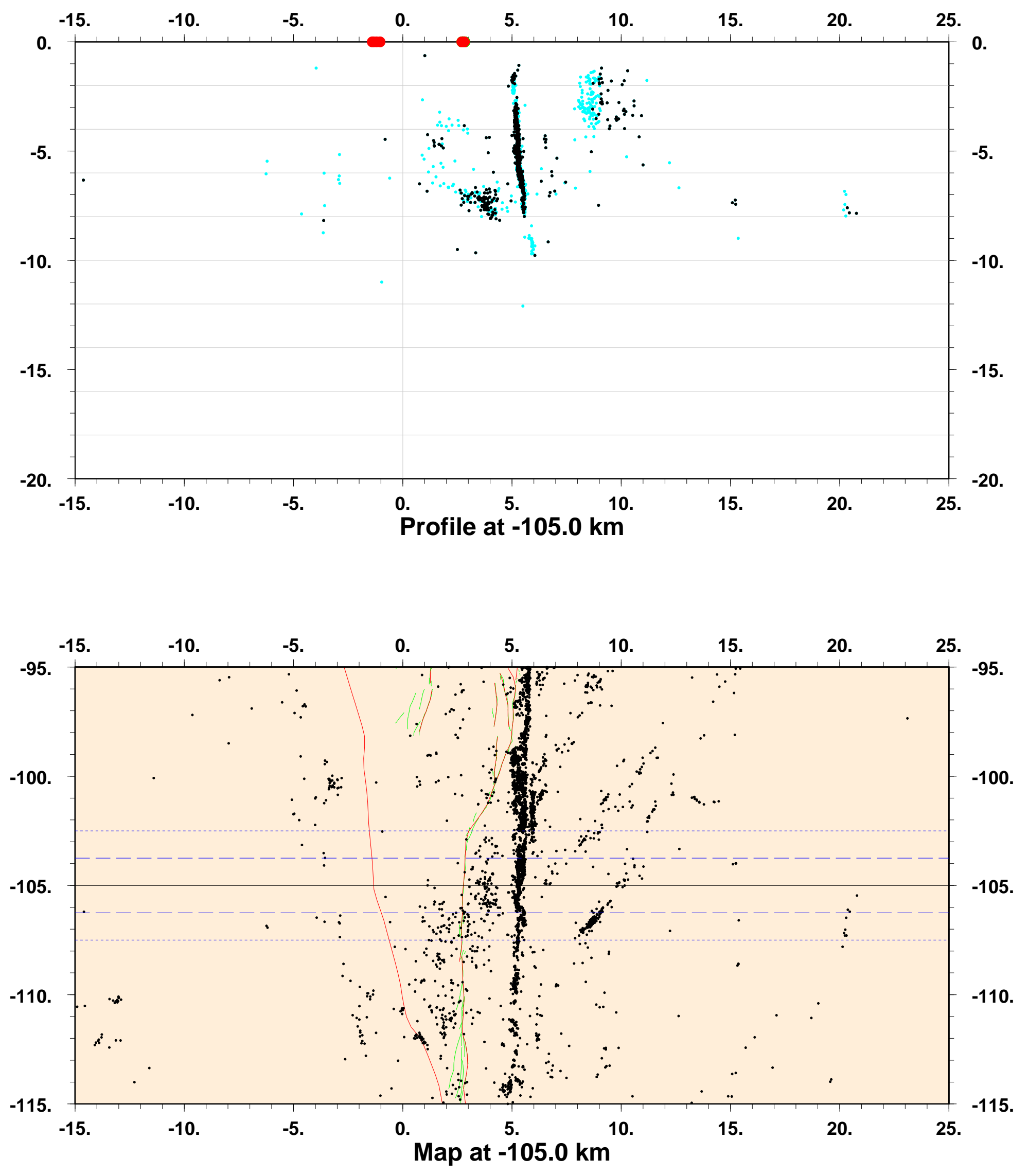

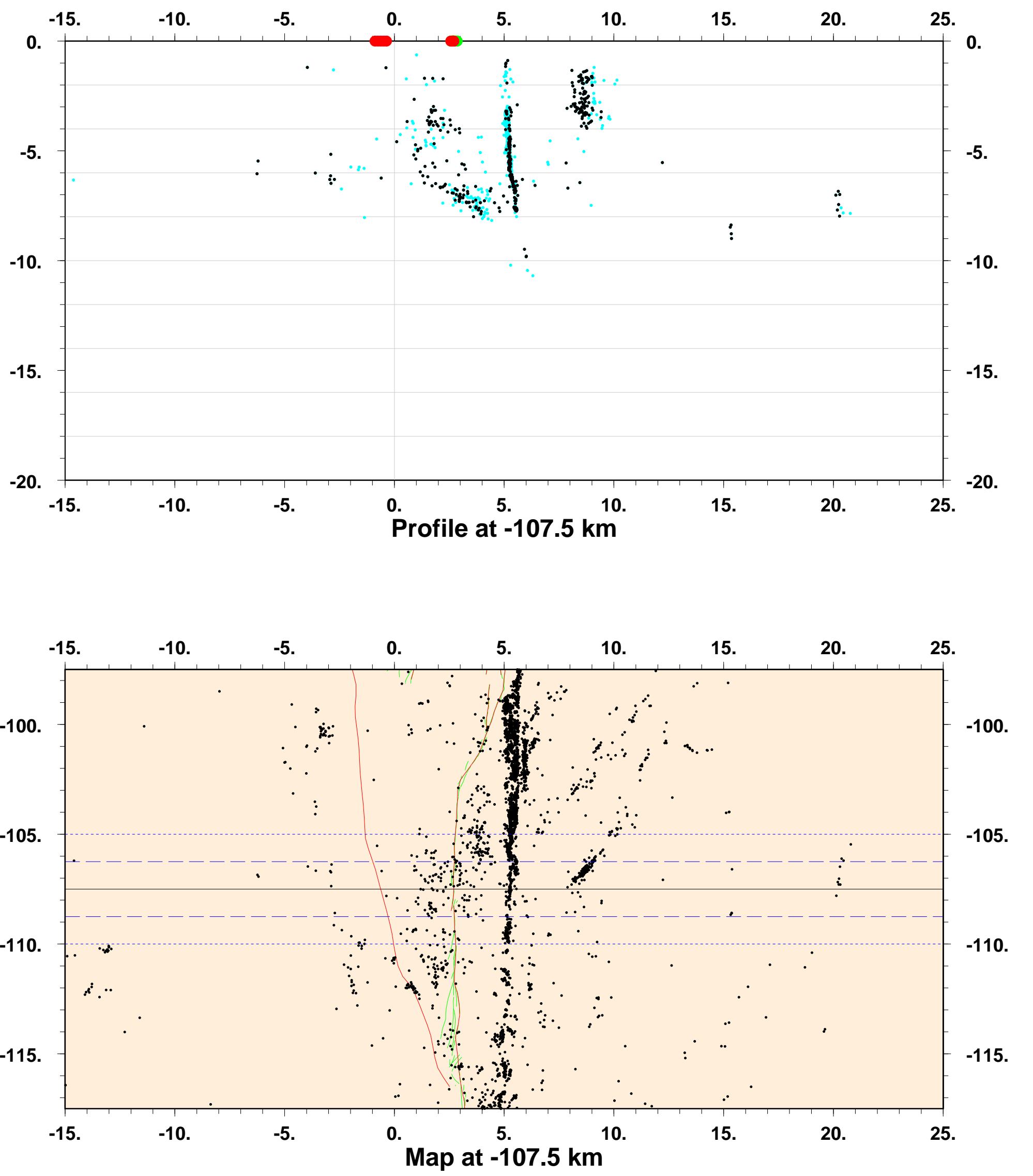

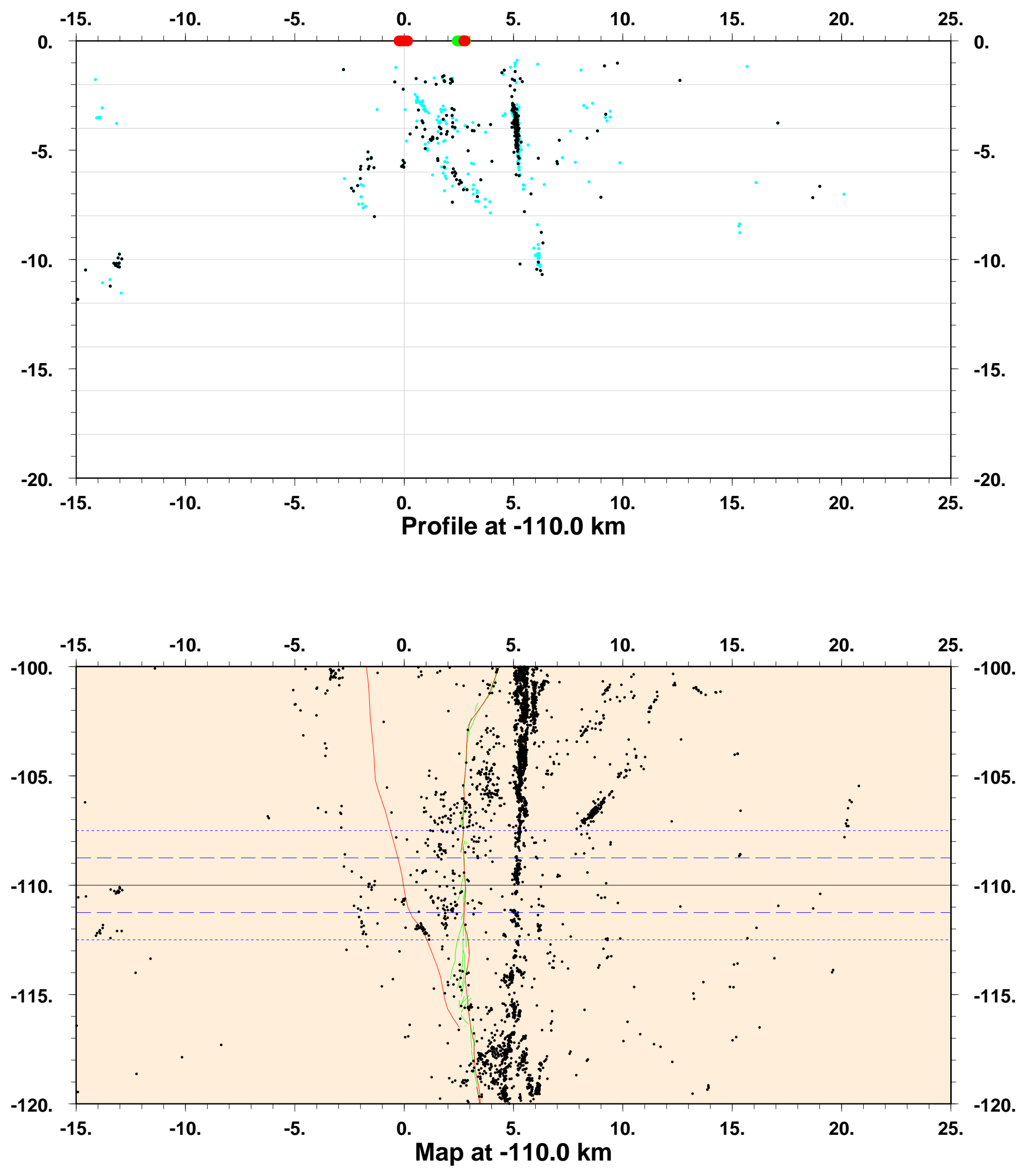

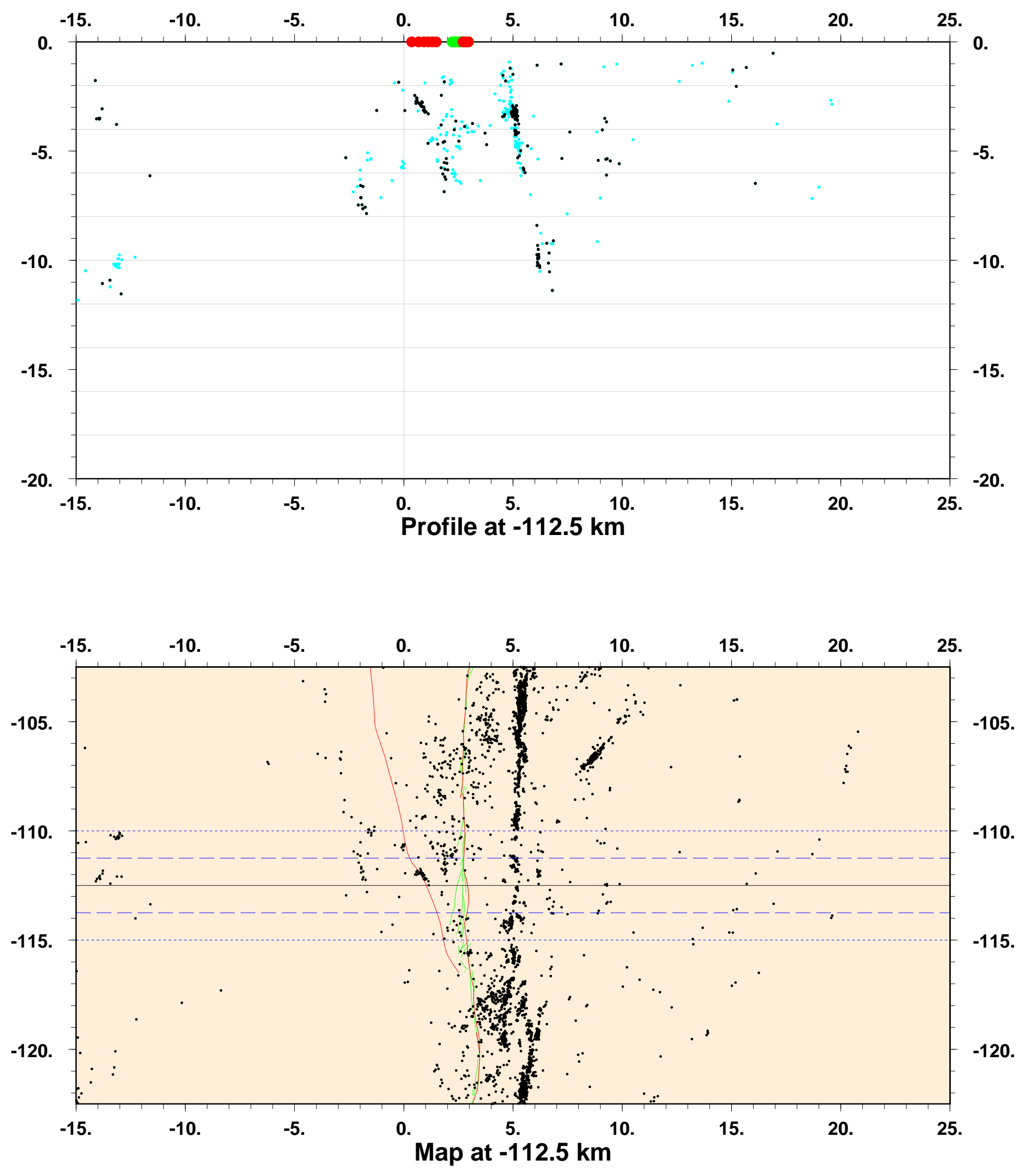

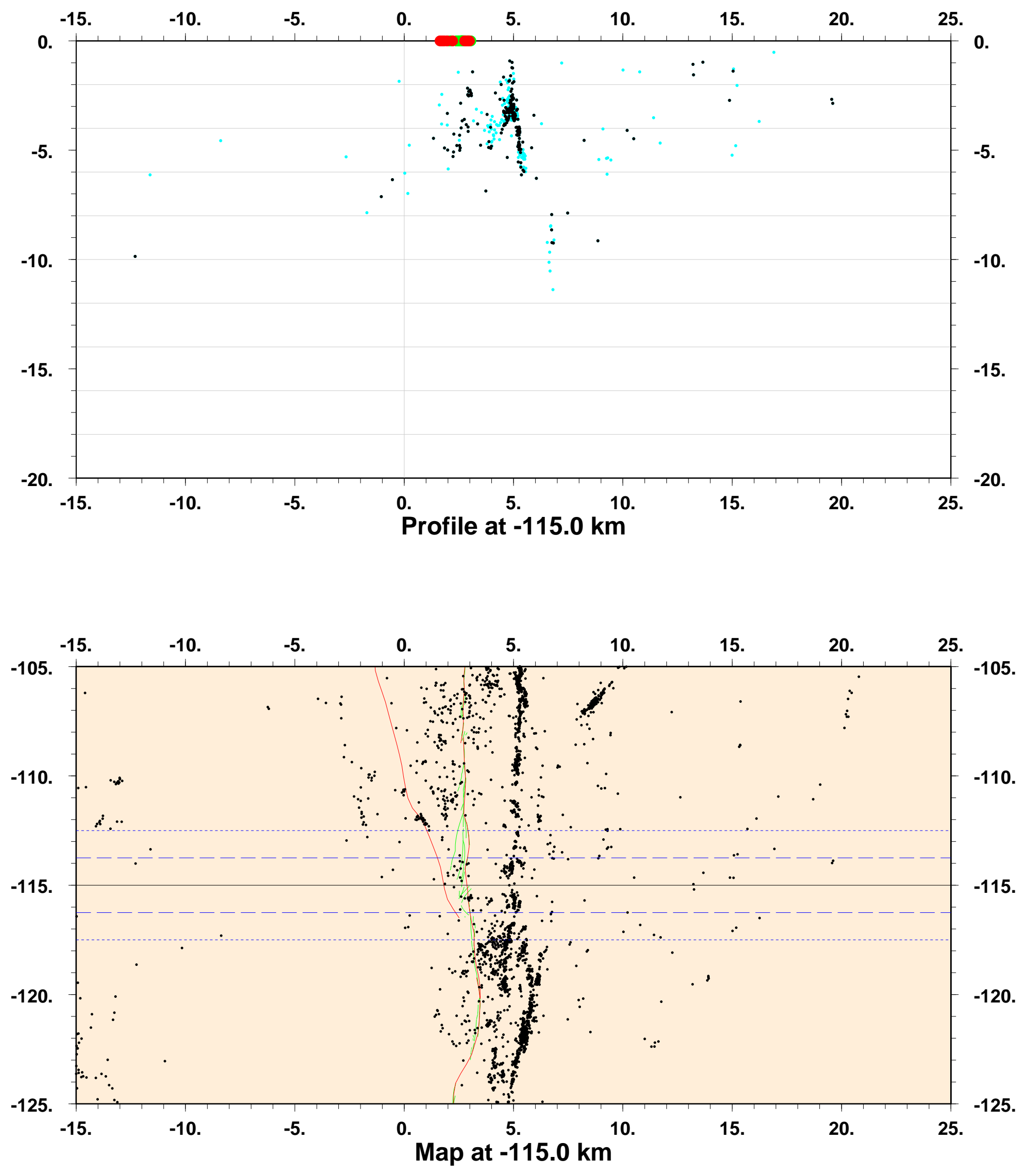

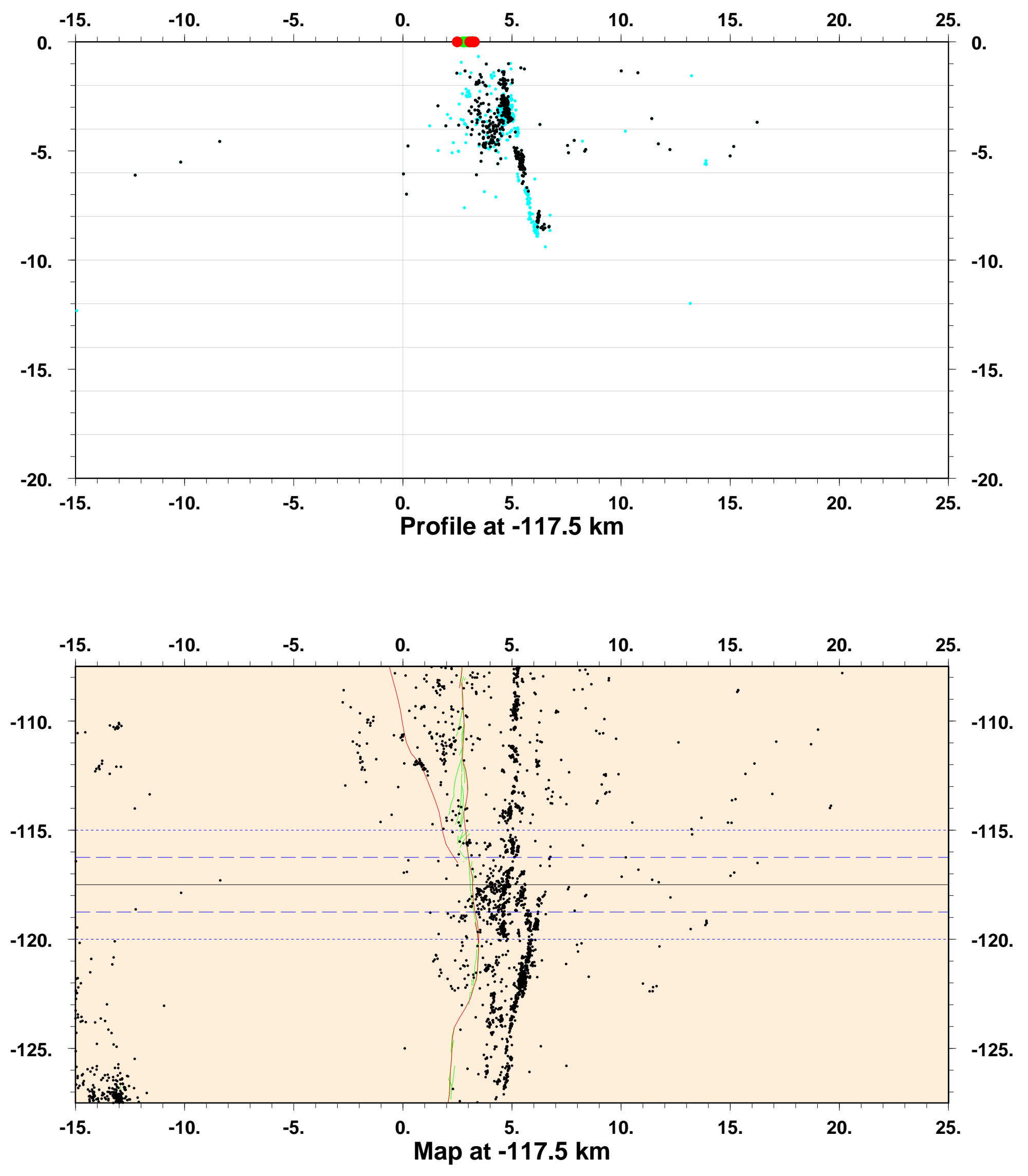

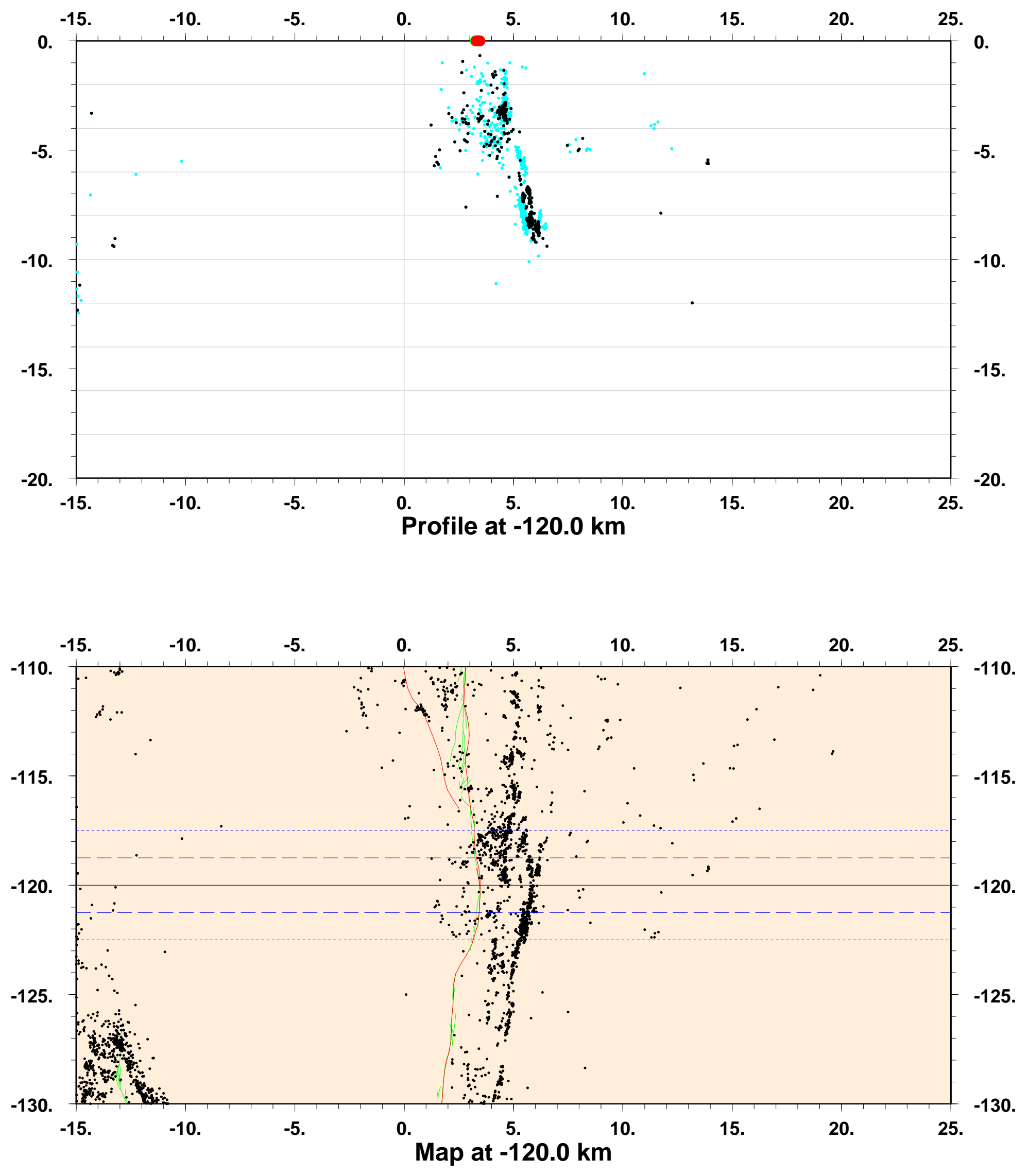

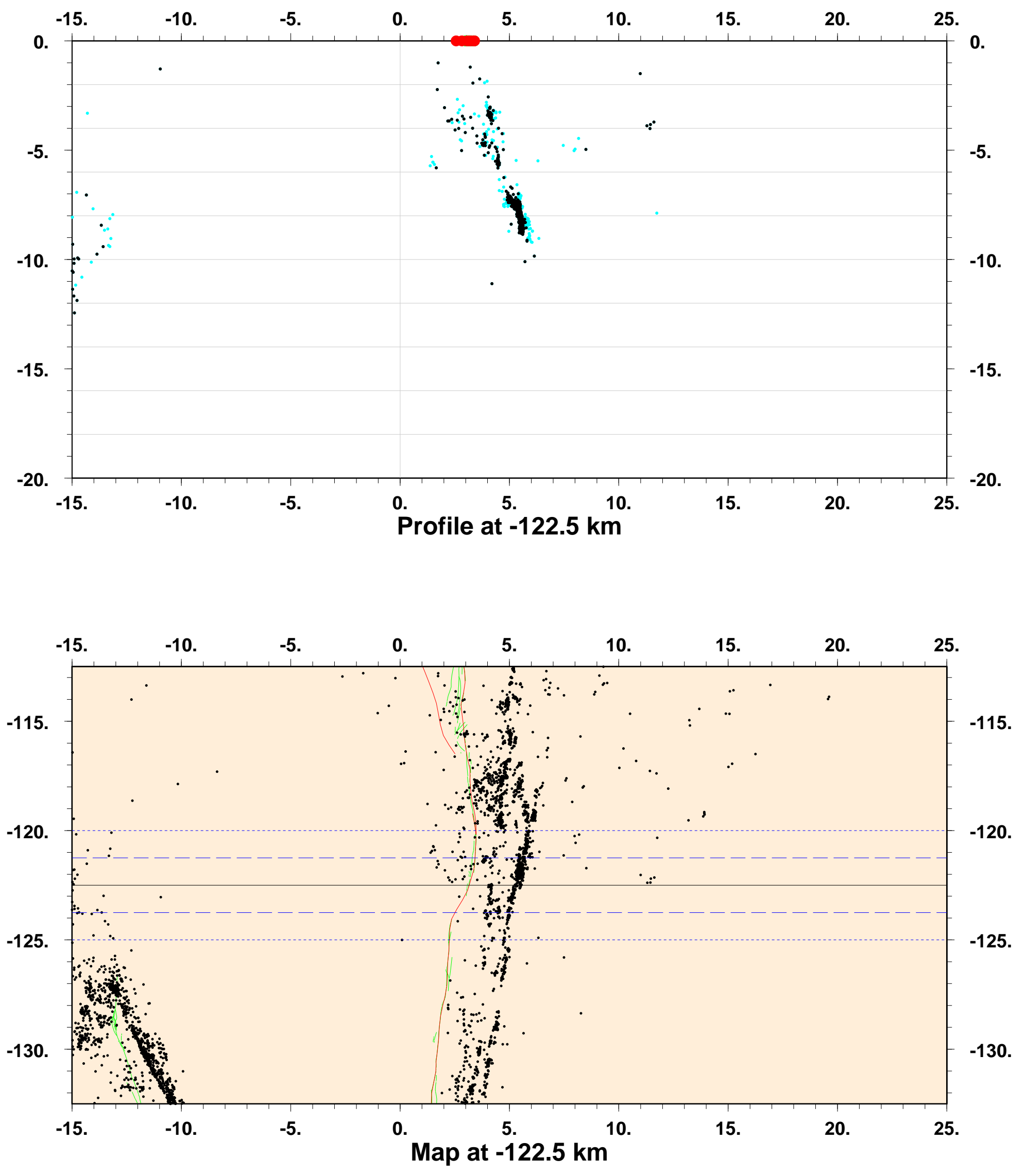

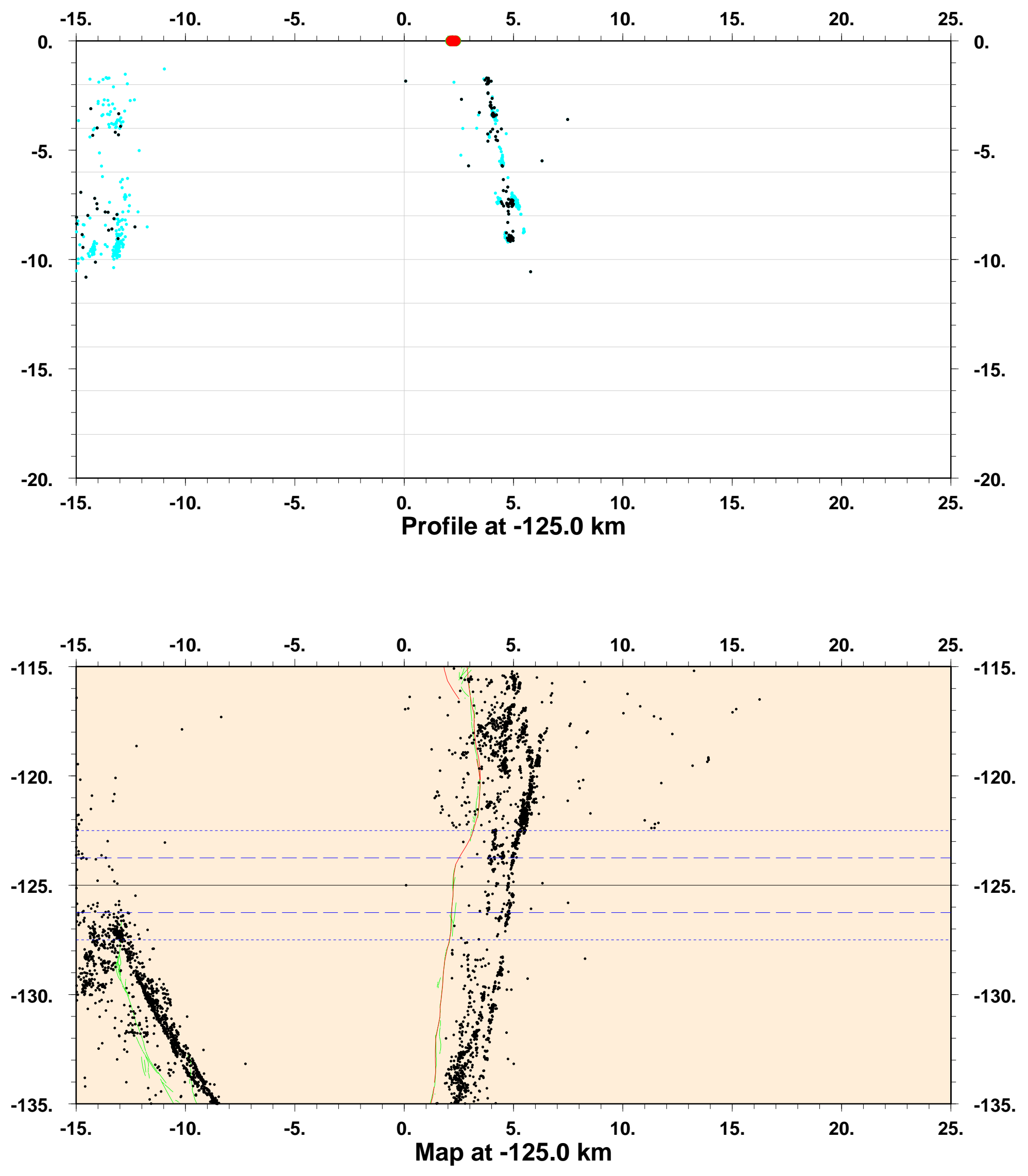

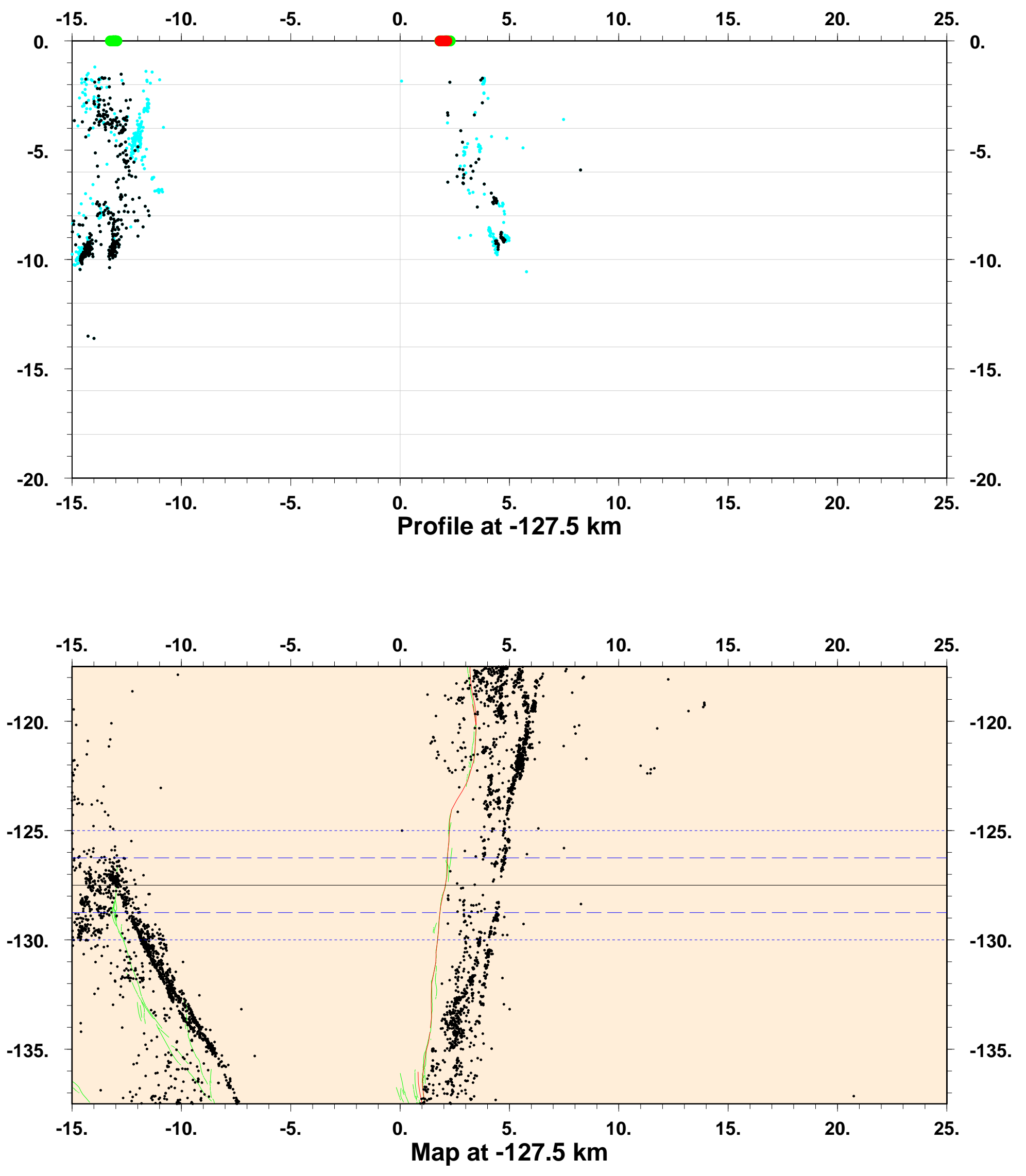

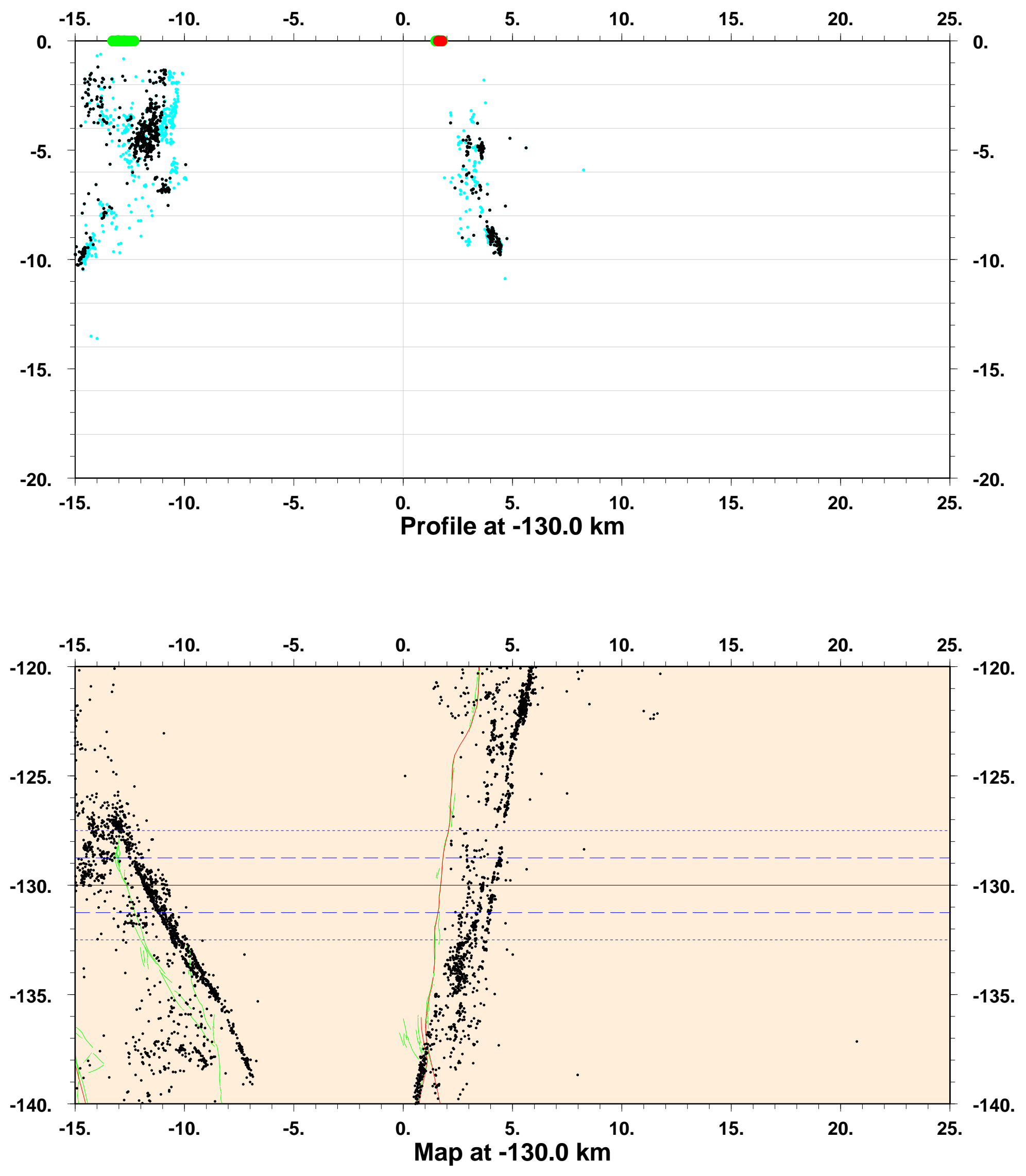

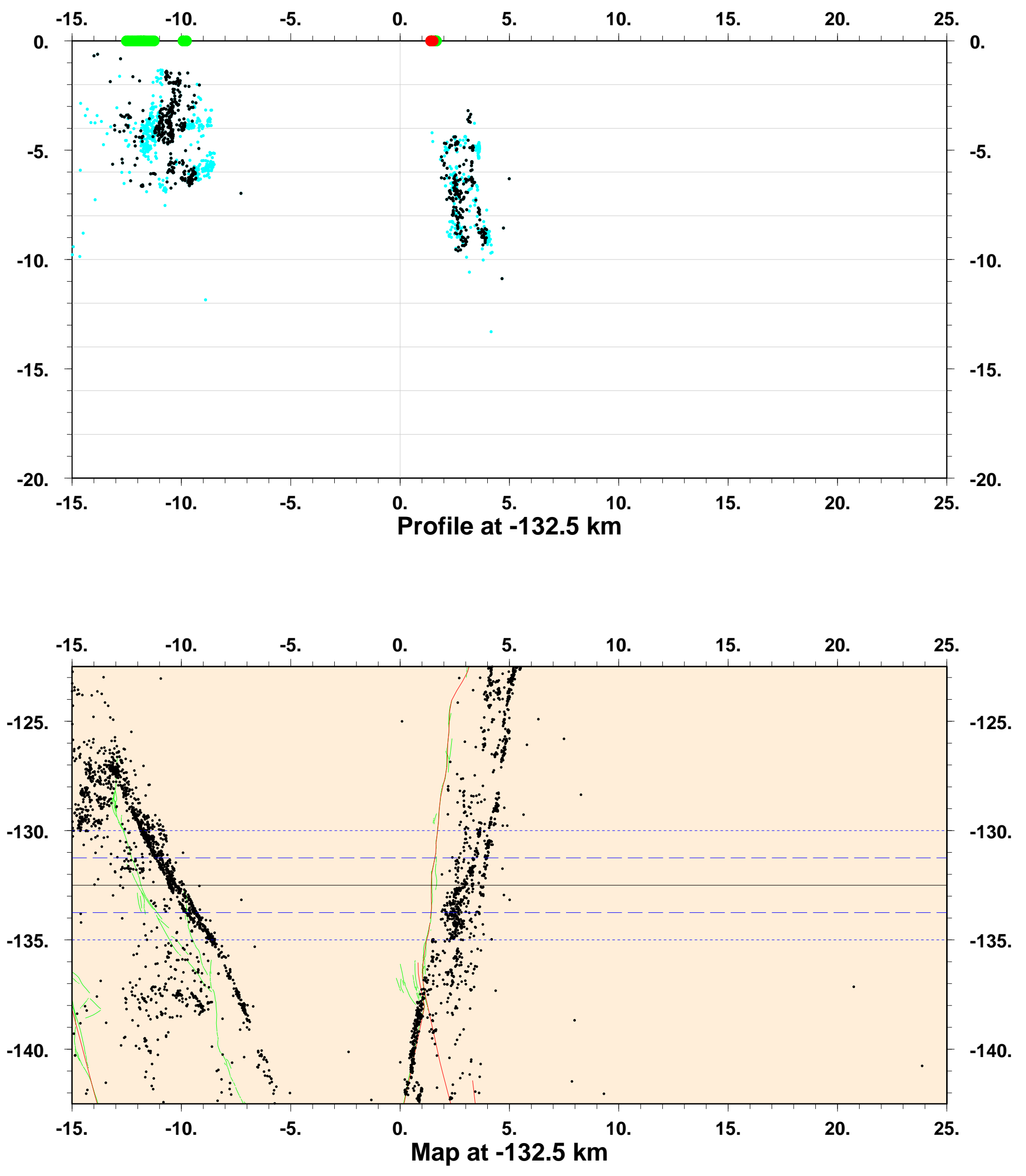

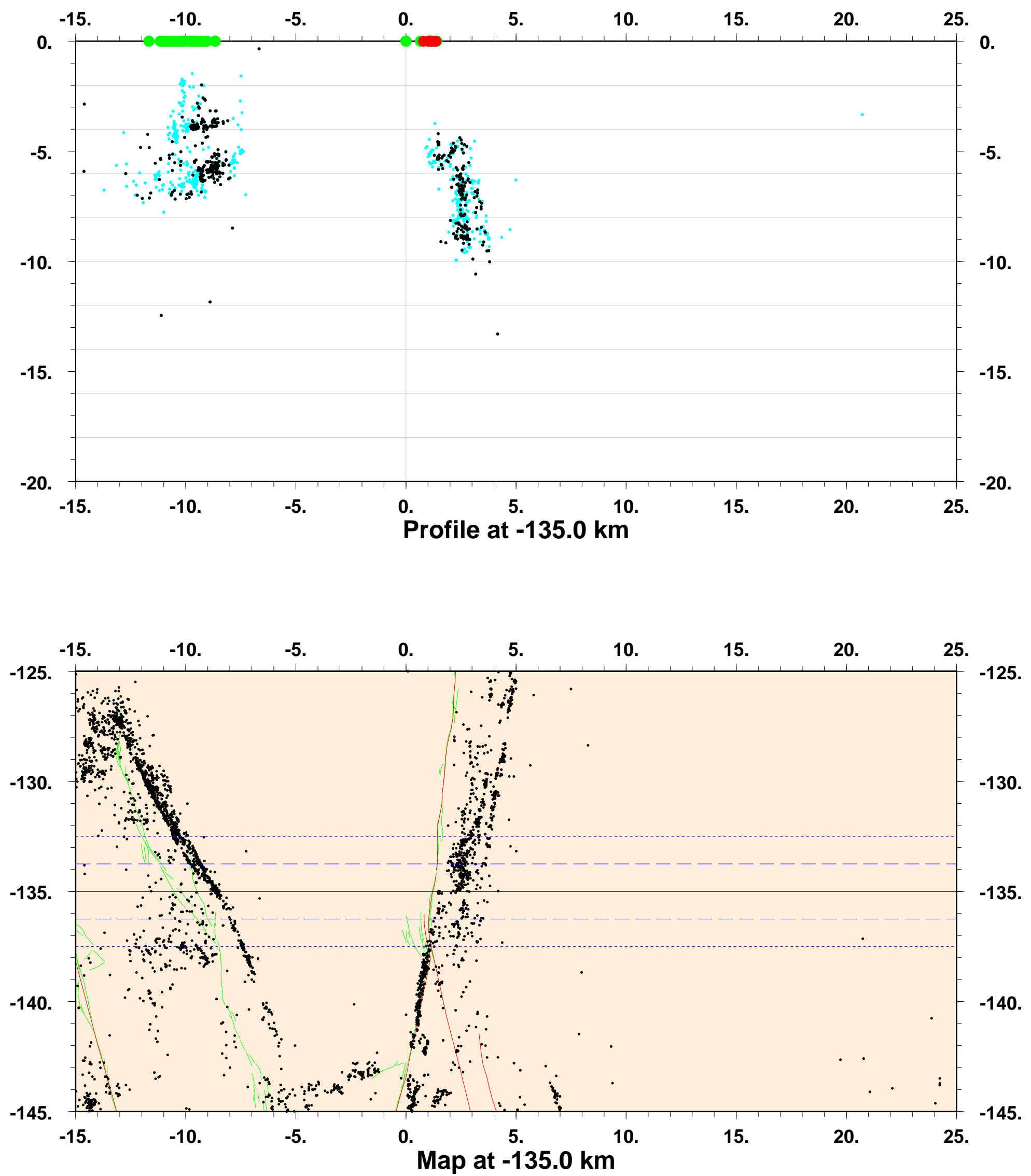

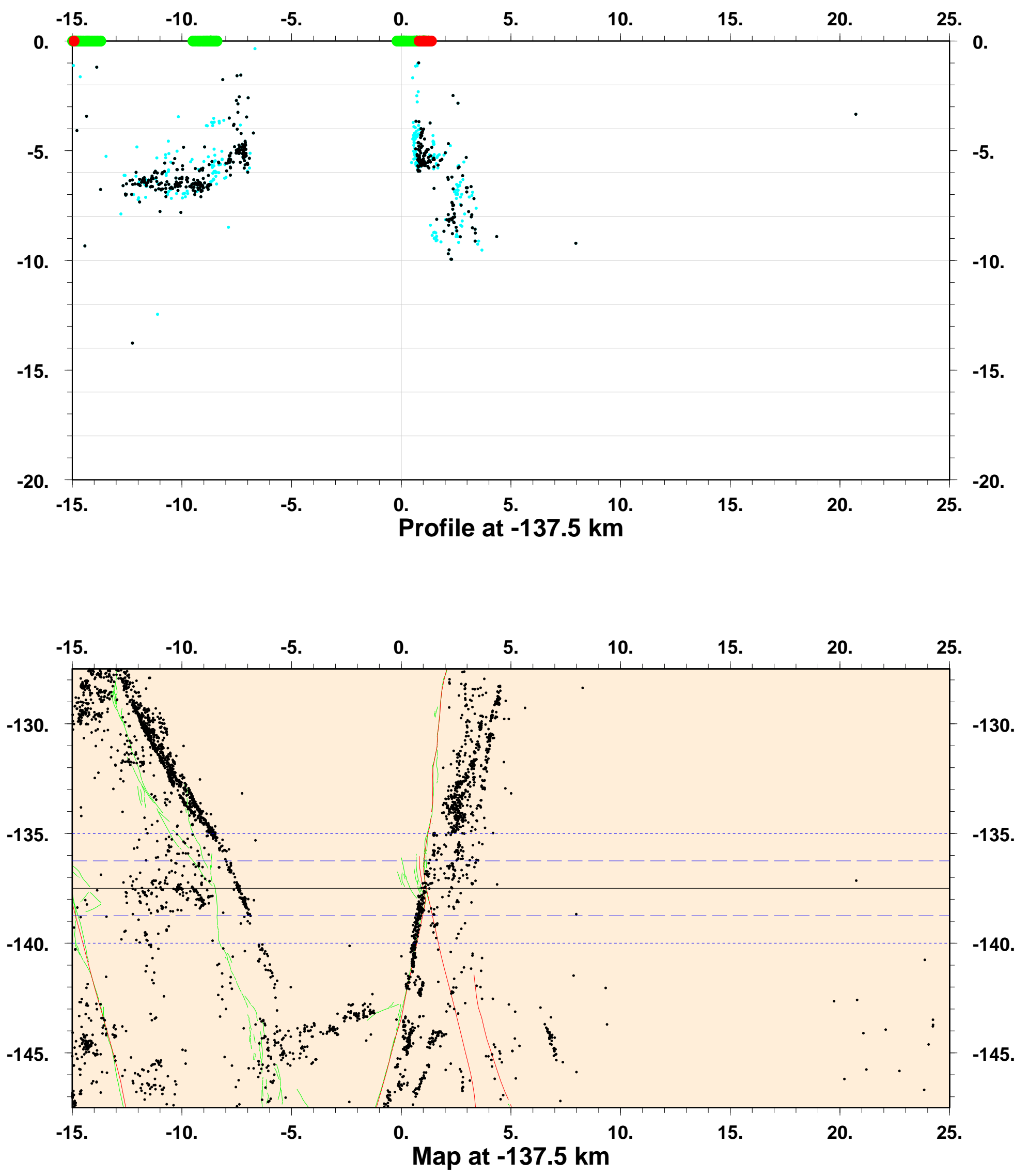


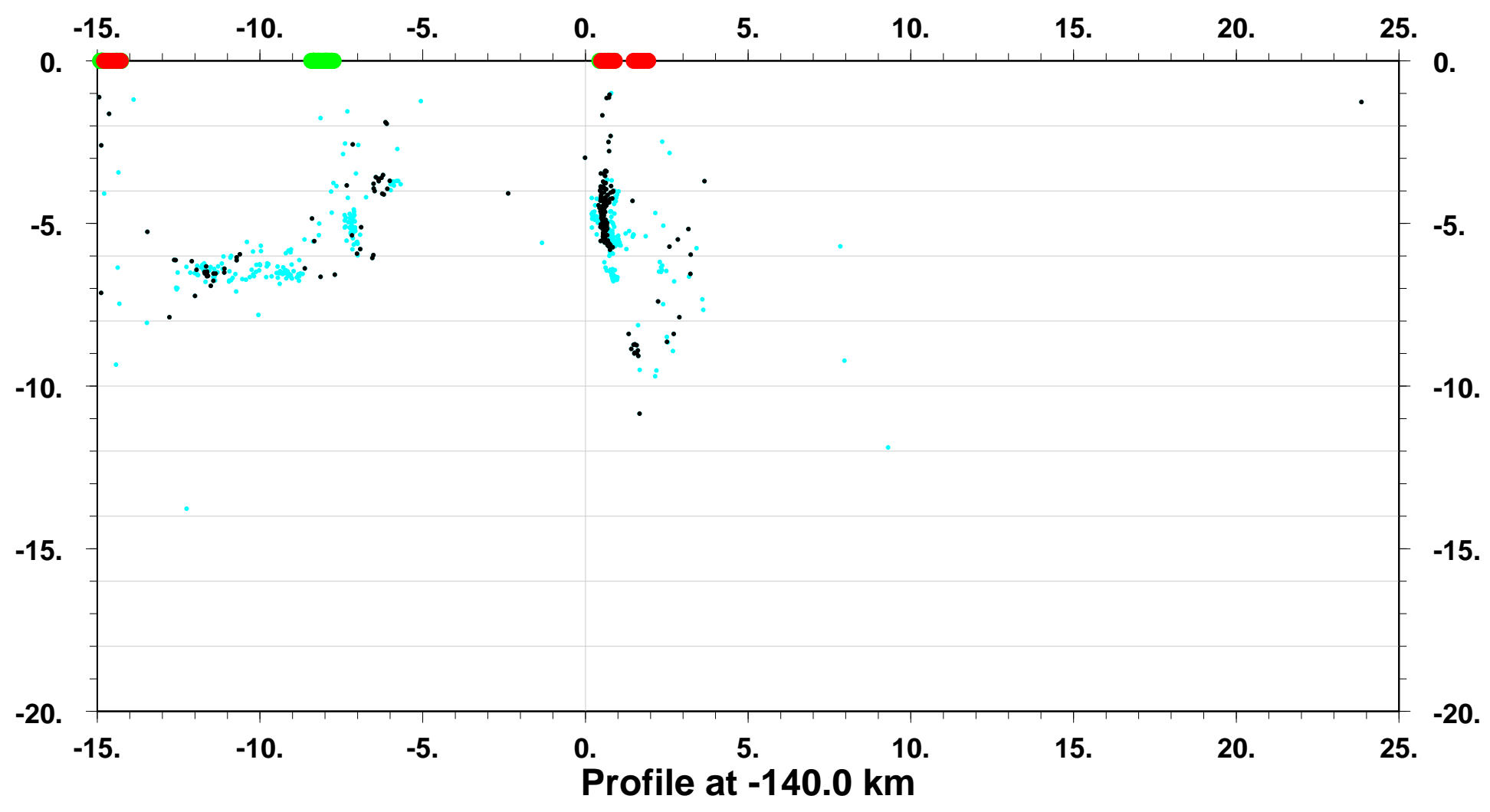

$\begin{array}{llllllll}-15 . & -10 . & -5 . & 0 . & 5 . & 10 . & 15 . & 20 .\end{array}$

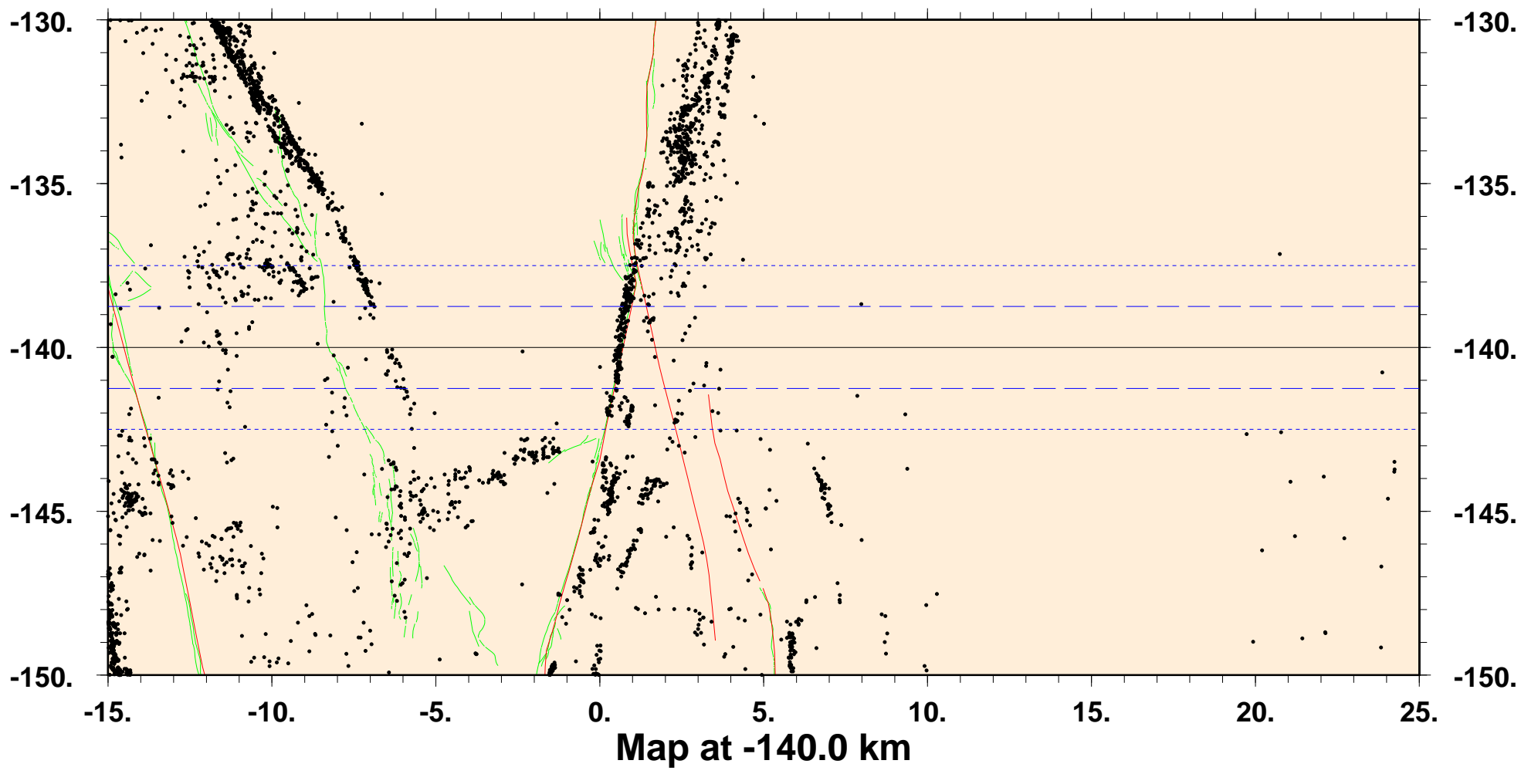



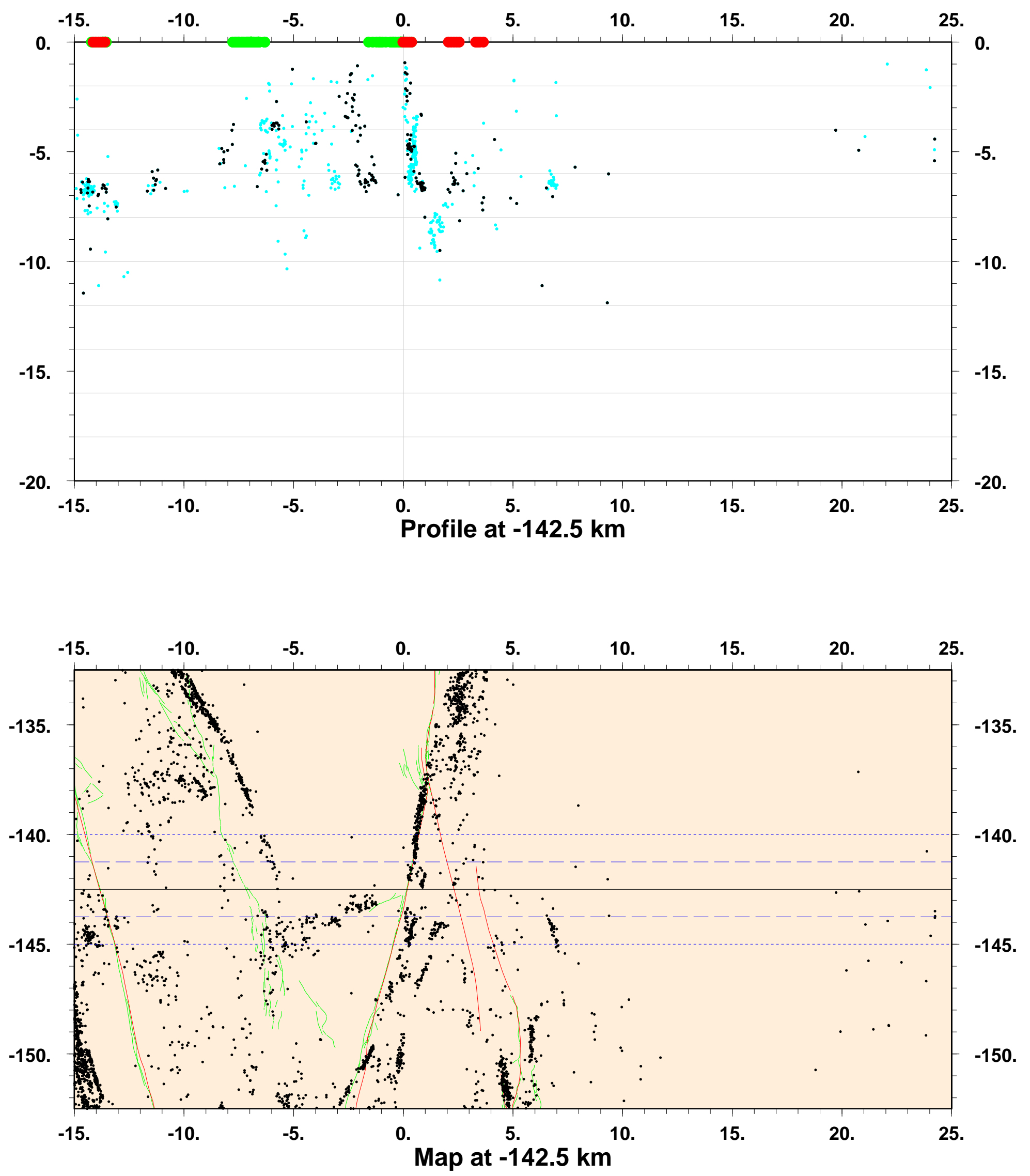

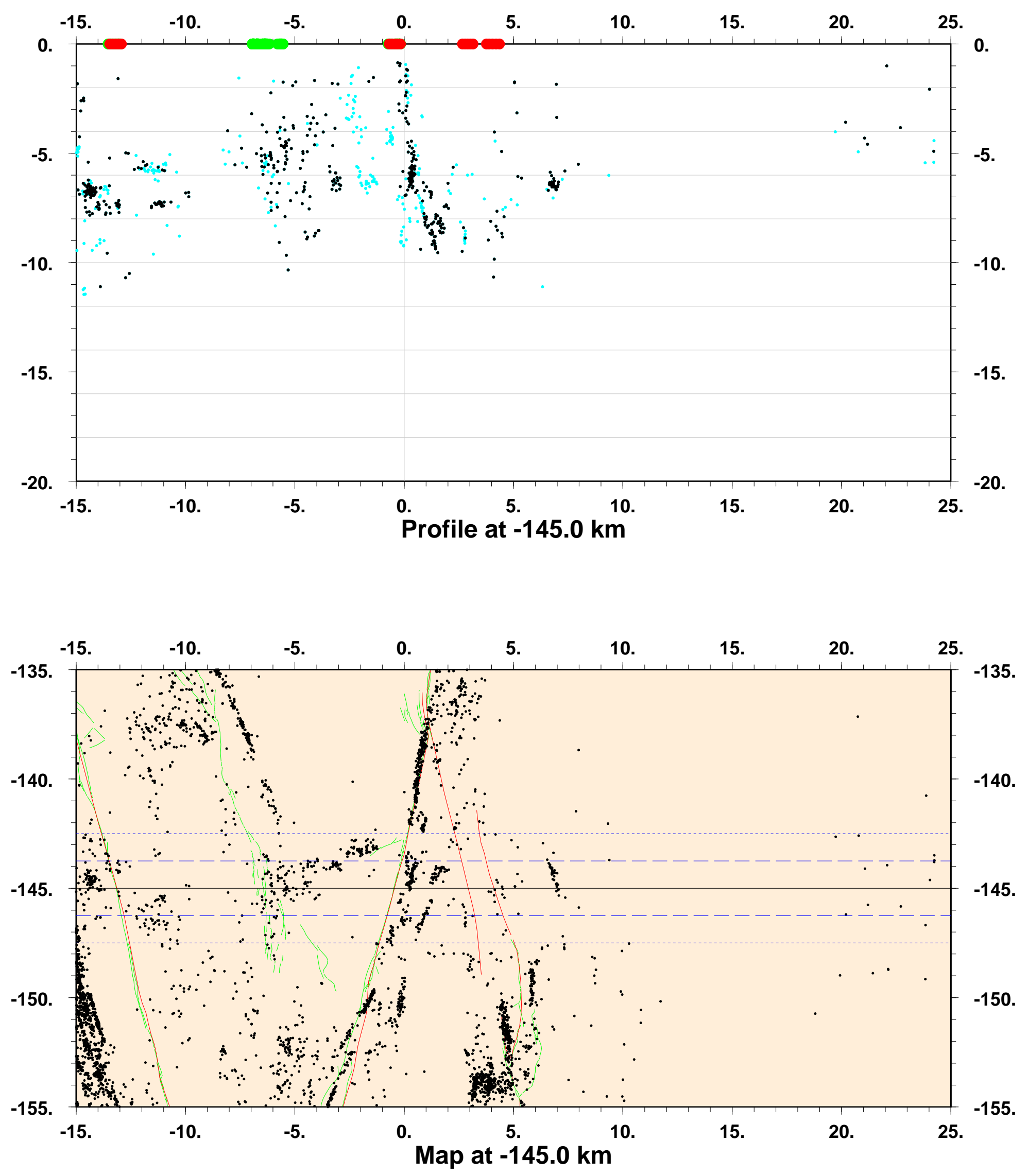

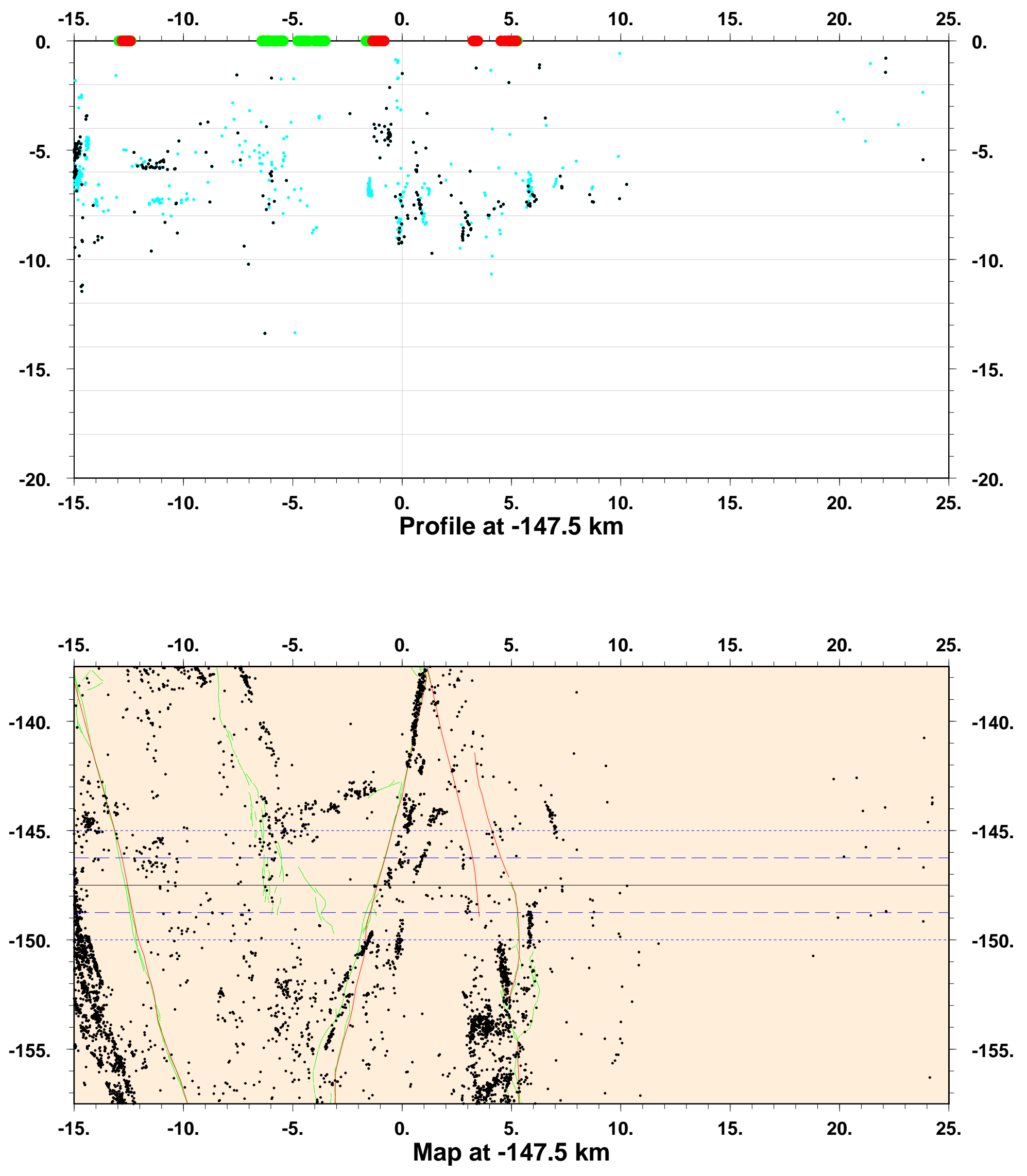

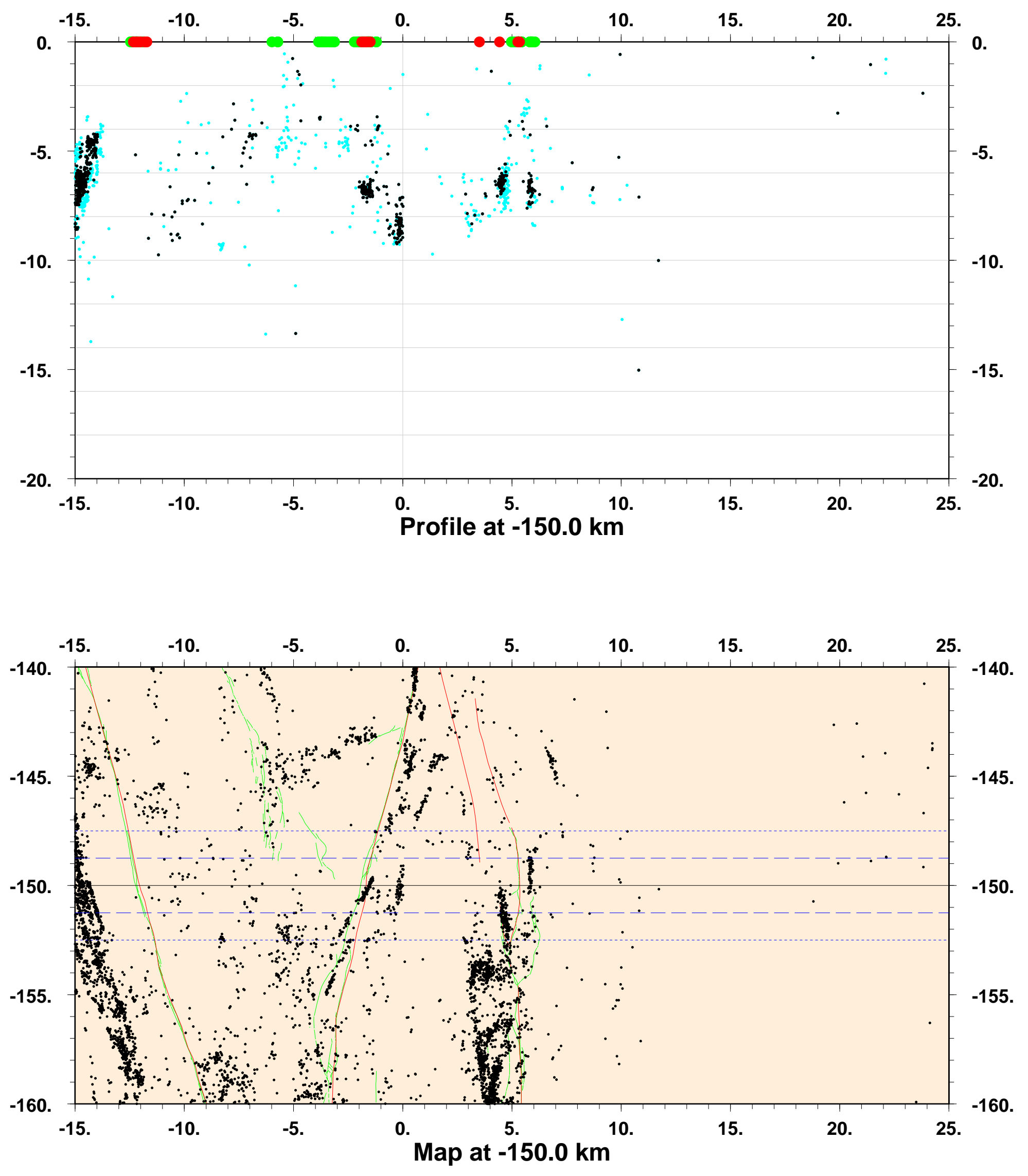


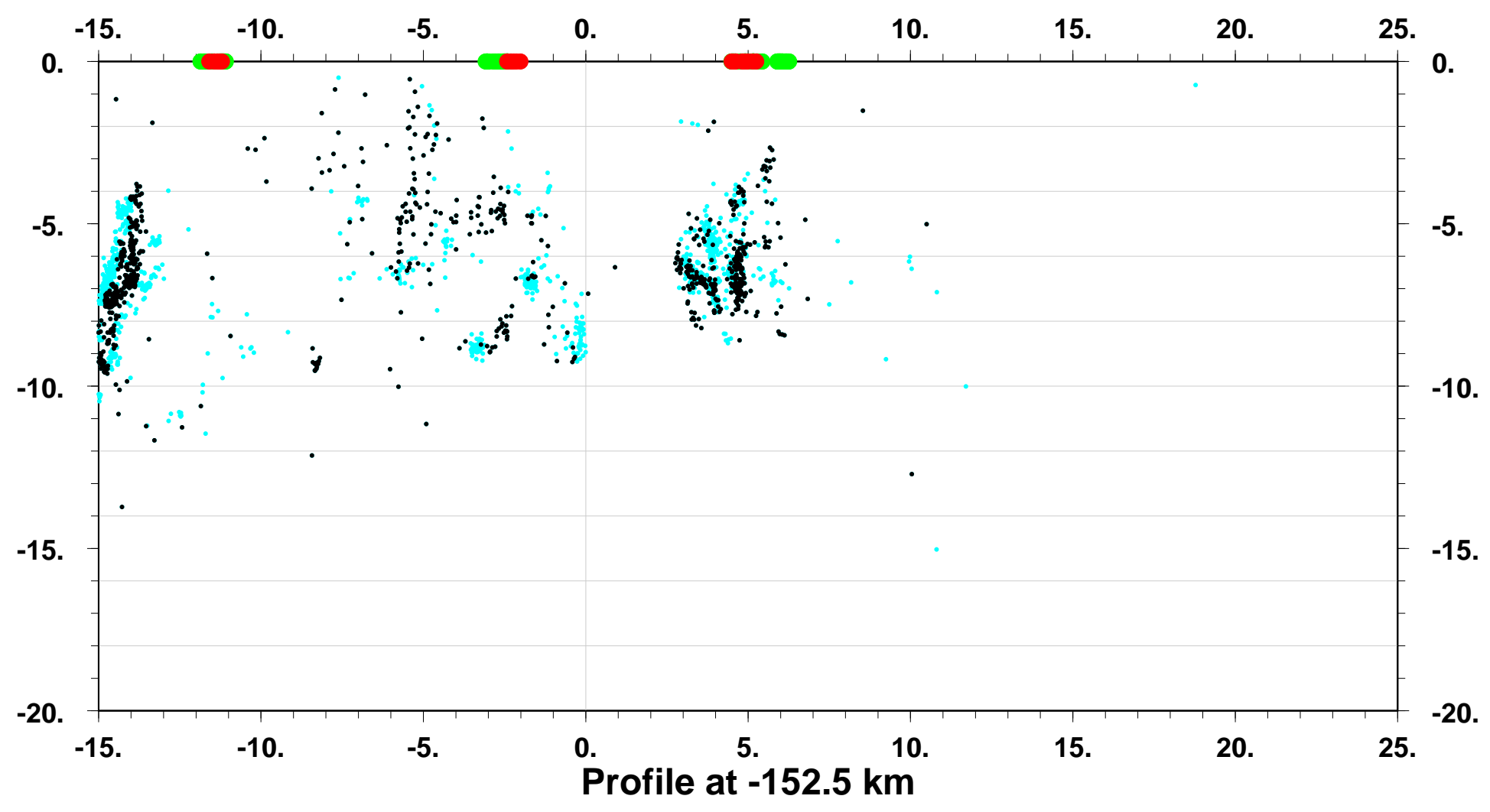

$\begin{array}{llllllll}-15 . & -10 . & -5 . & 0 . & 5 . & 10 . & 15 . & 20 .\end{array}$

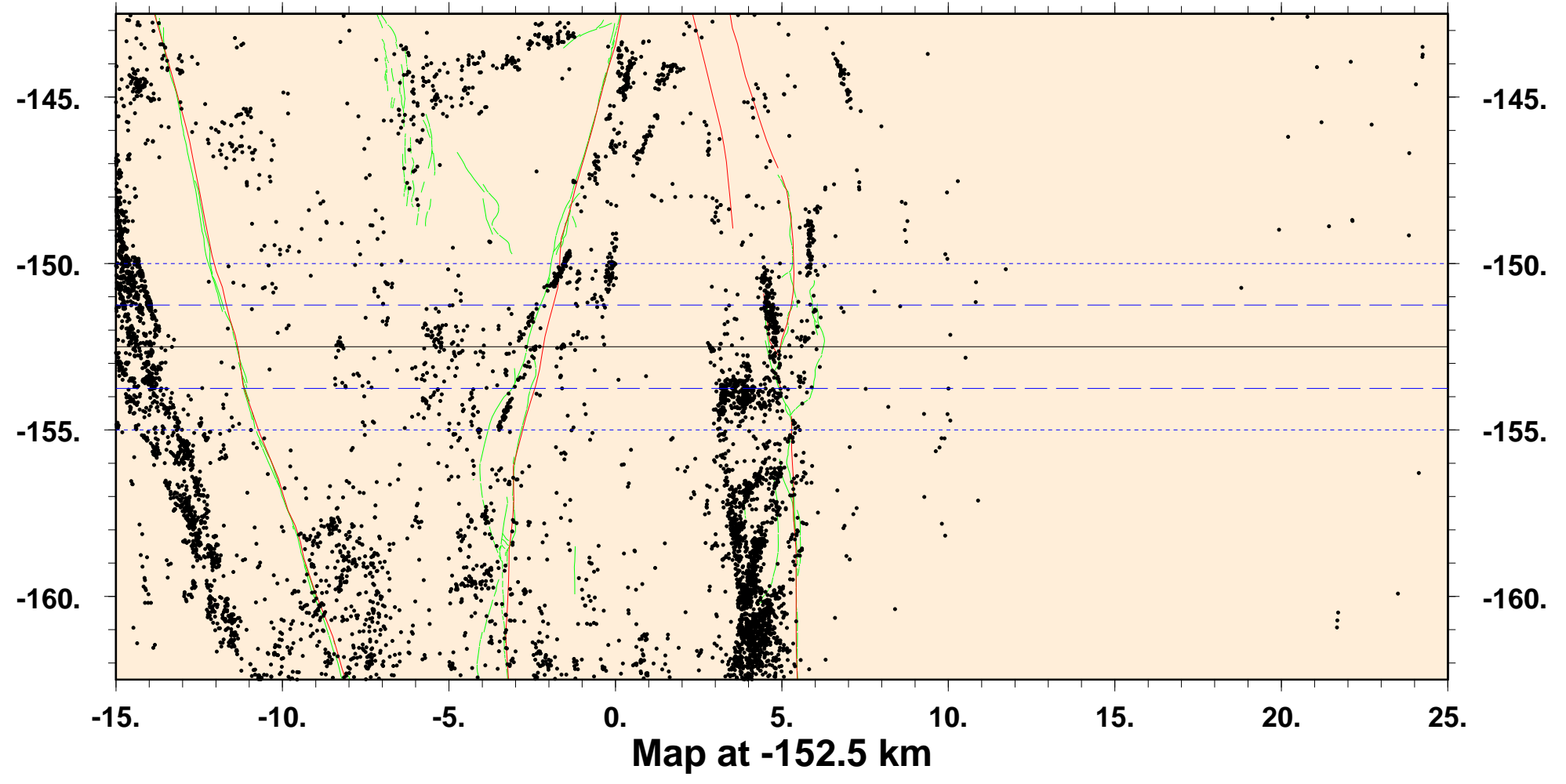




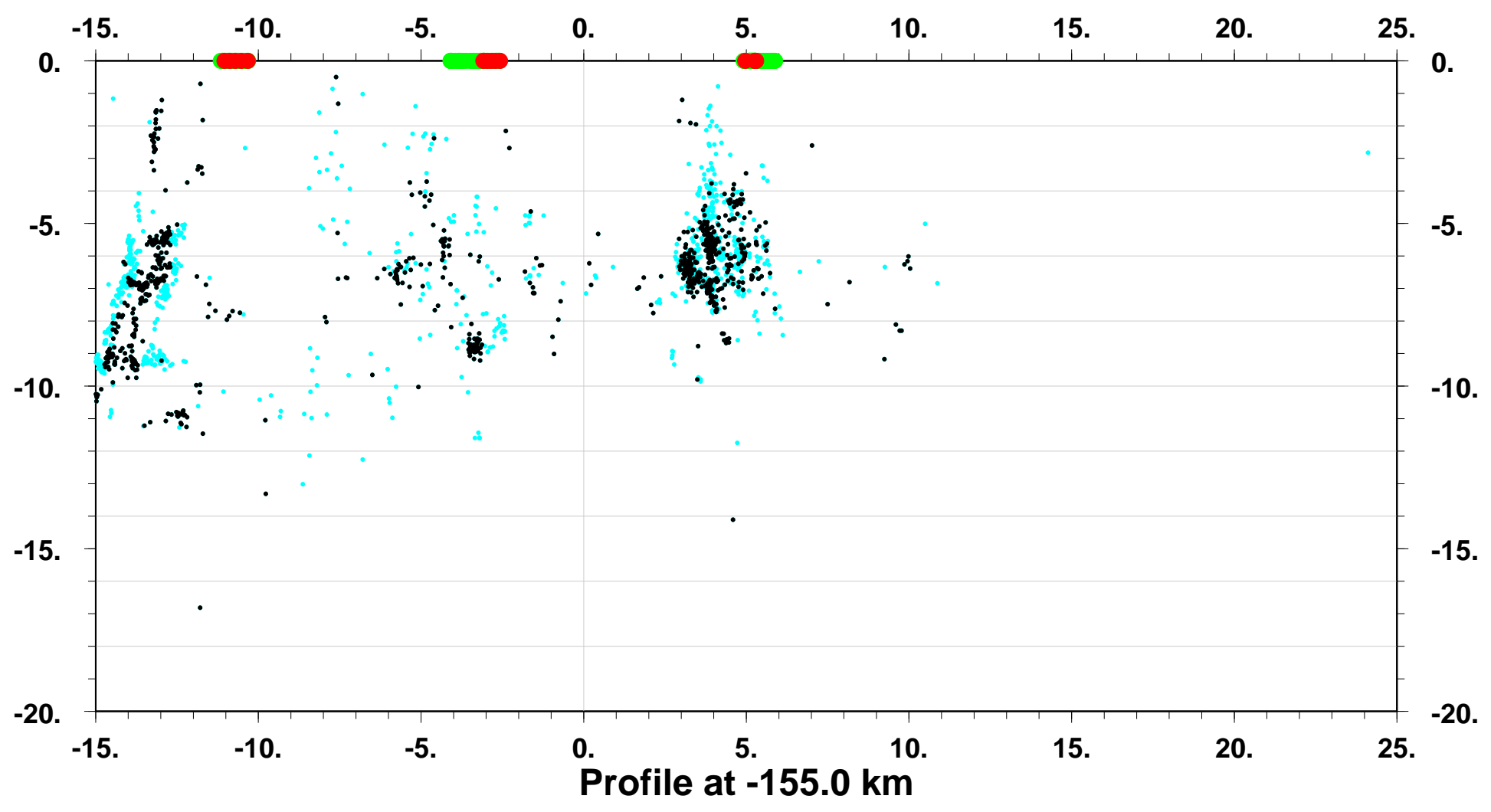

$\begin{array}{llllllll}-15 . & -10 . & -5 . & 0 . & 5 . & 10 . & 15 . & 20 .\end{array}$

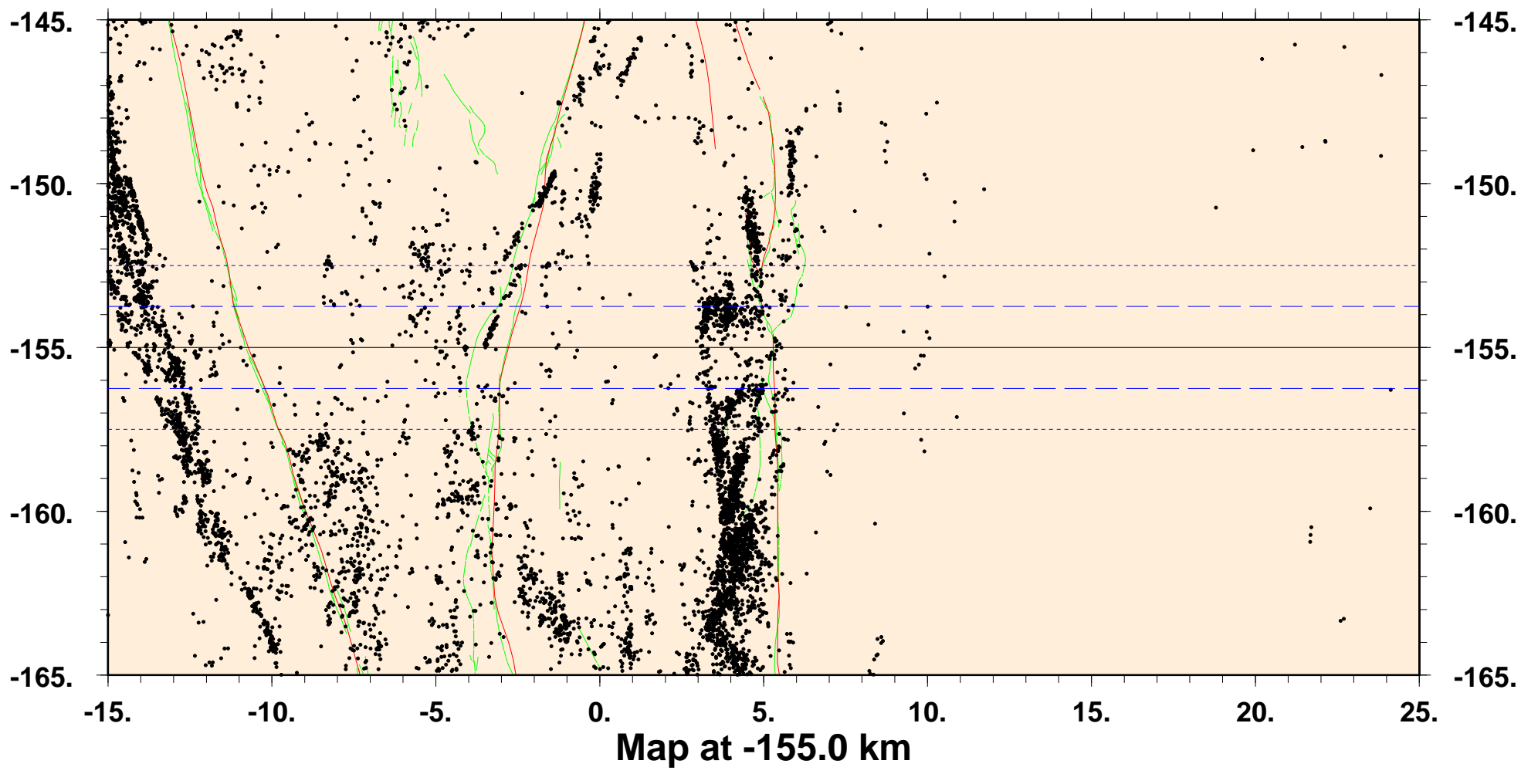



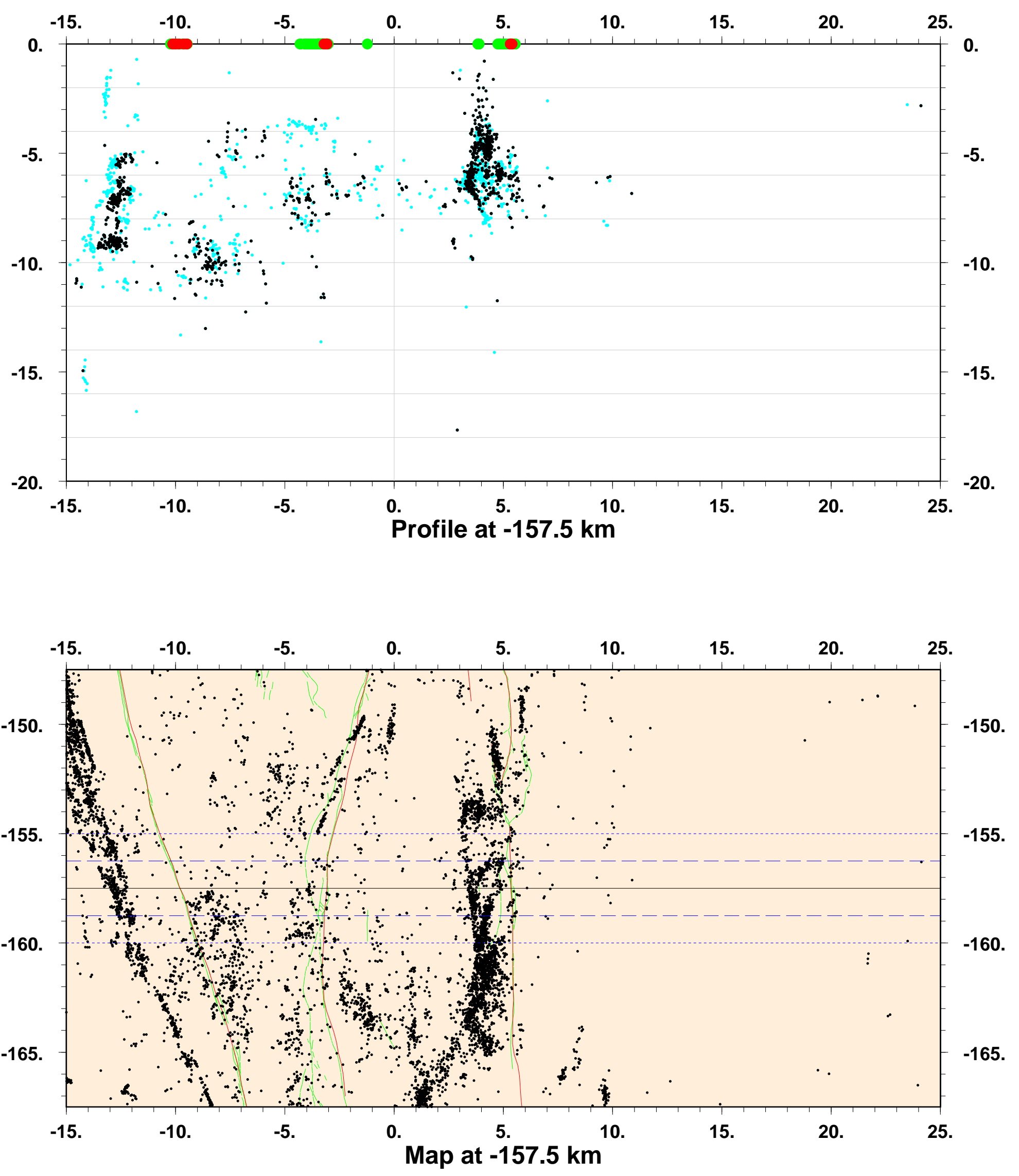


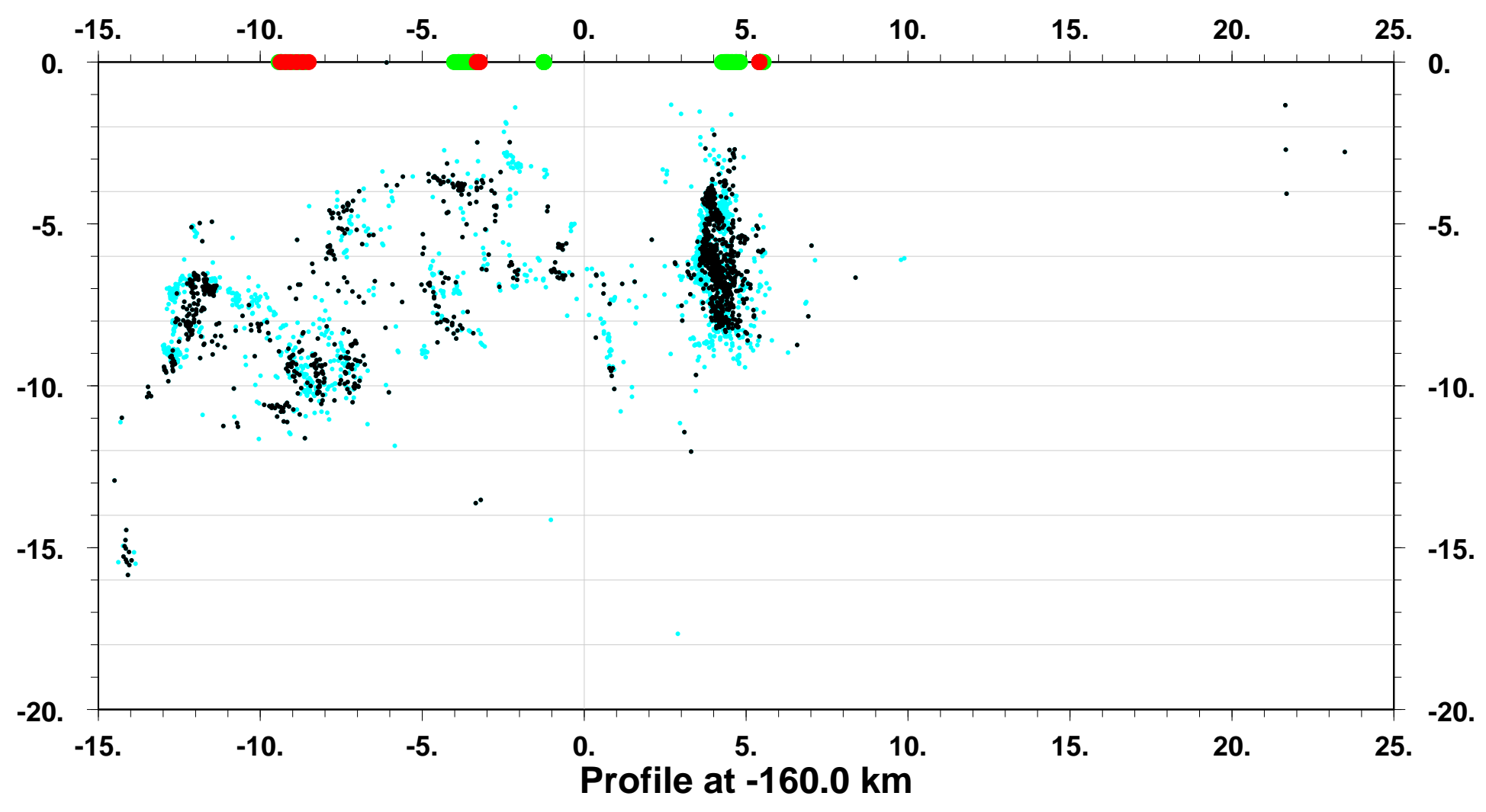

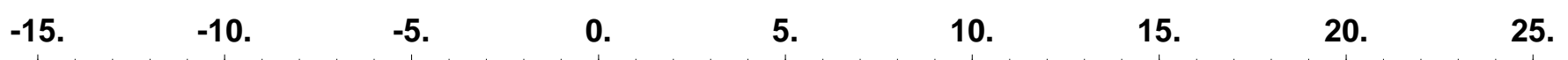

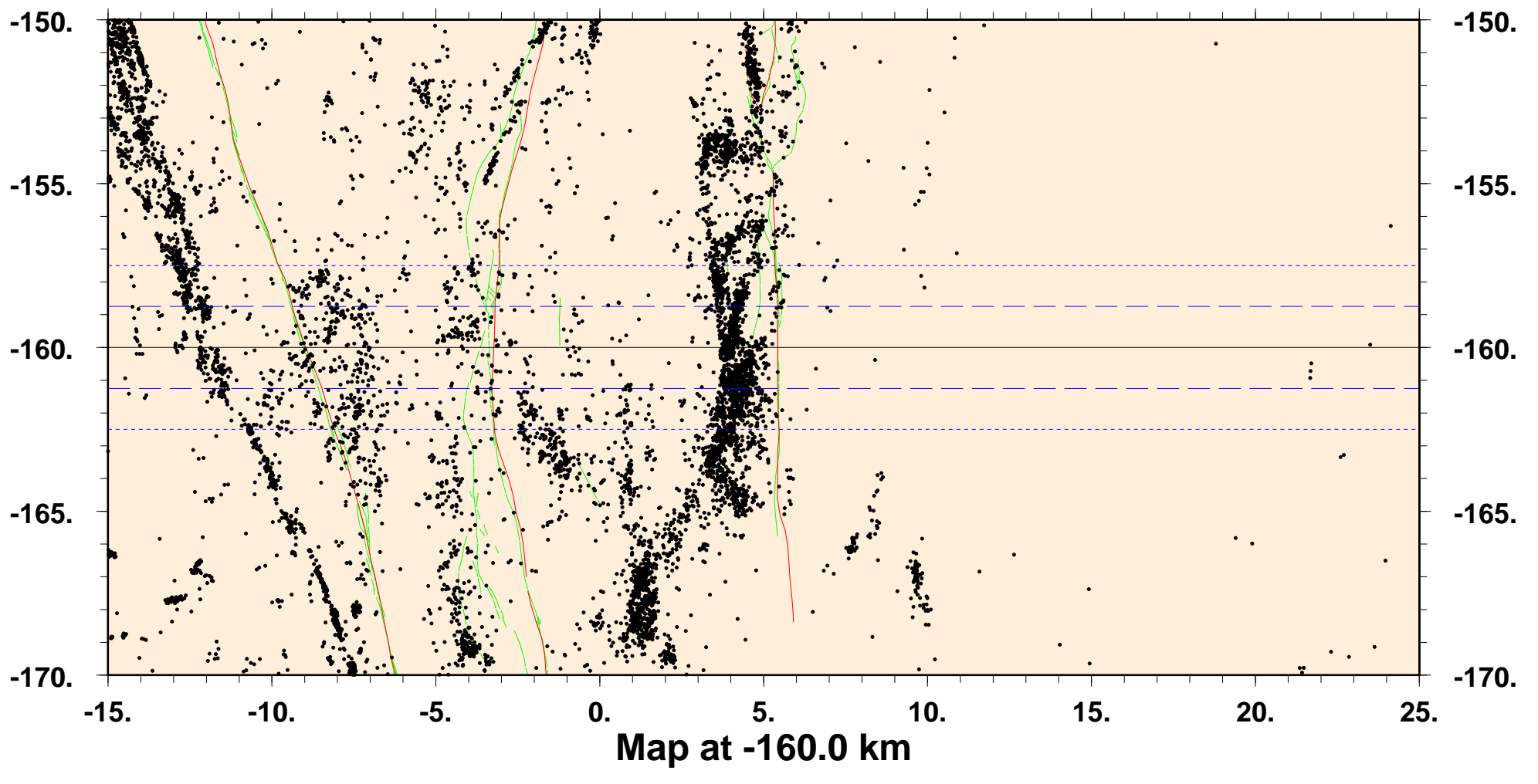



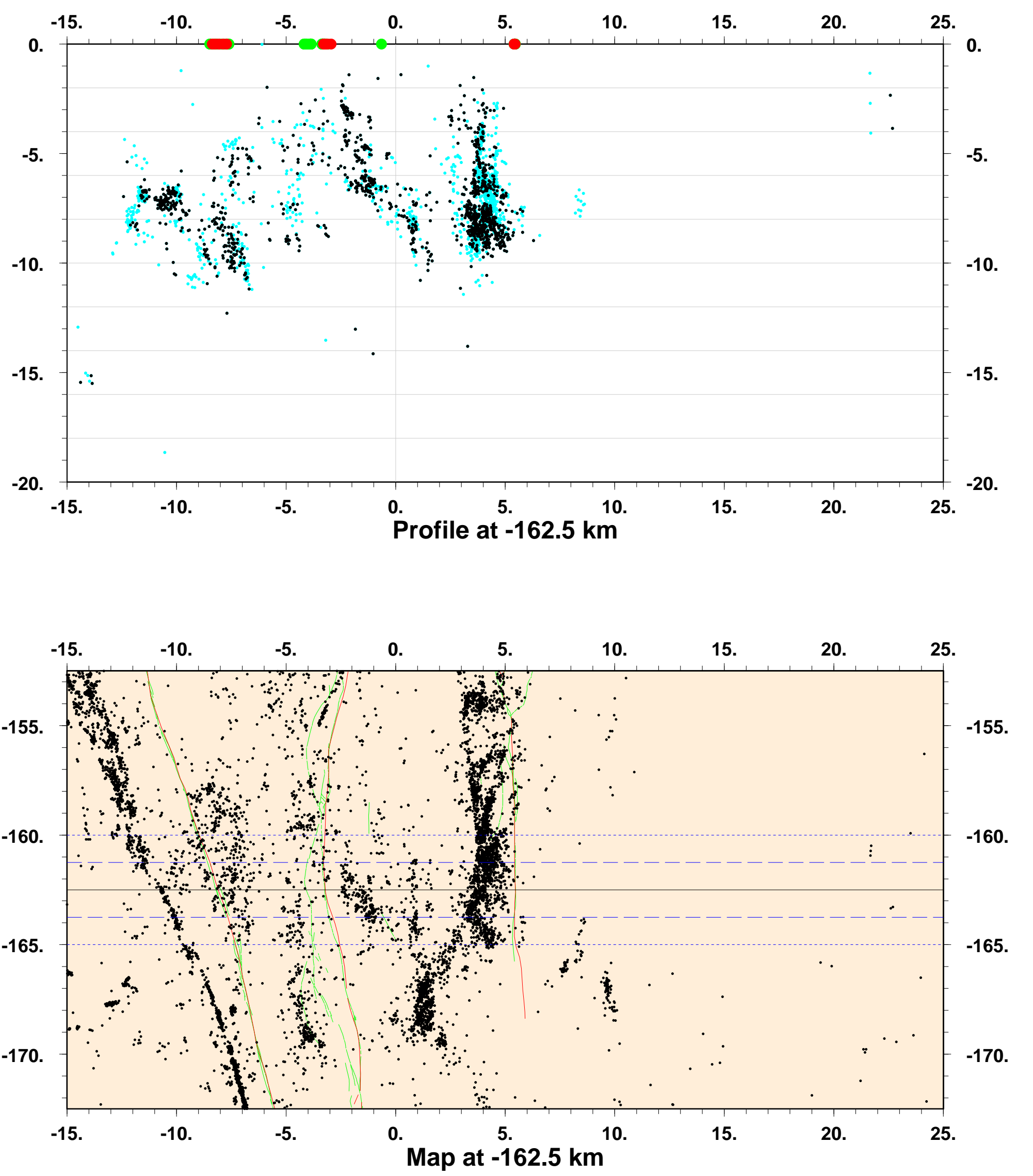

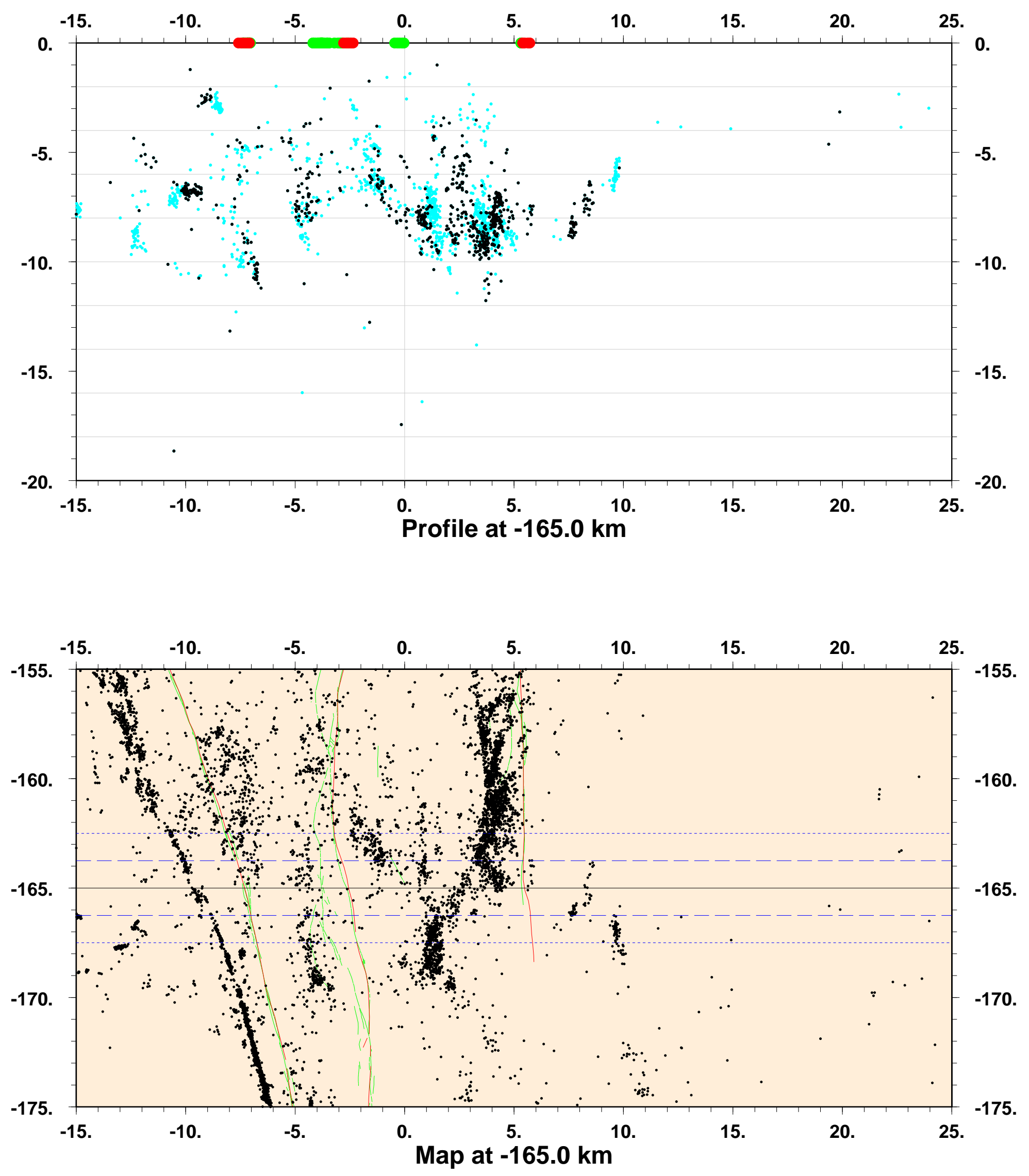

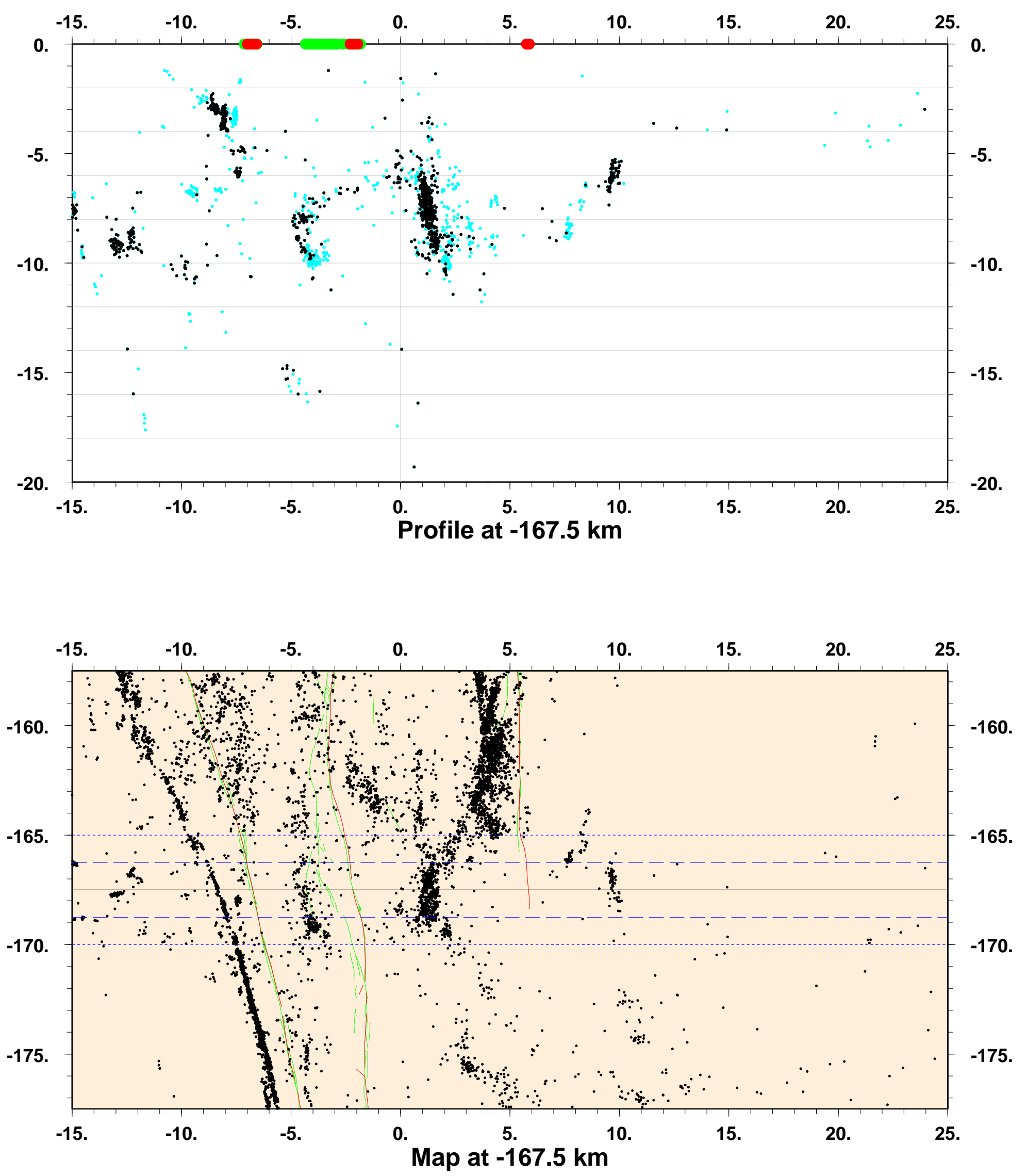

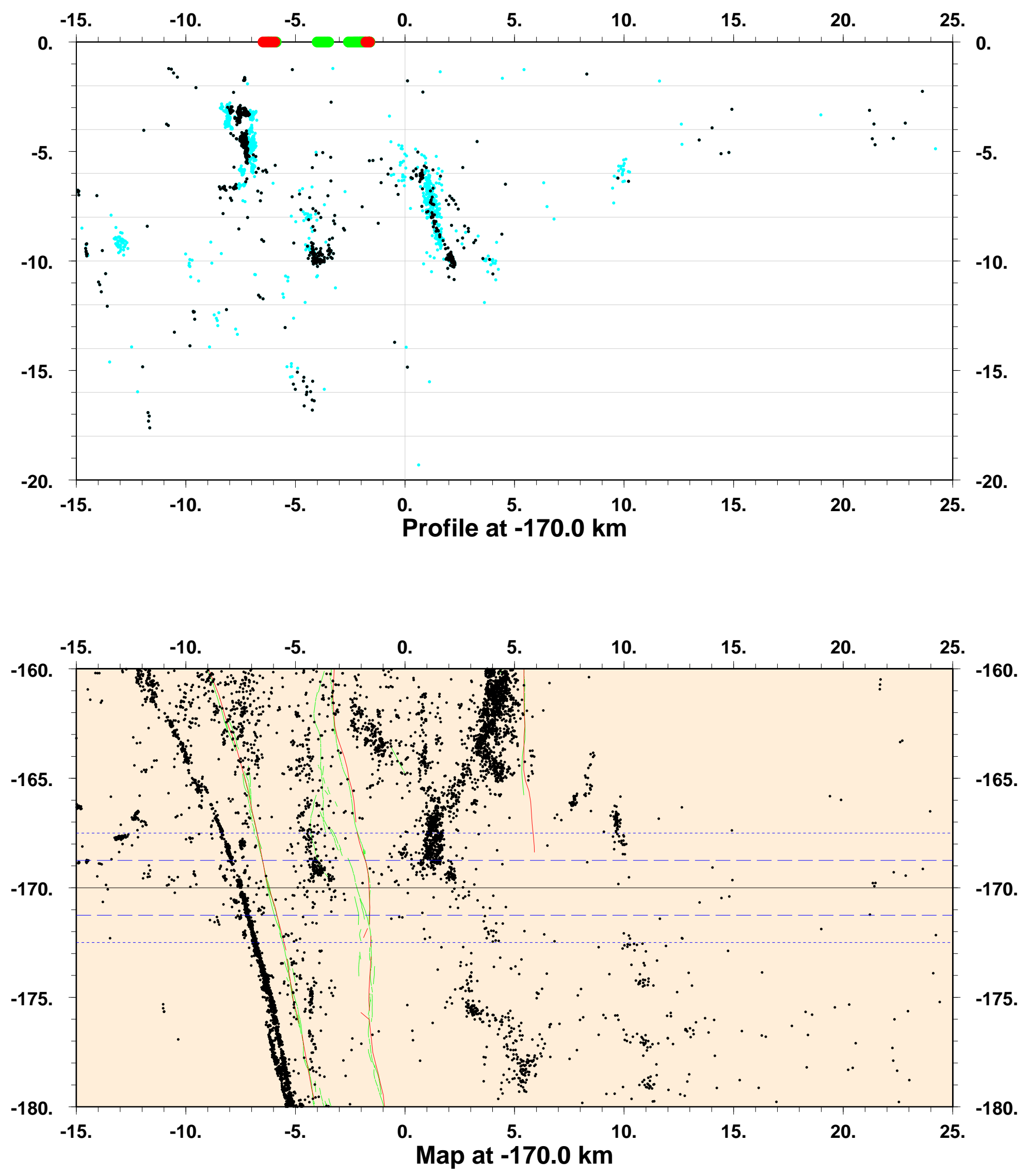

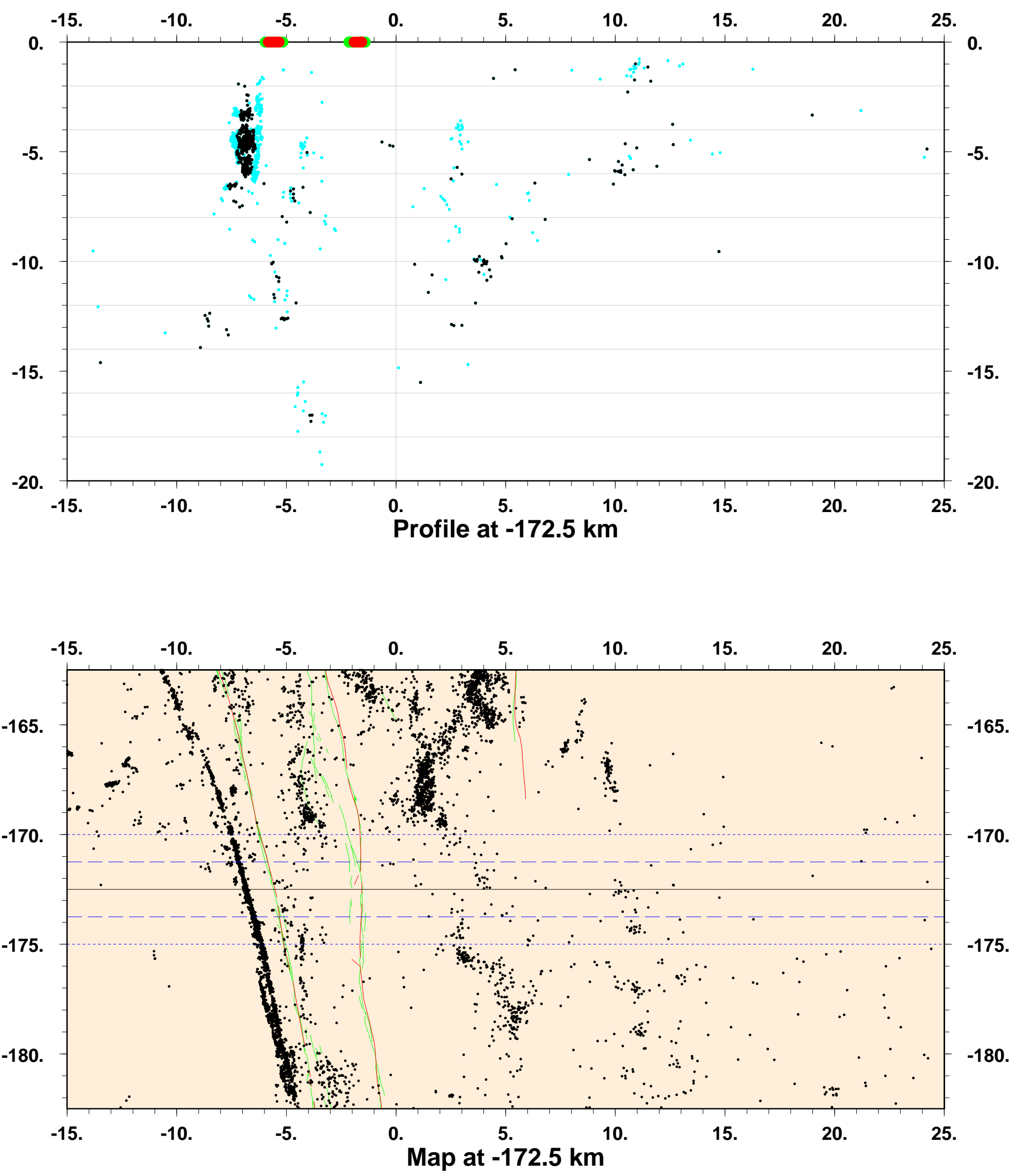

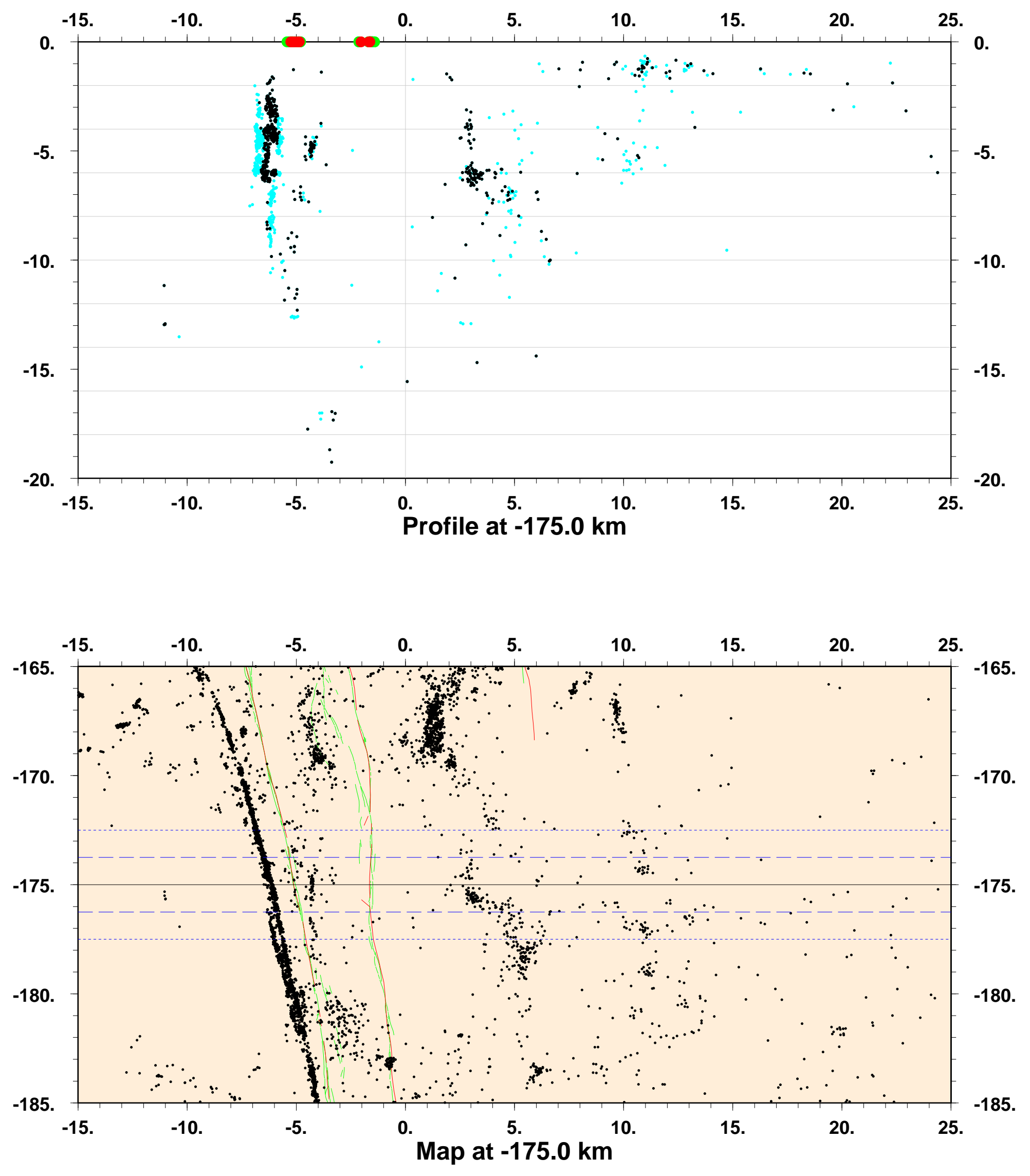

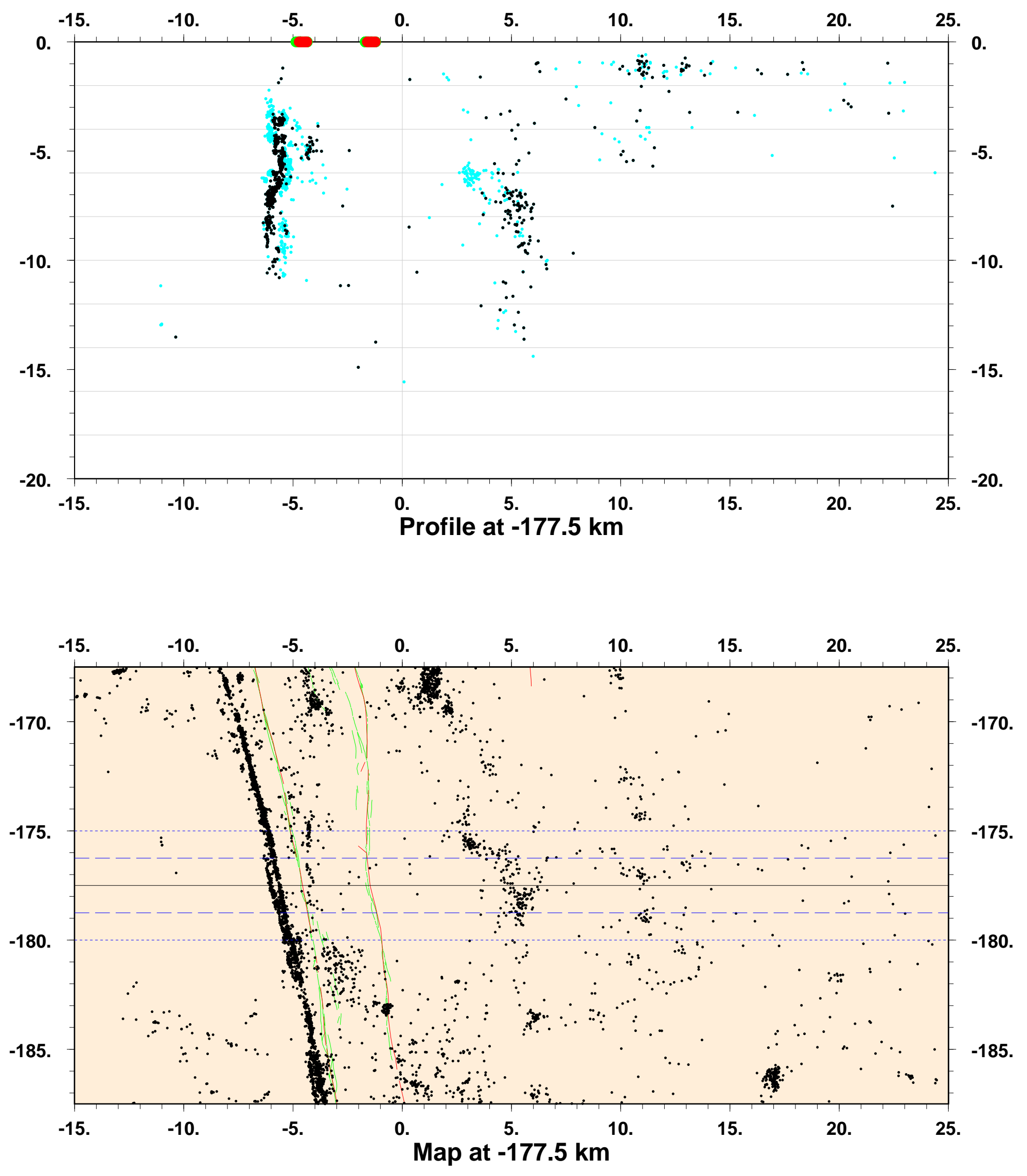


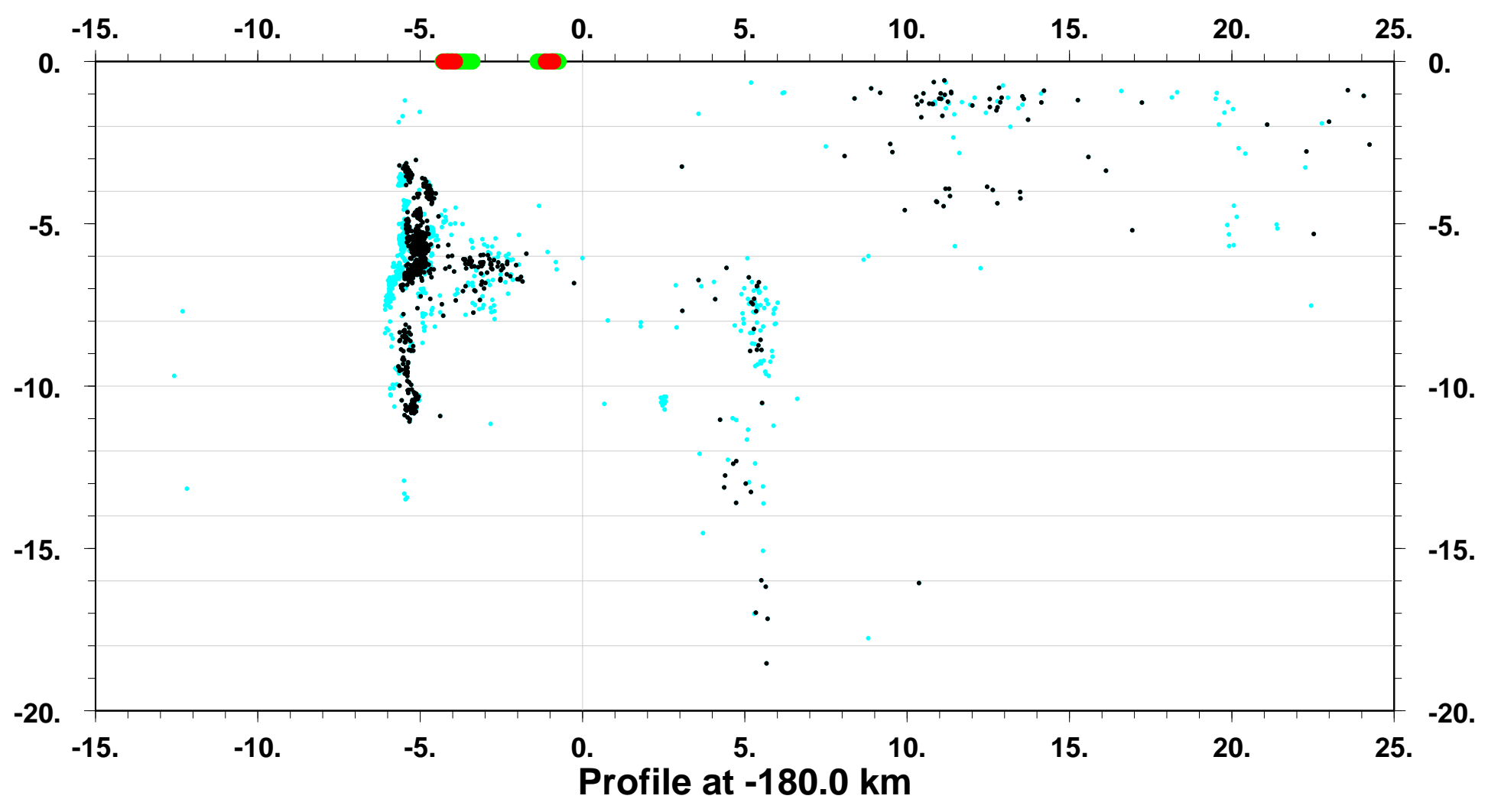

\begin{tabular}{rrrrrrrrr}
-15. & -10. & -5. & 0. & 5. & 10. & 15. & 20. & 25. \\
\hline
\end{tabular}

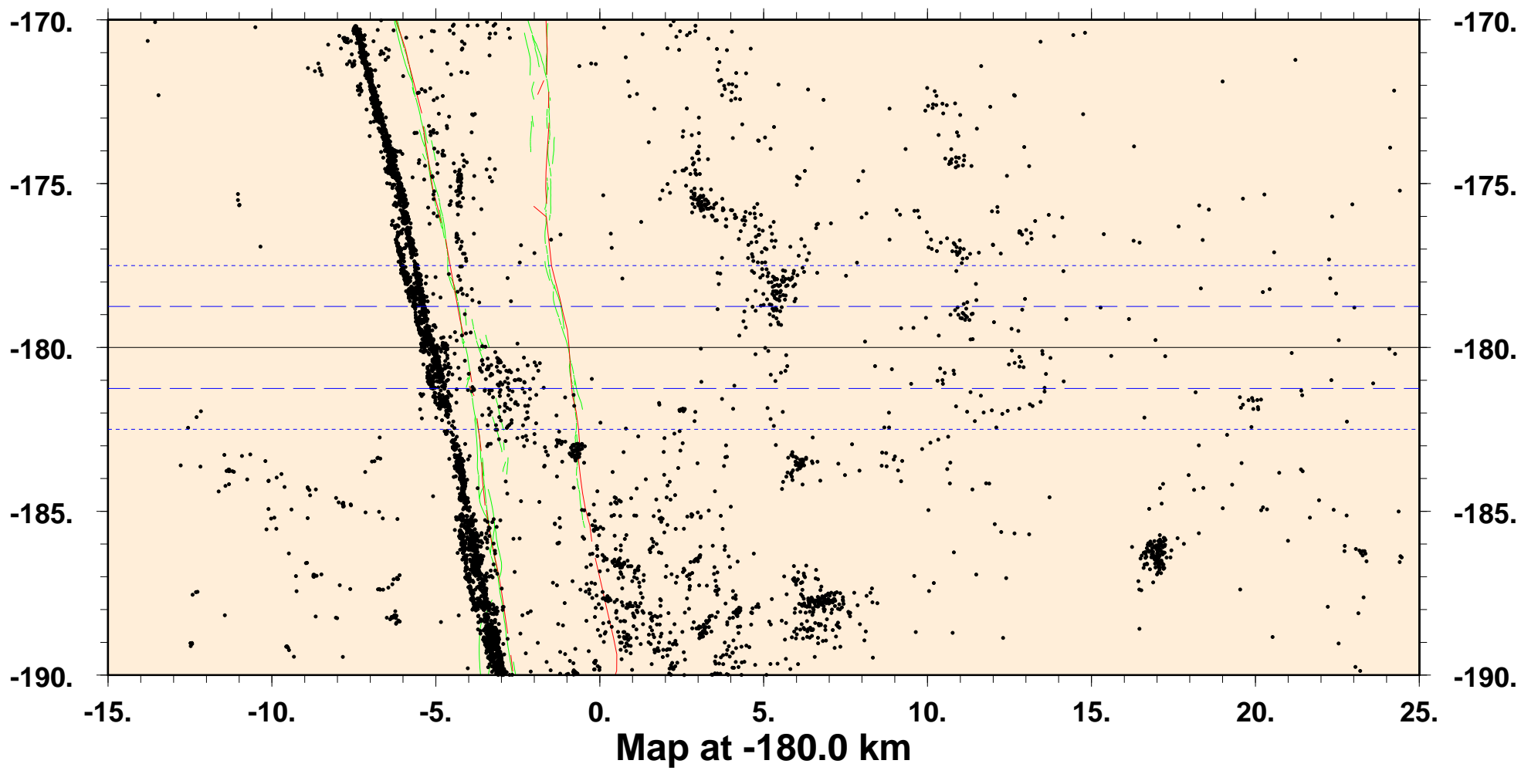



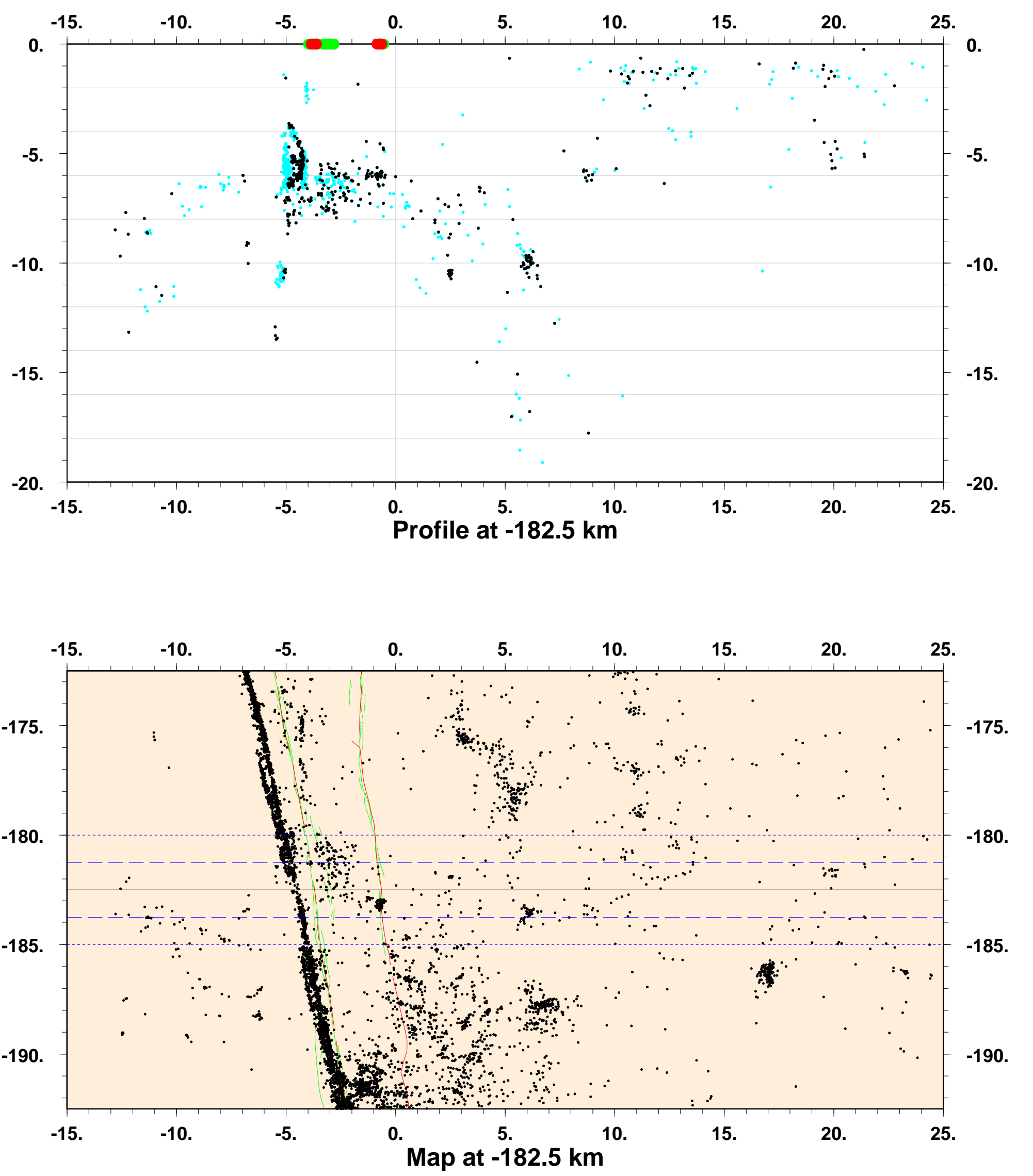


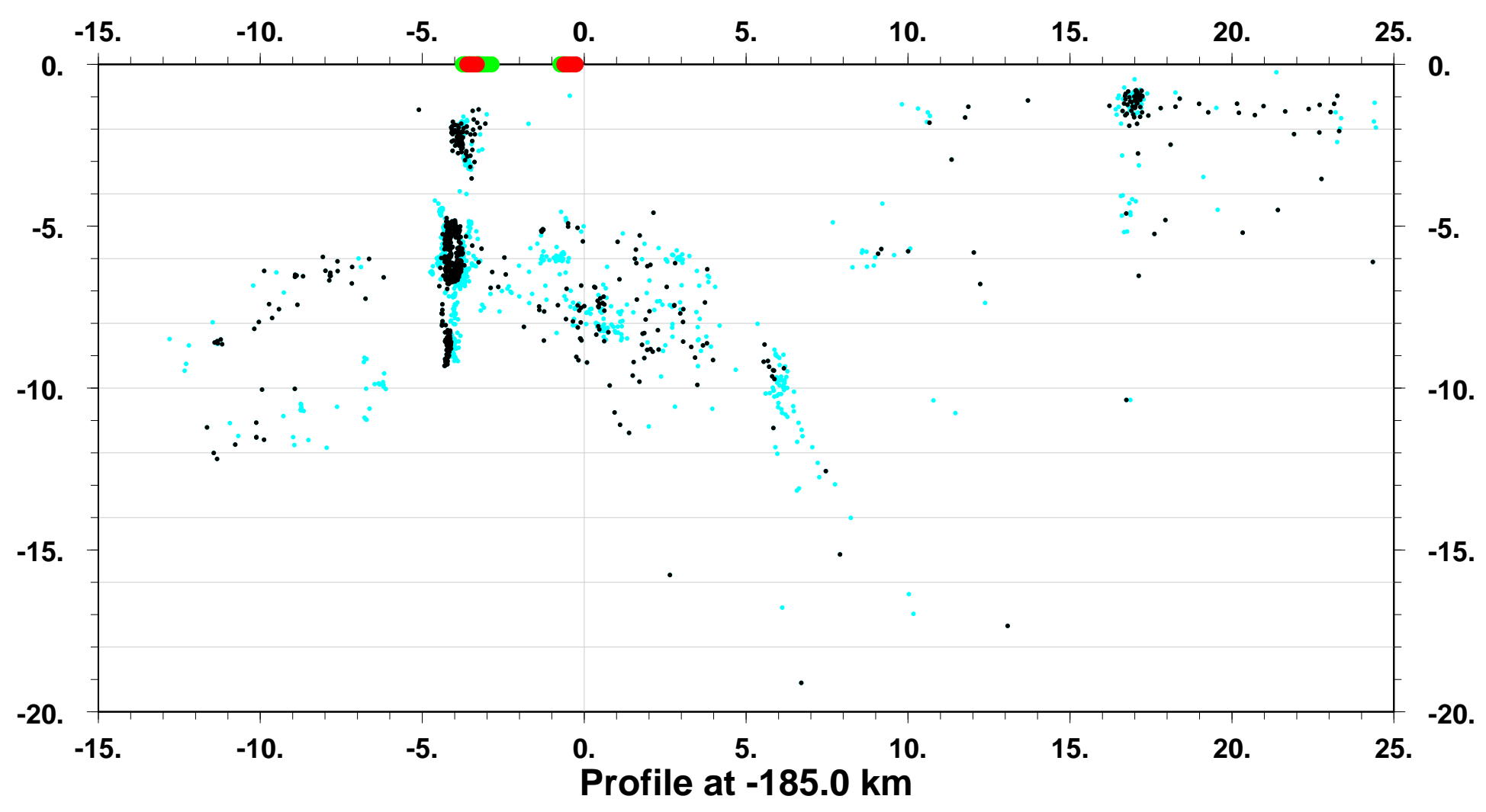

$\begin{array}{rrrrrrrrr}-15 . & -10 . & -5 . & 0 . & 5 . & 10 . & 15 . & 20 . & 25 .\end{array}$

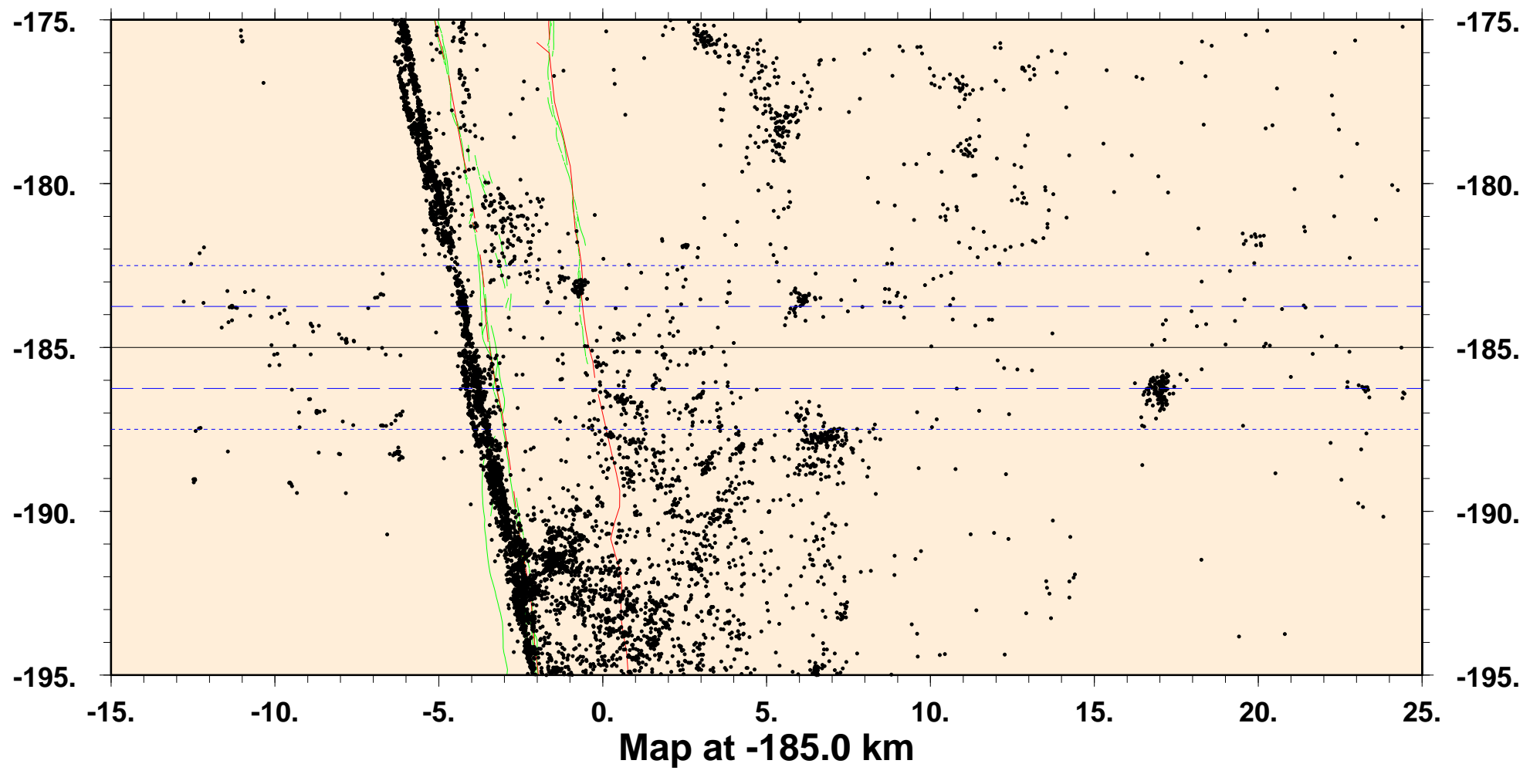



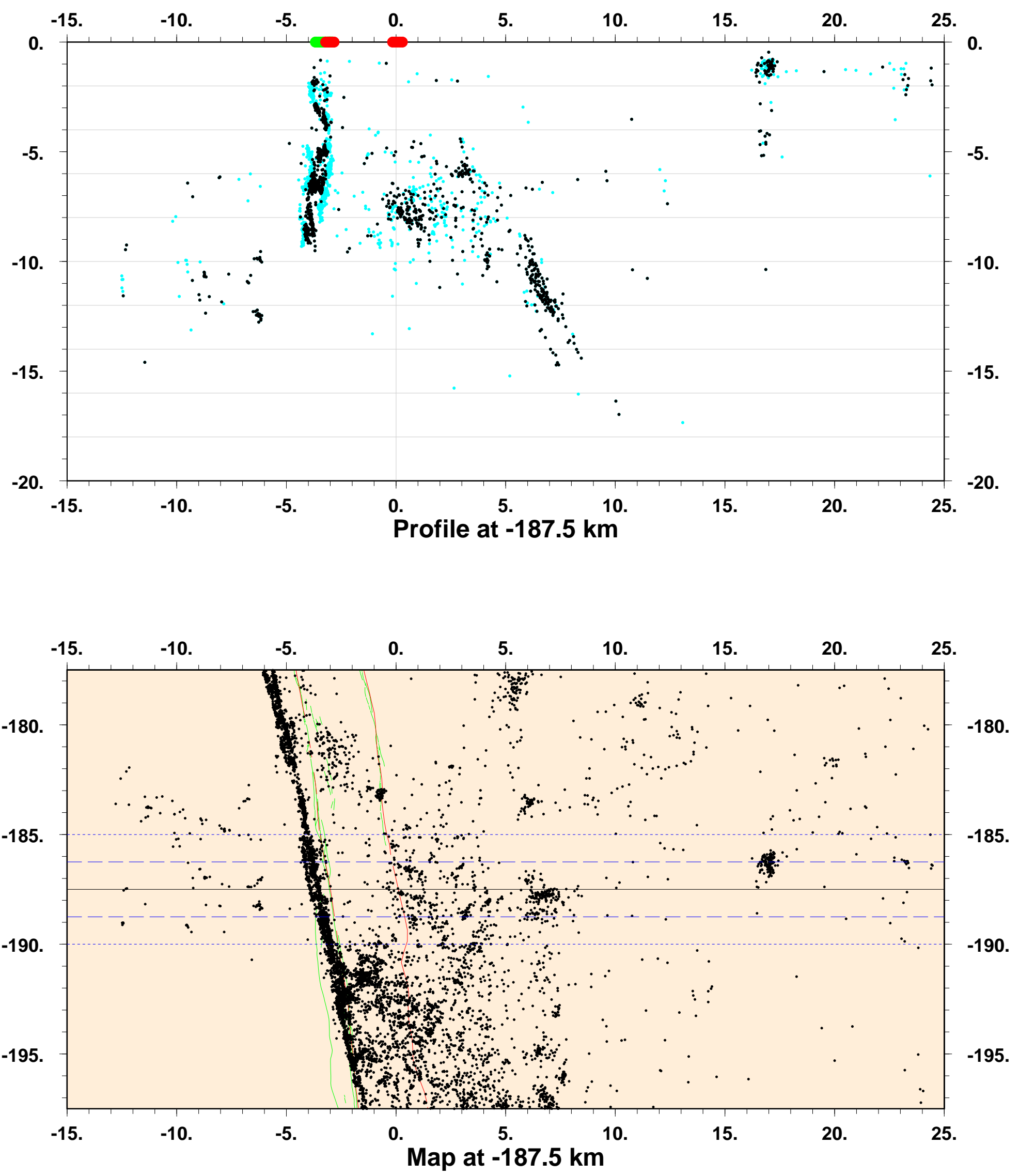


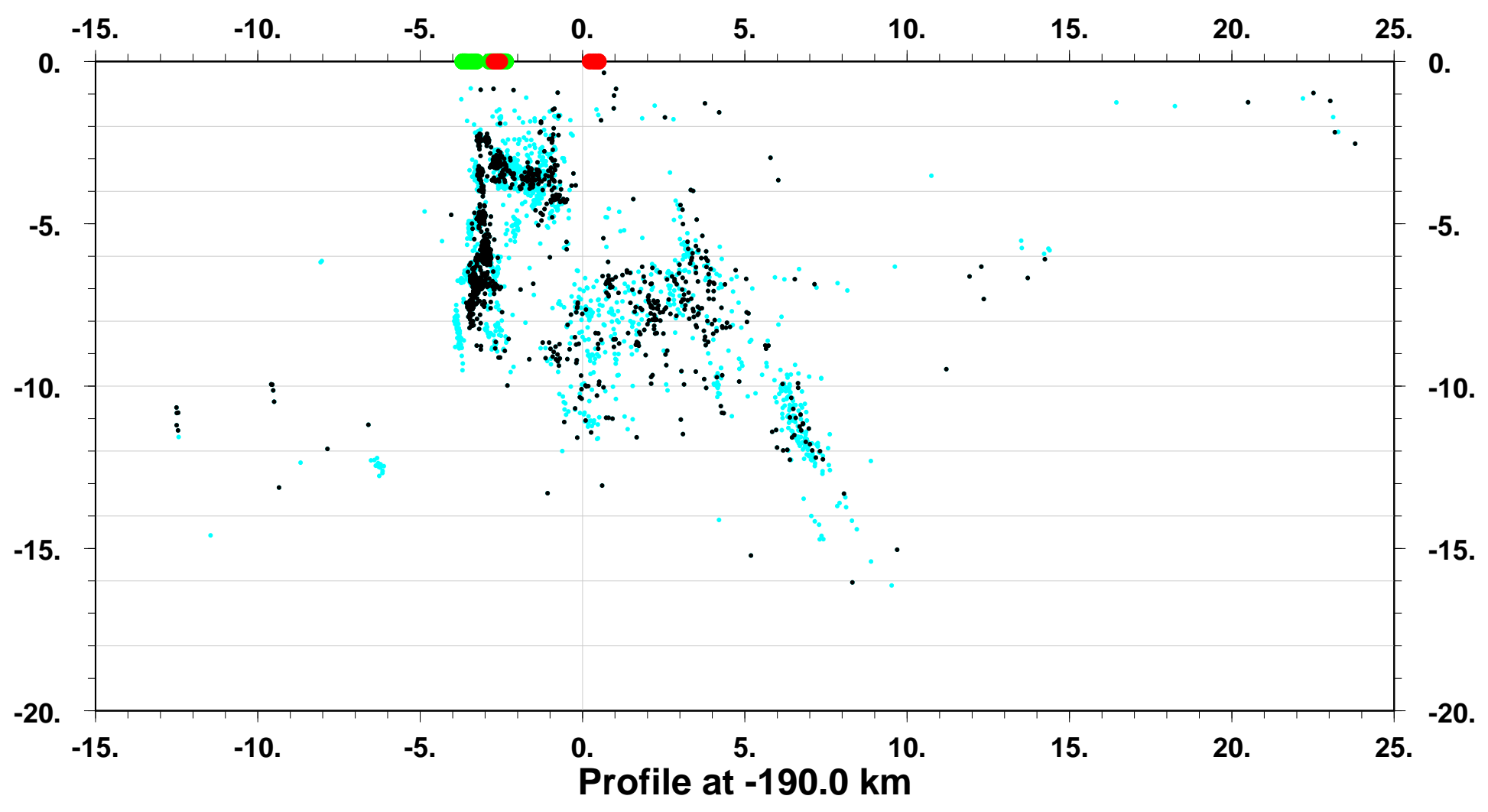

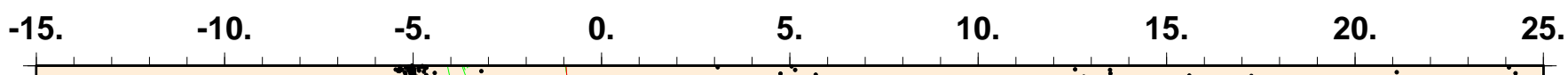

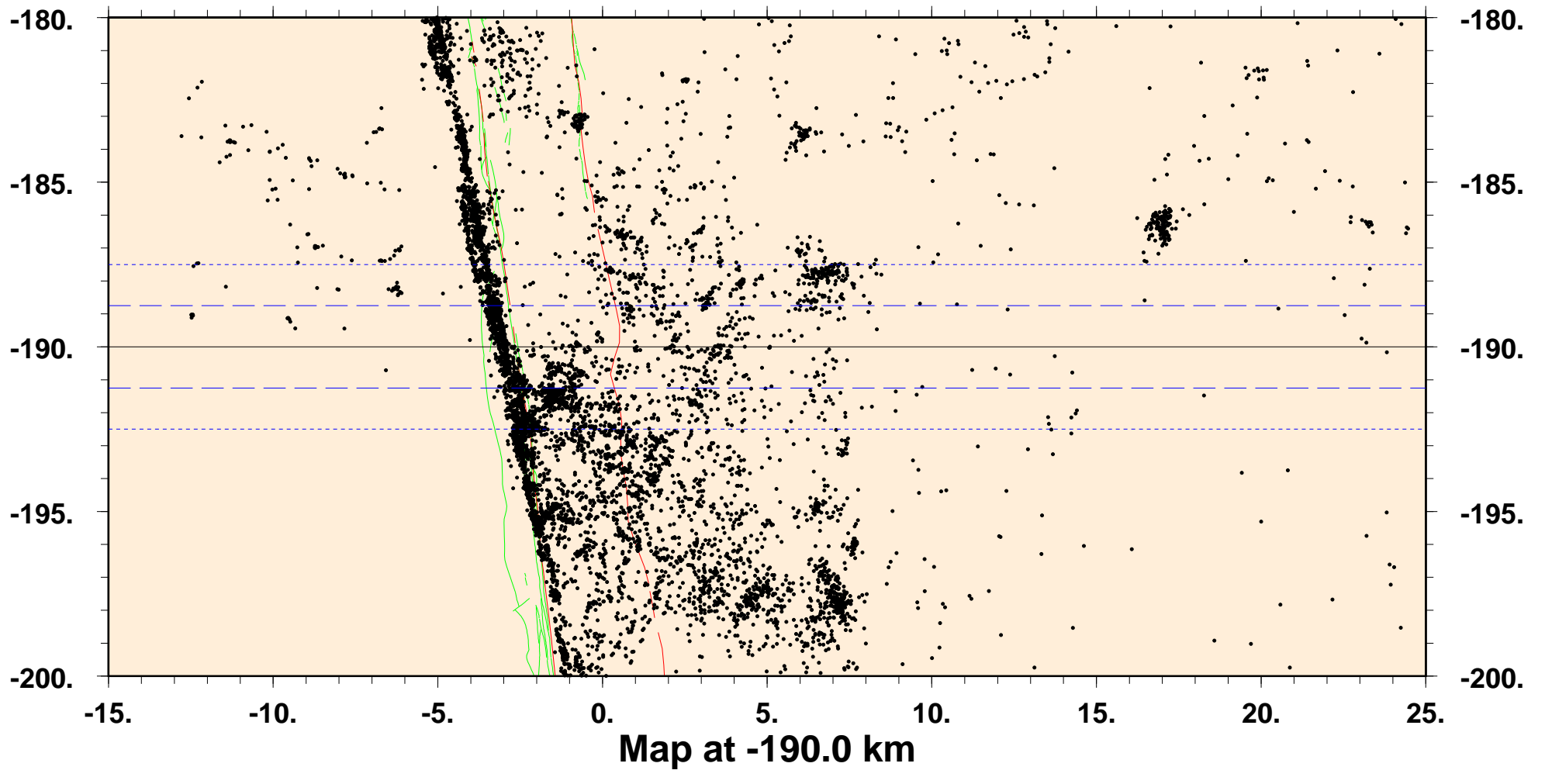



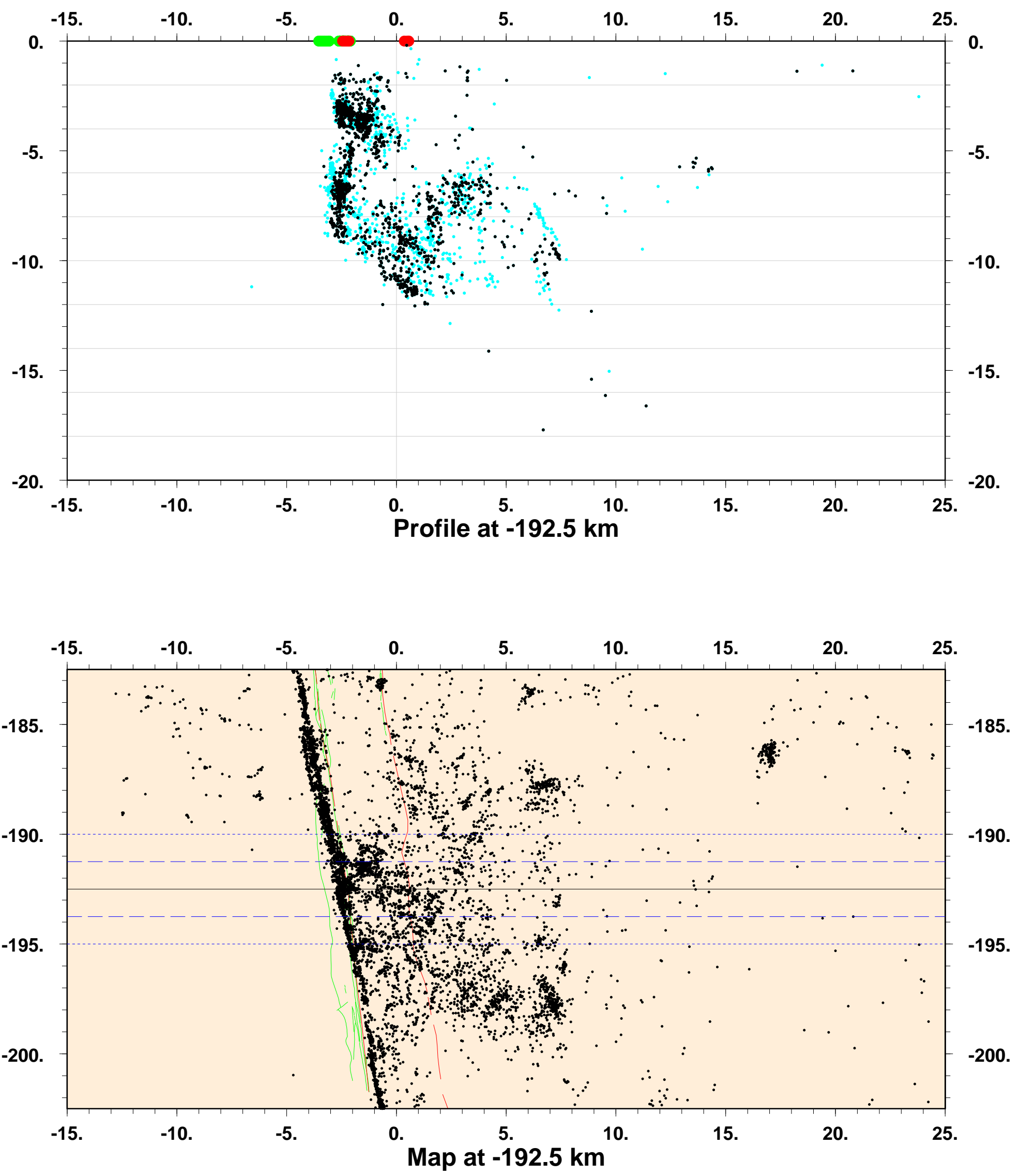

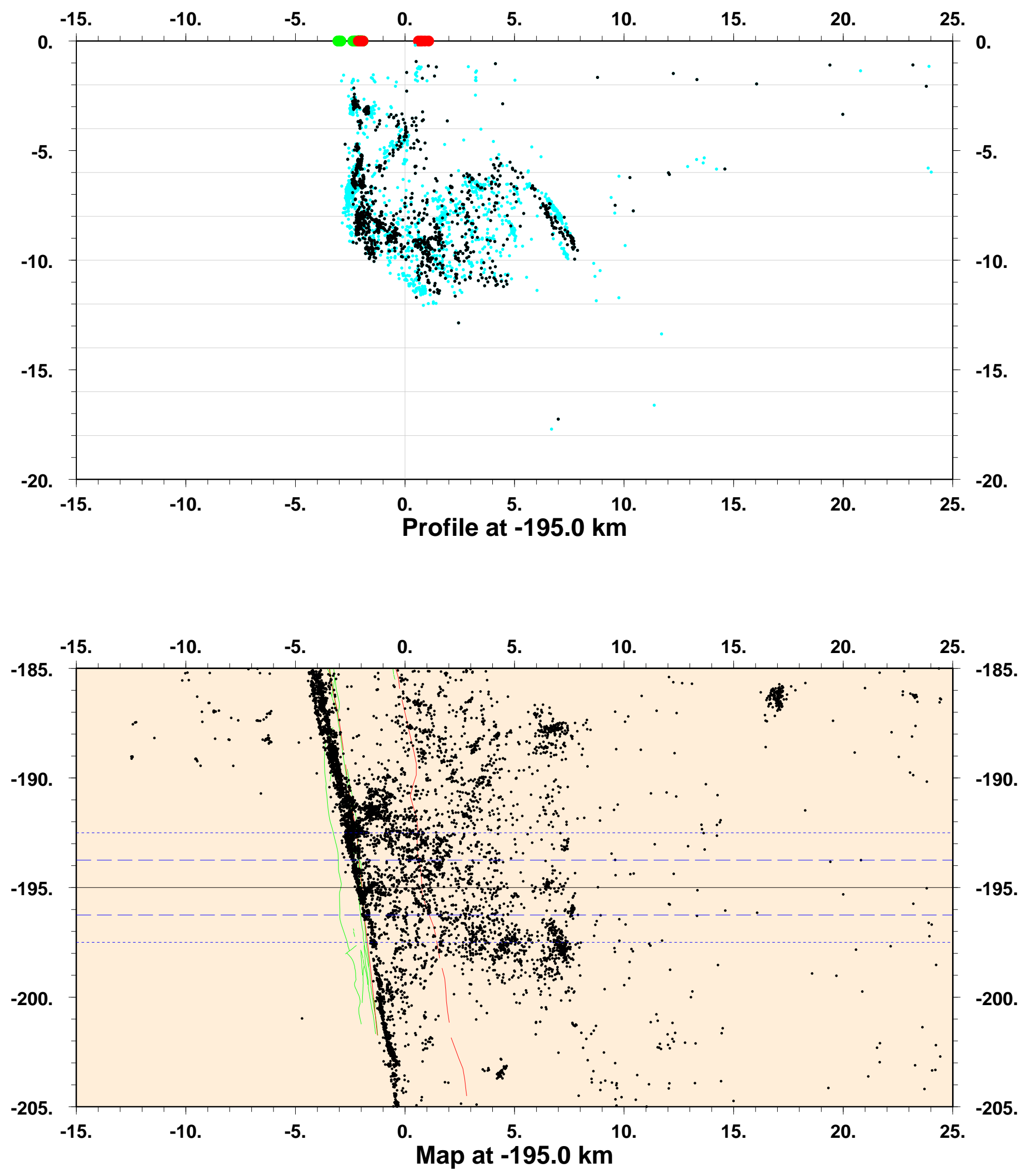

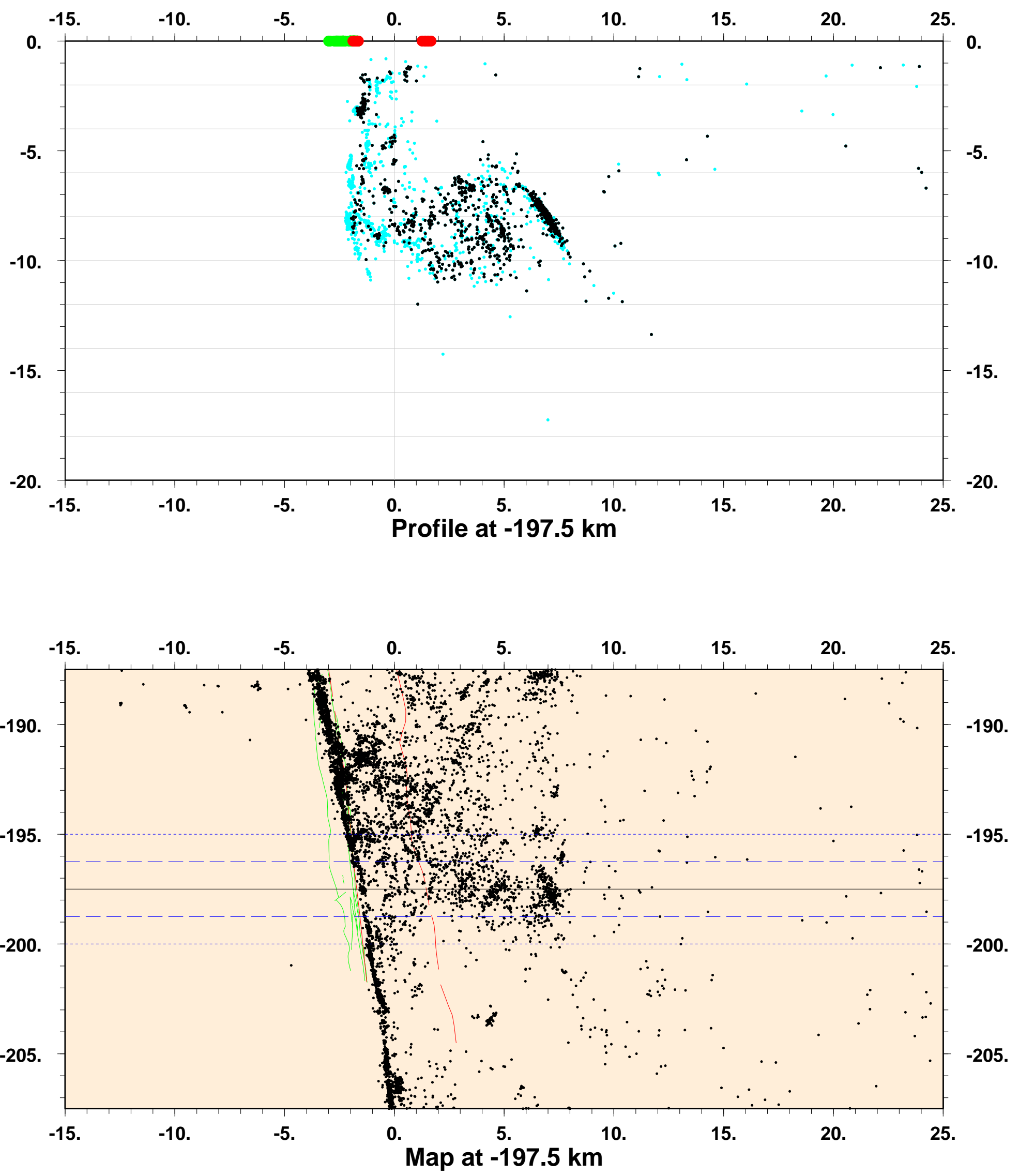

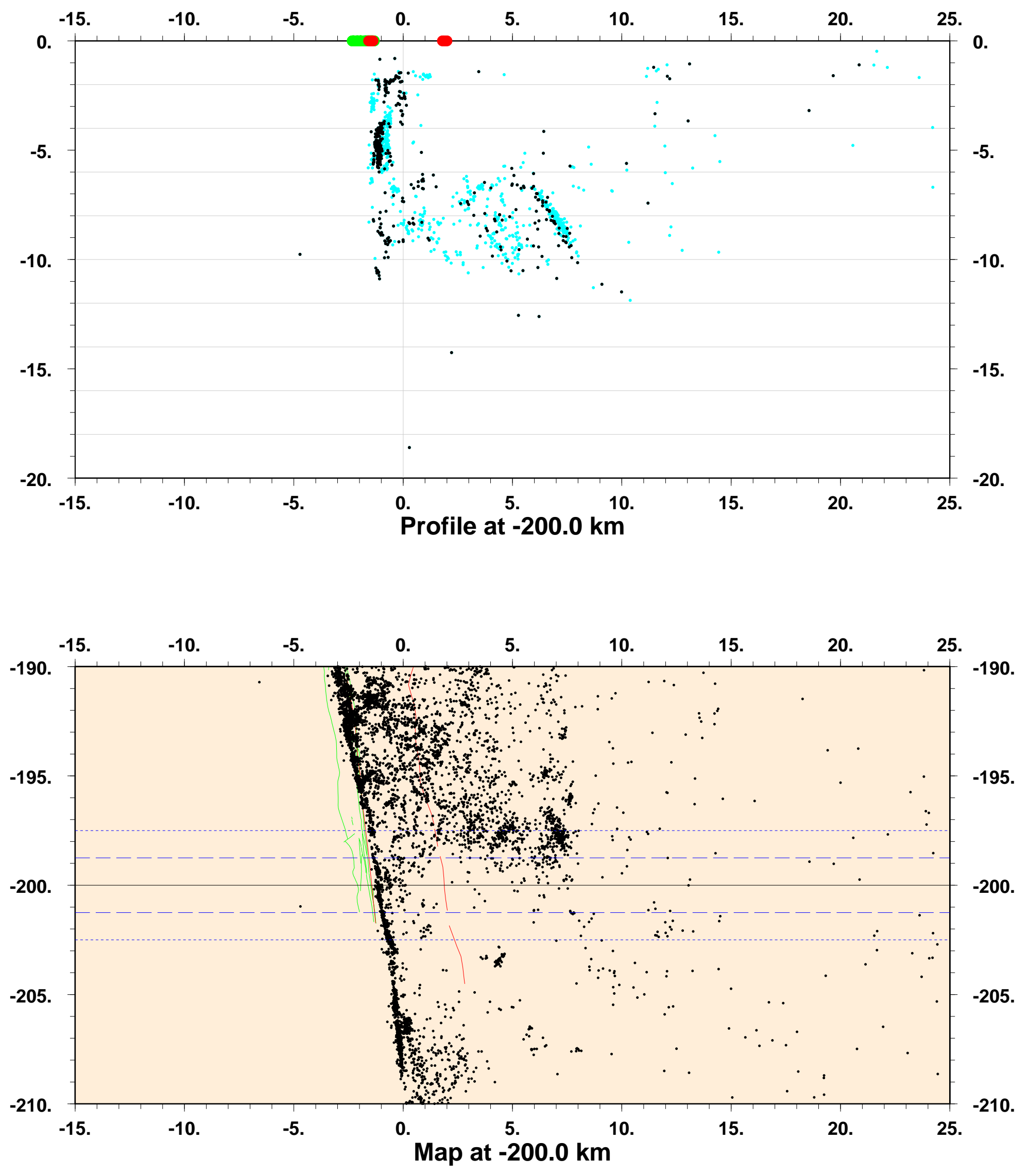
